\title{
REVIEW
}

doi: https://doi.org/10.15407/ubj92.06.005

\section{SCIENTISTS’ PURSUIT FOR SARS-COV-2 CORONAVIRUS: STRATEGIES AGAINST PANDEMIC}

\author{
S. V. KOMISARENKO \\ Palladin Institute of Biochemistry, National Academy of Sciences of Ukraine, Kyiv; \\ e-mail:svk@biochem.kiev.ua
}

The virus is just bad news, wrapped in a protein envelope. Peter Medawar, winner of the Nobel Prize, 1960

Human health costs are the best investment. Well known axiom

The SARS-CoV-2 coronavirus is the cause of the coronavirus disease 2019 (COVID-19), which in 2020 became pandemic and a global threat. As of January 10, 2021, 218 countries and territories have reported 90.783 million confirmed cases and 1.945 million deaths. The aim of this article is to briefly review the numerous information linked to this virus and the COVID-19 disease and to give an analysis and landscape of appropriate problems. In particular, to acquaint with information on the coronavirus biology, its origin, structure and ways of infection; on the features of COVID-19 disease, diagnostics, the use of pharmaceuticals for the disease treatment and the formation of immunity against SARS-CoV-2. Particular attention was given to the vaccines' development and the effectiveness of anti-epidemic measures (quarantine). The use of mathematical modeling of the epidemic process and the prospects of quarantine ending is also discussed. Finally, the data relevant to the emerging SARS-CoV-2 variant VOC 2020 12/1 are presented with special attention to its possible impact on the virus diagnostics and vaccination.

Ke y w o r d s: SARS-CoV-2 coronavirus, COVID-19 pandemic, ways of infection, COVID-19 diagnosis, antiviral immunity, vaccines, models of the epidemic process, SARS-CoV-2 variant VOC 2020 12/1.

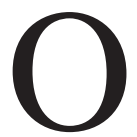
n November 16, 2002, an unknown form of SARS was first reported in rural area Foshan, southern China's Guangdong Province, which spread to 37 countries five months later, hit all continents, and nearly became the first pandemic of the 21st century. On March 15, 2003, the World Health Organization (WHO) officially named the disease Severe Acute Respiratory Syndrome (SARS). Initially, SARS was called the atypical pneumonia (synonyms - Chinese pneumonia, Hong Kong pneumonia) for its similarity in clinical symptoms to already known atypical pneumonia. The term 'atypical pneumonia' was introduced in 1938 by American virologist Hobart Reimann for cases of pneumonia caused by uncharacteristic pathogens: mycoplasmas, chlamydia and legionella [1].
The causative agent of the disease in 2002 appeared to be the SARS-CoV virus of the coronavirus family, which could infect humans from civets ${ }^{1}$, which became carriers of the virus from bats to humans. A total of 8,422 disease cases were registered in 2002-2004, of which 916 were fatal (10.9\%) [2]. The SARS epidemic was stopped despite the lack of effective etiotropic diagnostic, treatment and preventive method, as a result of consolidation of efforts by many countries in pushing forward unprecedented anti-epidemic measures, and a 'major' mutation in the virus genome, when a fragment of 29 nucleotides dropped off its RNA.

In 2012, a new disease emerged in Saudi Arabia - the Middle East Respiratory Syndrome (MERS), also known as camel flu that was very

(C) 2020 Komisarenko S. V. This is an open-access article distributed under the terms of the Creative Commons Attribution License, which permits unrestricted use, distribution, and reproduction in any medium, provided the original author and source are credited. 
A
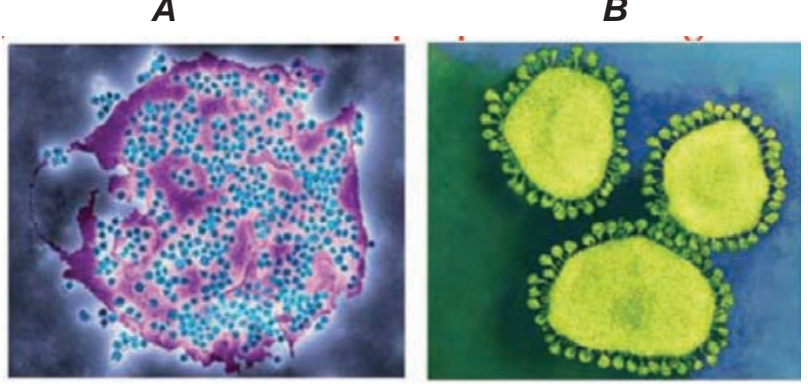

Fig. 1. A-Electronogram of a human cell overflown with SARS-CoV-2 coronaviruses (blue) [274]. B Electronogram of SARS-CoV-2 coronaviruses [275]

similar to SARS. It was caused by the coronavirus MERS-CoV infecting humans from camels, which also transmitted the virus from bats to humans. Recurrent MERS outbreaks were reported in South Korea in 2015 and in Saudi Arabia in 2018. The MERS epidemic spread to 26 countries (primarily in the Middle East) and caused 2,519 cases, of which 866 were fatal (34.4\%) [3].

The SARS and MERS epidemics were impressive for their fatal consequences (fortunately, they did not reach Ukraine), but the next epidemic, which emerged (as officially believed) in the Chinese city of Wuhan in November 2019, far exceeded all previous ones and has changed the way of living around the world. The new respiratory disease was called the Coronavirus disease 2019 - COVID-19 and it was caused by coronavirus SARS-CoV-2 (Fig. 1, A, B). Twelve months following the first cases of SARSCoV-2 infection (as of December 22, 2020), the virus spread to all continents (including Antarctic [4]), infecting more than 78 million people and taking more than 1,72 million - death toll.

In Ukraine, the first case of COVID-19 was registered in Chernivtsi on February 292020 (confirmed on March 3) in a man who had come from Italy [5]. Since then (as of December 21, 2020), more than 97,000 cases of infection have been reported, of which about 16,660 have been fatal.

In contrast to the SARS epidemic of 2002, when the cause of atypical pneumonia in patients (and deaths, accordingly) became clear only a few weeks later, the information about the new SARS-
CoV-2 virus, which caused severe respiratory COVID-19 disease was provided by the PRC healthcare to the WHO in late December 2019 [6], and as soon as January 10, Chinese scientists published the full sequence of the SARS-CoV-2 genome [7]. This allowed other countries to immediately undertake developing diagnostic preparations and vaccines to combat the COVID-19 pandemic.

Perhaps, for now, many questions remain unresolved: why do mortality differ in different countries and in different segments of the population; whether the probability of infection and the severity of the disease depend on the viral load; how effectively the immune system combats the viral infection and how long the immunity is preserved in recovered individuals; what mutations occur in the pathogen and whether they affect areas of the genome important for PCR diagnostics, encoding the most immunogenic epitopes of the virus that may be part of vaccines, etc.

\section{Origin and structure of the SARS-CoV-2 virus}

Coronaviruses ${ }^{2}$ were first isolated from chicken in 1937 [8], and human coronavirus was first obtained from a culture of the tracheal ciliatedepithelium of a human embryo in 1965 [9]. By 2003, scientists knew about 10 coronavirus types, including human, cattle, pig, rodent, cat, dog, and bird viruses. Since the identification of SARS pathogen (2002-2003), scientific laboratories around the world have actively and comprehensively studied the coronaviruses. Given SARS originated in China and this country is the largest natural reservoir of its existence in bats, the Chinese city of Wuhan was opted to be a location of the world's largest centre for the study of coronaviruses, which has successfully cooperated with scientists from around the world. Therefore, in recent years the number of known coronavirus species has increased several times as new coronaviruses of humans, horses, whales, birds and bats have been isolated [10].

Coronaviruses are characterized by extensive tropism and can hit liver, kidneys, intestines, nervous system, heart and eyes in addition to the respiratory tract. A typical coronavirus infection is clinically

${ }^{1}$ Civets, or Viverridae - brindled nocturnal animals, somewhat similar to cats or foxes; they are easily tamed, and are often kept in the Southeast Asia as pets.

${ }^{2}$ Order Nidovirales, family Coronaviridae, sub-family Orthocoronavirinae.

${ }^{3} 10-30 \%$ of human respiratory viral infections are associated with colonization of nasal and throat epithelial cells by 229E, OC43, HKU1, and NL63 coronaviruses. 
manifested by influenza-like syndrome and/or intestinal disorders. Prior to the emergence of SARSassociated coronavirus, coronaviruses were thought to cause serious illness in animals and merely mild upper respiratory tract disease in humans ${ }^{3}$ [11].

By a degree of genome similarity and antigenic properties, coronaviruses are divided into 3 groups: $\alpha-, \beta$ - and $\gamma$-coronaviruses. The coronaviruses of the first group (causative agents of peritonitis in dogs, cats, infectious gastroenteritis of pigs, human coronavirus 229E and NL63, etc.), as well as the second group (agents of hepatitis in cats, dogs, mice, swine encephalomyelitis, human coronaviruses OC43 and HKU1, etc.) cause diseases in mammals, in particular mild respiratory diseases in humans. The coronaviruses of the third group cause the disease in birds (infectious bronchitis in chicken and ducks). After lengthy studies and discussions, the SARS-CoV coronavirus was assigned to subgroup $2 \mathrm{~b}$ of the second group of coronaviruses [10]. The same subgroup is inclusive of viruses MERS-CoV and SARS-CoV-2 [12]. Therefore, SARS-CoV-2 became the seventh known human coronavirus, four of which periodically cause acute respiratory pathologies, and three became fatal to humans (SARS-CoV-1, MERS-CoV and SARS-CoV-2).

According to official Chinese data, COVID-19 was diagnosed on November 17, 2019 in a 55-year old person from Wuhan (Hubei Province) [13]. The first numerous cases were associated with the seafood market of Wuhan, but according to a study published in the Lancet [14], some of the first infected with SARS-CoV-2 did not claim any contact with this market.

There is an evidence that humans could have been infected with this virus much earlier (at least in mid-September 2019), and this happened not in Wuhan. Scientists at the Cambridge University conducted genomic studies of more than 1,000 samples of SARS-CoV-2 from different countries and plotted the spread of the virus in the world according to genetic mutations occurred over time [15]. It turned out that there were three types of virus: A, B and $\mathrm{C}$, each of which stemmed from the previous one. Type A was genetically closest to the bat coronavirus, and was believed to be the first to infect humans. This type was found in patients from China and the United States, and mutated versions had also been found in patients from Australia and the United States. Interestingly, in China, type A coronavirus was detected (7 of 11 isolates) in Guangdong Province, 500 miles from Wuhan, but in Wuhan itself, type
$\mathrm{B}$ virus was the dominant one. Type $\mathrm{C}$ coronavirus was diagnosed in the first infected in Europe, and also in South Korea, Singapore and Hong Kong, but not in mainland China. These data suggest that the transition of SARS-CoV-2 virus from bats to humans took place between September 13 and December 7, 2019, and it did not happen in Wuhan, because in this city until January 17, 2020, almost all isolates were of type B.

The SARS-CoV-2 genome is $88 \%$ (according to other data, 96\% [16]) identical to the genome of SARS-like bat coronaviruses, but the virus is genetically different from SARS-CoV and MERS-CoV (similarity is about 79 and $50 \%$, respectively) [7]. SARS-CoV-2 has been suggested to be originated from the bat coronavirus and transmitted to humans through an intermediate animal species when it entered the Wuhan seafood market, which was associated with the first mass outbreak of COVID-19 [17]. Subsequent studies revealed a $90 \%$ similarity of SARS-CoV-2 to pangolin virus (Manis javanica), especially pronounced in the protein $\mathrm{S}$ area, which is responsible for host cell recognition and penetration. However, pangolins have not been proved to be animals from which the coronavirus has been transmitted to humans. In fact, SARS-CoV-2 is a chimera combining the features of bats and pangolin coronaviruses, while its origin remain unclear. Studies continue, but so far neither a 'zero' patient has been identified among humans nor an intermediate species between bats and humans.

In March-April 2020, experts drilled into the possibility of artificial origin of SARS-CoV-2 and concluded that the probability of this phenomenon was extremely small [19]. The study of mutations in the genome of coronaviruses and their evolution almost unequivocally suggested the natural origin of SARS CoV-2. On April 30, 2020, the US National Intelligence also stated that SARS CoV-2 coronavirus was not artificially created or genetically modified [20]. However, on May 3, 2020, US Secretary of State Mike Pompeo supported the opinion of President Donald Trump and said that the United States had evidence of the laboratory origin of the virus, which was allegedly developed in a laboratory of Wuhan. Nevertheless, scientists consider this statement political rather than scientifically substantiated. A two-person WHO commission is currently working in Wuhan to identify the source of the SARS CoV-2 coronavirus and answer questions about the first outbreaks of the disease, as well as the conditions of research at the Wuhan Institute of 
Virology. And here it is worth mentioning that the natural source of the Ebola virus (also from bats) was found only 45 years after its discovery. However, in any case, the question of the SARS-CoV-2 origin requires further research, which will contribute to a deeper understanding of the evolutionary processes in viruses and the mechanisms of their transition to other species, especially humans.

Here it makes sense to make a short insert entitled "Why bats and what is their genetic evolution?", in which to briefly recall the evolution of bats' interacting with various viruses, including coronaviruses [22]. To many readers, it may seem weird that bats, with which we do not come into frequent contact in everyday life, play such an important role in the spread of the most dangerous viral diseases, including coronavirus - SARS, MERS, SARS$\mathrm{CoV}-2$, as well as rabies, Ebola, etc. Bats are the second most numerous mammals on Earth and there are more than 1,400 bat species [22]. Genome analysis shows that bats have been the 'hosts' of many viruses for more than 65 million years, including the now infamous coronaviruses, which are safe for their health. It is clear that such a huge and virus-friendly 'reservoir' has created unique opportunities for virus evolution and increased the diversity through mutations and selection. Studies of genomes of different bat species and coronaviruses thereof started in 2002-2003 after the SARS epidemic in China, and then intensified significantly after the MERS outbreak in 2012. The results provided some insight into the evolution of bats and their relationship with viruses, especially why they were insensitive to coronaviruses. Among other things, it was found that at least 10 genes 'did not work' in bats, which in other mammals were responsible for the mechanisms of inflammation caused by infections, but they had additional copies of antiviral genes, which might explain their insensitivity to the disease. However, socalled residual genes had been found in the genome of bats - traces of previous viral diseases, even those that were characteristic rather of birds than of mammals. Who knows, might be four strains of coronaviruses (229E, OC43, HKU1 and NL63), which cause only acute respiratory diseases in humans, were once also highly pathogenic, as now SARS, MERS and SARS-CoV-2 are, but then evolved to the present state. Studies of bats' immunity to viruses may happen to be crucial for building a system of human protection from these viruses.

However, let's go back to the SARS-CoV-2 virus. It has a thin, medium size $(60 \mathrm{~nm})$ nucleocapsid of uneven structure and spherical shape. As in other coronaviruses, the envelope of SARS-CoV-2 consists of 4 proteins: 'spike' glycoprotein $\mathrm{S}$, nucleocapsid protein $\mathrm{N}$, membrane protein $\mathrm{M}$ and super-capsid (envelope) protein E. In addition, there are 16 nonstructural (NSPs) and 9 additional proteins. Each of the nonstructural proteins (nsp1-16) plays a specific role in the replication of SARS-CoV-2 and in the development of replicative-transcriptional complex (RTC), which is responsible for synthesis of subgenomic RNAs (sgRNAs) [23, 24]. It has recently been found that in addition to the known 29 proteins, SARS-CoV-2 expresses 23 previously unknown proteins, including both completely new proteins and truncated or expanded versions of known proteins. The function of some discovered proteins is to control the synthesis of known viral molecules, but the role of most of them remains unknown [252].

Inside the nucleocapsid there is a positive strand of polyadenylated RNA with a length of approximately 30,000 nucleotides, which holds the genetic information (5 genes have been described [25]). Externally, the nucleocapsid is covered with a lipid-containing envelope and a protein membrane (Fig. 2). On the surface of the virion there are 20-nm-long spike-like processes - peplomers, which have the shape of a club expanding to the distal end. This shape on electron microscopy images resembles a solar corona in an eclipse, which is why they were called (corona)viruses [26].

The spike protein, or protein S (SARS2-S, strain Wuhan-Hu-1), is a major 'player' in the process of infecting human cells. It is responsible for the interaction (recognition) with the receptor on the surface of the host cell and for ingress of the virus into the target cell (that is for target cell binding, fusion and entry). It is a homotrimer, i.e. formed by three identical subunits (each consisting of 1273 amino acid residues), and each subunit has two domains - S1 (amino acids from 1 to 685) and S2 (ami-

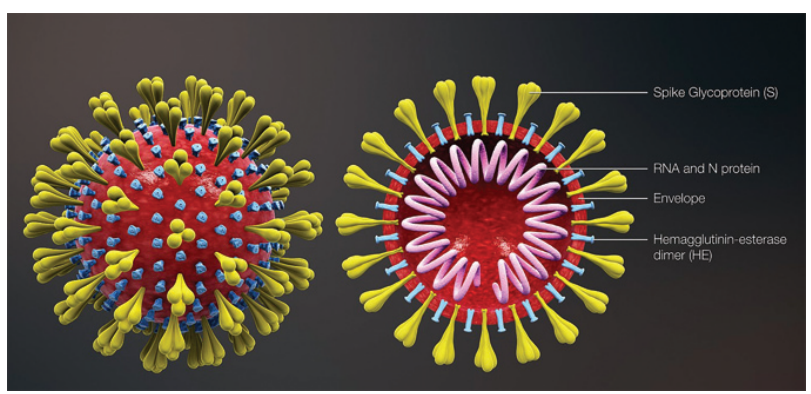

Fig. 2. A coronavirus sketch [276] 
no acids from 686 to 1273). The outer part of the subunit (from the N-terminus) forms the outer ectodomain (amino acids 1-1208), to which the transmembrane 'anchor' and short C-terminal inner 'tail' adjoin from the C-terminus. Each S1 domain has one receptor-binding domain (RBD - amino acids 319541), which binds to the host cell membrane protein angiotensin-converting enzyme 2 (ACE2), which is a receptor for penetration of the virus into the cell [27]. Therefore, each protein $S$ (trimer) has three receptor-binding domains. SARS-CoV-2, in contrast to SARS-CoV, is able to more close interaction with the ACE2 protein, which provides for its more effective penetration into the target cell [19, 28]. Glycan binding sites are located at the apex of the protein $\mathrm{S}$ trimer. Each protomer of trimeric protein $\mathrm{S}$ was found to have 22 glycosylation sites, and the SARS$\mathrm{CoV}-2$ gene encodes $22 \mathrm{~N}$-glycan sequences for each protomer. These glycans originating from the Golgi apparatus of the host cell are involved in the folding of viral proteins and in the immune response. Interestingly, no mutations of the virus have been found so far (in July 2020) that affect the glycosylation sites (glycans) of S-glycoprotein [29]. The carbohydrate components of glycoprotein S play an important role in protecting the virus from the host immune system, in particular from antibodies to epitopes on protein S. Nevertheless, publication in Cell in September [289] clearly demonstrated that mutations in spike protein $\mathrm{S}$ and in its RBD, which ablated glycosylation at RBD (N331 and N343) drastically reduced viral infectivity and antigenicity. Some mutations (N234Q, L452R, A475V, and V483A) made virus resistant to neutralising monoclonal Abs but not N234Q that can be important in the development of vaccine and therapeutic antibodies [289].

The mechanism of SARS-CoV-2 penetration into the cell, as well as the pathogenesis of COVID-19, has not been sufficiently studied, but it is known that the virus interacts not only with ACE2 receptor but also with other cellular structures, in particular with TMPRSS2 - a membrane-bound serine protease with a little-known biological function. When infecting, the protease TMPRSS2, or furin, activates the protein $\mathrm{S}$ of SARS-CoV-2 [30, 31] by breaking several peptide bonds between $\mathrm{S} 1$ and S2 domains of the protein S. This process - S priming - opens the way to involvement of the S2 domain in the fusion of the virus with the plasma membrane of the target cell. This forms a channel through which $\mathrm{N}$ proteins and viral RNA enter the cytoplasm of the target cell, where RNA is translated and fosters the formation of complexes for replication and transcription of the virus, while $\mathrm{N}$ proteins bind to RNA to preserve its stability.

Thus, the effective ingress of the virus into the host cell occurs in three stages [23, 27]: the first the virus binds to the receptor(s) of the cell; second the lipids of the envelope and membrane of the virus (probably with the corresponding proteins) fuse with the plasma membrane of the cell; third - the genome (RNA) of the virus is released in the host cell, where replication of its genomic material begins. Spike protein $\mathrm{S}$ plays a key role in the first two stages, which last about 10 minutes, and the third stage, which ends with the creation of new viruses about 10 hours. Synthesized viruses leave the host cell, which dies either from depletion of internal resources used for virus synthesis, or under the action of the immune system, which destroys infected cells, and new viruses infect new cells or are excreted in the air while breathing (if these were lung epithelial cells).

Probably, SARS-CoV-2 uses several different receptors for penetration into cells. It is known about the interaction of protein S with CD26 - membrane enzyme dipeptidyl peptidase-4, which is important for immunoregulation [32]. In addition, the possibility of SARS-CoV-2 virus entering the cell through the CD147 receptor (or basigin), an inducer of matrix metalloproteinases belonging to the superfamily of immunoglobulins and a receptor for penetration of malaria causing agent into erythrocytes, has been proved [33].

New findings have recently been published that, in addition to the well-known ACE2 receptor for SARS-CoV and SARS-CoV-2 viruses (although their tropism differs), there is another cellular receptor [34] which significantly amplifies the infectivity of SARS- CoV-2 and, perhaps, explains its tropism to 'not generally accepted' organs and atypical course of COVID-19 disease. It is neutropilin-1 (NRP1), which binds furin-cleaved substrates and interacts with the endothelial growth factor (VEGF). It plays an important role in angiogenesis, vascularization, development and metastasis of malignant tumours, etc. NRP1 is mostly expressed in the respiratory and olfactory epithelium covering the surface of the nasal cavity, and in endothelial cells. The autopsy of patients with COVID-19 revealed that NRP1-positive cells of the olfactory epithelium and buds were infected with SARS-CoV-2 with a particularly large amount of virus in NRP1-positive endothelial cells of capillaries and the average-size blood vessels of 
the olfactory bud [35]. Intranasal administration of NRP1-positive particles commensurate with the virus to mice showed their transport to the central nervous system, which may explain the intensive tropism and pathways of SARS-CoV-2 virus proliferation, as well as its direct effect on the brain.

Symptoms of COVID-19 are associated with the phases of virus replication in the body cells. Following infecting with the virus and its interaction with cells prior to RNA replication (several hours), no symptoms are manifested. In the initial stages of RNA replication, the first symptoms occur - fever and cough (this is the first phase of the disease lasting few days). The second phase is associated with a significant replication of the virus (possibly in different organs) and is accompanied by a very high temperature, generalized weakness and symptoms characteristic of pneumonia. The progression of the disease leads to the final phase - acute respiratory distress syndrome - ARDS, and possible death [23].

Quite a large number of publications are devoted to SARS-CoV-2 mutations. A comparison of 106 SARS-CoV-2 and 39 SARS genomes suggested that the rate of SARS-CoV-2 mutations was significantly lower than in SARS, and that the Spike S-glycoprotein in SARS-CoV-2 and its receptorbindingdomain (RBD) were very conservative [2]. At the same time, a mutation of SARS-CoV-2 was isolated in India, which no longer interacts as effectively with the ACE2 cell receptors. Therefore, on one hand, such mutations are less dangerous to humans, and, on the other hand, they might question the effectiveness of current vaccines [35]. One of the most interesting, important, and perhaps most dangerous mutations of SARS-CoV-2 is the D614G mutation at position 23403 of RNA virus, which replaces aspartic acid at position 614 (SD614) at the C-terminus of S1 domain of the spike protein S for glycine (SG614). A virus with such a minor mutation (one amino acid only!) much more effectively infected both humans and cell lines in the experiment [36]. Moreover, if the G614 genotype was not found at all in February, scarce in March, then in April it was revealed in $65 \%$ of those infected, and in May - in 70\% of them. That is, the virus of G614 genotype has the priority in spread. It is more contagious and infects more people, although fortunately it neither worsens the course of COVID-19 nor in-creases mortality [221]. It is even possible that D614G mutation makes SARS-CoV-2 easier target for vaccines. Thus, experimental RNA vaccines against COVID-19, including a vaccine developed by the pharmaceutical company
Pfizer, induced in mice, monkeys, and humans the synthesis of antibodies that were more potent in neutralizing viruses of G614 genotype than viruses of D614 genotype [271].

Due to a large-scale pandemic, the SARS$\mathrm{CoV}-2$ has become the focus of researchers from around the world. Many leading laboratories have rearranged their work for studying the scientific problems associated with the virus. Recently, just during a week, SARS-CoV-2 virus was fully reproduced from the DNA sequence using a reverse synthetic genomics platform, yeast cells, T7-RNA polymerase, and a cloning method based on transformation-associated recombination (TAR), which allows preserving the virus genome creating an artificial yeast chromosome [37]. In addition, transgenic mice expressing human ACE2 have been bred. They can be infected with SARS-CoV-2 and used in studies as a COVID-19 animal model [38]. Such technical possibilities open new perspectives for studying the structure, mechanisms of SARS-CoV-2 functioning and its pathogenetic properties, which is important for development of antiviral medicines and vaccines for combating COVID-19.

\section{Ways of SARS-CoV-2 infection and anti-epidemic quarantine measures}

Despite the fact that SARS-CoV-2 is a highly contagious virus, the question remains as to what is the infectious dose of SARS-CoV-2, i.e. what is the number of viruses that cause the infection [39]. For example, in the case of influenza virus, 10 virus particles may be enough for a person to develop the disease, and for other viruses, the infectious load may be several thousand. It is also unknown whether the severity of COVID-19 is related to the number of viruses that has infected an individual [39]. It is reasonable to assume that the more viral particles enter a patient's lungs, the more severe the disease will be, but in fact there are a number of various factors that determine the incidence of COVID-19 and its course, such as human immunity and health status, comorbidities, age, obesity, etc.

The incubation period of SARS-CoV-2 virus (the period from infection to onset of the first disease symptoms) was believed to last from 2 to 12 days (average 4-5 days), although recent studies have shown that its duration is likely much longer, up to 21 days (about 8 days, on average) [216].

SARS-CoV-2 is transmitted between humans very efficiently, easier than the influenza virus. In patients with COVID-19, the virus was found main- 
ly in nasal washes, throat swabs, saliva, and lung secretions [40], but in some cases viral RNA was also detected in faeces, urine, blood, spinal and pleural effusion [41]. It is well known that it, like other coronaviruses, is transmitted by airborne droplets, i.e. by tiny drops containing viral particles, which are released by patients while coughing or sneezing. Secondary way of transmission is through contact with the surfaces, on which these drops fall, and subsequent contact with nose, mouth or eyes. At the same time, the possibility of virus transmission by faecal-oral route and through kisses is still not ruled out $[42,43]$. The studies have revealed active and long-term SARS-CoV-2 infection in the gastrointestinal tract of people with confirmed COVID-19, and also showed that the virus can be excreted in faeces within a week after receiving negative results of nasopharyngeal tests for COVID-19. Moreover, high viral activity was observed in people with more pathogenic bacteria in the intestine [273].

The characteristic (and extremely dangerous) feature of SARS-CoV-2 is the ability to spread from infected individuals who do not yet have had any manifestations of the disease. This property is not characteristic of coronaviruses SARS and MERS, which caused the epidemics of 2002 and 2012, respectively, during which patients became contagious only 24-48 hours after appearance of obvious clinical manifestations of the disease, usually after hospitalization. Possibly, this same difference caused a much higher prevalence of coronavirus in the current pandemic caused by SARS-CoV-2. According to findings of the US Center for Disease Control and Prevention (CDC), 25\% of COVID-19 patients have mild symptoms or are asymptomatic [44], and the analysis of prevalence of SARS-CoV-2 in 7 countries showed that infection by people without manifestations of the disease occured in $43 \%$ of cases, and the portion of diagnosed patients with minor symptoms of the disease was $40 \%$ [45]. Such patients can spread the virus by spitting, touching various surfaces after touching their mouth or nose, or talking or singing loudly. The studies have shown that SARS$\mathrm{CoV}-2$ can persist for a long time on various surfaces (up to 4 hours on copper, up to one day on cardboard, up to three days on plastic (polypropylene), and up to three days on stainless steel] [46]), though this does not mean that such viral particles can still infect other humans.

It should be noted that these data have led some people to exaggerate the risk of SARS-CoV-2 transmission through surfaces. In fact, these stud- ies used much higher concentrations of the virus than humans could find in the real life. The probability that you may get COVID-19 by touching the packaging of products from the supermarket or the soles of your shoes is very small. Although such a possibility exists for 1-2 hours, if you touch the surface on which a COVID-19 patient sneezed. Thus, recent studies have proven the possibility of transmitting the virus through an elevator button and infected medical equipment. However, excessive use of antiseptics can even be harmful as they irritate the skin, lungs, worsen the condition of people with asthma. Therefore, the main means of protection are social distancing for $2.0 \mathrm{~m}$ from other individuals and wearing a mask, which can reduce the risk of COVID-19 infection by approximately 65\% [269].

It turned out that SARS-CoV-2 can infect not only humans but also animals, including cats, dogs, ferrets, minks, hamsters, rabbits, monkeys, etc., and some of these animals could infect other animals of the same species in laboratory conditions. Mice, pigs, chickens and ducks do not appear to catch or spread the infection. For the first time in the United States, a positive animal test for COVID-19 was found in a tiger at the Bronx Zoo in New York City. In most cases, animals become infected with COVID-19 from people who have been in contact with them and sustain the infection relatively easily. However, the question of the role of animals, in particular domestic cats and dogs, in the spread of the COVID-19 pandemic among humans remains open [222].

A study conducted during the COVID-19 outbreak in Italy revealed neutralizing antibodies against SARS-CoV-2 in 3.4\% of dogs and 3.9\% of cats, with positive tests more likely in dogs living under the same roof with COVID-19 patients [234]. The latest data show that pets are much more likely to be infected with SARS-CoV-2 by humans than to infect humans. Therefore, most researchers believe that pets with SARS-CoV-2 pose a minor risk to humans and other pets and do not play a significant role in the spread of the virus [223].

At the same time, SARS-CoV-2 has been reported in minks on many farms in the Netherlands, Denmark and Spain. Infection in these animals manifested itself by symptoms of respiratory disease and increased mortality. The researchers tested 97 workers of such establishments and found evidence of SARS-CoV-2 infection in 66 of them. Genetic analysis showed that the minks became infected with the virus from humans. Then the virus spread 
among the minks, evolved and returned to farm workers able to transmit it to other people. Despite stringent biosafety measures and immediate culling of infected animals, the transmission of the infection between mink farms continues in an unknown manner [255].

The amount of virus in the cells of various organs and tissues is predetermined by the level of expression of receptors and enzymes important for penetration of the virus into their cells. Study of expression of such important molecules as ACE2 (SARS-CoV/SARS-CoV-2 receptor), CD26/DPP4 (MERS-CoV receptor), ST6GAL1 and ST3GAL4 (enzymes required for the synthesis of sialic acid residues, which are associated with influenza virus), TMPRSS2 (protease required for virus penetration into the cell), etc., has explained why at the beginning of infection SARS-CoV-2 is contained in the upper respiratory airways in much larger quantities than MERS-CoV and influenza virus (especially in the nasal cavity), where the high levels of expression of ACE2 and TMPRSS2 were registered [47]. Probably this could be the cause of three times higher contagenisity of SARS-CoV-2 (compared to the influenza virus) and the ability to infect other people before the onset of symptoms. Upon onset of symptoms, the spread of the virus gradually decreases. Perhaps, there is evidence that people continue to discharge the virus from saliva and faeces for two weeks after recovery [48]. So, even after the symptoms disappear, it is still possible to infect other people. That is why during the pandemic, physical distancing of people is so important (preferably at least $2 \mathrm{~m}$ ) in order to prevent the spread of the virus from carriers who do not manifest the disease symptoms.

There has been a vast discussion about the possibility of aerosol transmission of SARS-CoV-2 by small droplets (up to $5 \mu \mathrm{m}$ in diameter) while speaking, singing and breathing. Having researched this issue, various groups of scientists from China, Singapore, and USA found viral RNA in places where it could only get by aerosols in the rooms with COVID-19 patients, although no facts of infecting cell culture by virus were recorded. It was also shown that the virus can survive in aerosols for up to 3 hours in the laboratory settings. Therefore, physicians should wear respirators that protect them from aerosols [49]. According to other studies, during 1 minute of speaking, an individual releases into the air at least 1000 droplets with a size of $12-21 \mu \mathrm{m}$ (4 $\mu \mathrm{m}$ after drying in the air), which can carry the virus and cause infection. The droplets remained in the air for $8-14$ min, which is sufficient for probable infection of other individuals [50].

For several months, the WHO denied the possibility of such a way of virus transmitting. Only on July 8, 2020, after publication of an open letter by 239 scientists from 32 countries, the evidence of aerosol transmission of coronavirus in specific conditions, including indoors and in overcrowded premises was recognized. Confirmation of this evidence after careful evaluation changed the WHO's advice on preventing the spread of the virus and lead to greater use of masks and stricter distance, especially in shops, restaurants, and public transport [51].

Of particular concern to humans is the possibility of SARS-CoV-2 infection in long journeys by trains and aircraft, where a significant number of people spend a long time in a limited space closely distanced between each other. On the one hand, studies have shown that the risk of infection of passengers during short flights in the United States with masks on is only 1 of 4300, and with vacant middle seats - 1 of 7700 . Probably, such results could be explained by the fact that the air inside modern aircraft is replaced every 2-3 minutes, and most aircraft are equipped with air filters designed to capture $99.99 \%$ of particles. On the other hand, cases of inflight infection still occur, and airlines suffer from significant financial losses due to reduced passenger traffic while trying to do everything possible to ensure maximum safety, including offering protective shields and gloves in addition to masks, checking the temperature, intensive cleaning, restricting movement during flights, free middle passenger seats, although it is economically unprofitable [220].

We advised the officials in charge of the National Security and Defence Council of Ukraine to take a decision on installation of ozonators in public transport (subway cars, trains, buses, etc.), as ozone effectively neutralizes viruses in the air and on surfaces. Unfortunately, our advice has not been accepted yet.

The studies have shown that increasing absolute humidity and temperature somewhat reduces the spread of SARS-CoV-2. Perhaps, as expected [52], the increase of temperature in the summer season did not reduce the spread of the virus. Given no specific prophylaxis or treatment of COVID-19 is currently available (as of November 2020), the spread of the virus can only be stopped by epidemiological measures, during which all infected persons (or at least the vast majority of them) are detected and isolated, all their contacts tracked. 
A number of recommendations have been developed to reduce the level of human infection with asymptomatic vectors. In order to prevent airborne transmission of the virus, it was recommended to wear masks in crowded places. To minimize the possible risk of transmitting the virus by aerosols, it is necessary to thoroughly ventilate the premises.

There is a lot of contradictory information about the effectiveness of different types of masks. The CDC recommended the citizens wear tissue masks and leave surgical masks and respirators for physicians [53]. Some WHO recommendations were that tissue masks should not be used at all, unlike medical masks [54]. It is known that masks prevent the spread of viruses, as they stop droplets while coughing and sneezing of a sick person. However, whether medical masks can protect a healthy person remains unclear. At least wearing a mask is recommended for individuals who contact with sick patients, because the mask is able to retain a certain portion of droplets. Moreover, it prevents the face from touching by hands, although, on the other hand, wearing masks can cause a feeling of unwarranted security and encourage neglect of other safety measures, such as hand washing. In addition, masks should be properly removed and disposed to prevent contamination of hands, which requires certain skills from individuals and can put them at risk due to improper actions.

Therefore, in everyday life, the main precautions detailed in the WHO and the Ministry's of Health of Ukraine recommendations, are hand washing, ventilation, wearing masks in public places to protect those around, and decontamination of virtually contaminated surfaces. However, the most important thing is physical and social distancing.

The effect of such measures on the spread of the disease has been studied in detail in a large-scale study [55], which showed that lockdown in 11 European countries made it possible to avoid from 21 to 120 thousand deaths. Relying on forecast of the Imperial College of the University of London, authorities of the United Kingdom, at the beginning, hoped that isolation of only risk groups and development of collective immunity would make it possible to keep the disease under control. However, soon after the catastrophic increase in the number of patients, strict lockdown measures were introduced. A similar pattern developed in Singapore, where easing of a lockdown introduced in the first week of April, only exacerbated the situation, although before that the country controlled COVID-19 quite successfully. It is clear that lockdown measures should be continued (perhaps in a somewhat eased version) to prevent recurrent outbreaks of COVID-19 in so far unaffected regions.

\section{Special features of COVID-19 course}

The pathogenetic processes caused by SARSCoV-2 infection (as well as by SARS and MERS pathogens) are explained by changes in a target cell, which relate to the patterns of transcription and translation, cell cycle, cytoskeleton, signalling pathways of apoptosis and coagulation, inflammation, and response to stress. Coronavirus is able to induce cell apoptosis, which leads to the destruction of affected tissues and the development of fibrous post-recovery scars in lungs. The virus disrupts water-salt metabolism and protein transport caused by induction of cell fusion and the effect on permeability of membranes thereof. Under such conditions, surfactant deficiency develops, which leads to the collapse of alveoli and pulmonary distress syndrome [56]. The most dangerous feature of SARS-CoV-2 is its ability to cause hyperreactivity of the innate immune system driven by macrophage damage and induction of a cytokine 'storm,' which causes serious pathogenic damage.

Interesting and rather unexpected findings were obtained at the Max Planck Institute for Evolutionary Anthropology in Leipzig. Svante Pääbo, the Director of the Institute, known for his pioneering research into the origin and settlement of humans over the planet, in cooperation with his colleagues, found that a sequence of six human genes located in chromosome 3 inherited by our ancestors from Neanderthals about 60 thousand years ago, significantly increased the risk of COVID-19 complications. In human evolution, these genes had probably played a positive role in countering infectious diseases, but now, on the contrary, they significantly increase the risk of mortality [57].

Most of the COVID-19 course peculiarities were established on the basis of analysis of data obtained from the epidemic in China, where various factors of patient condition were recorded extremely carefully and in great detail, as well as in Western Europe and later in the United States. The average length of stay of patients at hospital in China was 24.7 days; in case of lethal outcome, an average of 17.8 days passed from the onset of symptoms to death. Mortality of laboratory and clinically confirmed cases in China was $3.67 \%$, while among patients aged 80 years and older $-18.4 \%$. In other countries, 
mortality rate ranged from $2-3 \%$ to $11-12 \%$ [58]. According to the statistics of Johns Hopkins University (USA), the global COVID-19 mortality rate was 4.6\% as of July 8, 2020 (544,996/11,865,335). This indicator gradually decreased over the time [4], perhaps because of better medical aid but not of virus new properties. It's worth noting that assessment of the mortality rate in the country is a difficult task, since insufficient testing sometimes makes it impossible to assess the total number of people who had minor symptoms and recovered from COVID-19.

When studying the prevalence of SARS-CoV-2 infection and COVID-19 disease, it was found that males were more likely than females to become infected, get sick and die $[59,60]$. These findings have been confirmed in almost all countries, although they differ depending on epidemiological factors. The first results were obtained in China, where mortality (regardless of age factor) was 2.8\% and 1.7\% for men and women, respectively. In Italy, the risk of getting sick was three times higher for men than for women. In New York state (USA), the mortality rate was $42 \%$ for women versus $58 \%$ for men [61].

Possible causes that make males more susceptive to COVID-19 include: comorbidities (primarily hypertension, diabetes, cardiovascular disease, and obesity), behavioral factors (smoking, alcohol abuse), age-related features, and ACE2 receptor level. It turned out that men's blood has a much higher ACE2 level than that of women. Another important reason is the difference in sex hormones. For example, in Spain, a disproportionate number of men with male pattern baldness associated with high testosterone level were admitted to hospitals with COVID-19 diagnosis. Female steroid hormones appeared to be immune stimulants in contrast to the male hormone testosterone, which inhibited immune protection and increased the ability of SARS-CoV-2 to penetrate into cells [62]. In particular, 17ß-estradiol and progesterone reduce the innate immune inflammatory response, simultaneously increasing immune tolerance and antibody production. The therapeutic use of these hormones is considered a way of soothing the cytokine 'storm' in COVID-19 patients [245]. Probably, the combination of all these factors constitutes the cause of higher male mortality in COVID-19.

One of the possible explanations for the high mortality of elderly people from COVID-19 may be a decrease of the immune system functional activity while aging. Thus, a study conducted in England in 109 thousand people of different age showed that $6 \%$ of adolescents and young people had antibod- ies capable of neutralizing SARS-CoV-2 [218]. The analysis of lethal cases showed that the risk of death increased with age, and the factors that contribute to mortality were obesity and comorbidities in patients, especially diabetes, hypertension, cardiovascular, cancer and respiratory diseases, or other infectious diseases that could cause sepsis [63]. A considerable indirect evidence that diabetes mellitus is not only a COVID-19 lethal risk factor, but itself may emerge from coronavirus damage to the pancreas and induction of autoimmune processes in it [64].

Obesity is a risk factor not only because overweight people are at higher risk of diabetes, hypertension and cardiovascular disease. This condition forms a unique microenvironment for the pathogenesis of COVID-19, characterized by chronic mild inflammation, which causes tissue hypoxia, depletion of immune cells, greater susceptibility to infections and less susceptibility to vaccinations, antiviral and antimicrobial drugs, and active secretion of proinflammatory cytokines which cause even more inflammation, closing the circle [250]. The increased severity and a spectrum of clinical manifestations of COVID-19 in patients with metabolic syndrome may also be associated with significant expression of ACE2 receptor with which SARS-CoV-2 interacts for penetrating cells in some sections of the pancreas, vascular endothelium, and adipose tissue [251].

Differences in mortality from COVID-19 in different countries can be explained not only by differences in the operation and supply of the healthcare system, the spread of diabetes, obesity and cardiovascular disease, genetic features, but also by different research methods and a possibility of spreading the disease at centers for seniors [218].

It is still unclear why SARS-CoV-2 infection is asymptomatic in some people and causes severe COVID-19 and death in others, even if they are not characterized by the above-mentioned risk factors. Therefore, the pursuit for markers that would help predict the development of the disease following infection with SARS-CoV-2 continues. Recent studies have shown that high level of cortisol is a better marker of the risk of death for COVID-19 than levels of C-reactive protein, D-dimer or the ratio of neutrophils and leukocytes [65]. Other studies suggest that a deficiency of certain subpopulations of $T$ cells and a sharp decrease in the level of basophils, cells involved in tissue repair, may be markers [66]. The above-mentioned risk factors for critical conditions in COVID-19 have also been associated with increased Th17 cell activation and interleukin-17 sig- 
nalling, which may lead to an increased likelihood of lung damage and respiratory failure [246].

It has been shown that the disease course at early stages can be predicted by a degree of immunodominance of SARS-CoV-2 antibodies to protein $\mathrm{S}$ or protein $\mathrm{N}$, calculated on the basis of five indicators: level of IgG1, IgM, IgA1 antibodies specific for protein S, and level of IgM, IgA2 antibodies specific for protein $\mathrm{N}$. The shift in the dominance of antibody specificity towards protein $\mathrm{S}$ indicated recovery of a patient, while the shift towards protein $\mathrm{N}$ suggested a high probability of death from COVID-19 [215].

Half of severe COVID-19 patients manifest elevated plasma sodium concentration (> $150 \mathrm{mmol}$ per liter), which is associated with abnormally high renal sodium reabsorption due to increased angiotensin II activity caused by decreased regulation of ACE2 receptors [249].

Scientists of Cornell University (USA) were able to predict the death of some patients with $90 \%$ accuracy in 10 days by identifying three markers, including elevated level of lactate dehydrogenase, an enzyme involved in the production of energy by each cell, which gets into the bloodstream upon tissue damage [67]. Studies in Indonesia among 780 COVID-19 patients demonstrated that $95.8 \%$ of lethal cases were associated with vitamin D deficiency (below $20 \mathrm{ng} / \mathrm{ml}$ ); while $93 \%$ of surviving patients had a normal vitamin D level. Similar results were obtained in studies in the Philippines and the United Kingdom [68]. A retrospective study in Illinois revealed that people with vitamin D deficiency might be nearly twice as likely to become infected with SARS-CoV-2 as people with adequate vitamin D levels. As vitamin D strengthens innate immunity, we can expect it able to suppress SARS-CoV-2 infection and transmission. Moreover, vitamin D also contributes to zinc metabolism, which inhibits coronavirus replication [265]. The answer to question of whether taking vitamin $\mathrm{D}$ can reduce mortality for COVID-19 had to be given by the results of clinical research in elderly patients ( $\geq 70$ years) conducted by the University Hospital of Angers (France) and scheduled for completion in 2020. [68].

The severity of COVID-19 may be related to variation amount of ACE2 protein, which is expressed on the surface of some cells in the nose, lungs, intestines and utilized by the virus for penetrating the cell. Concerns have been expressed that people with diabetes, hypertension, or cardiovascular disease are more vulnerable to coronavirus because they often take ACE2 inhibitors, which cause increasing the number of these receptors on cells [69]. However, studies have shown that administration of ACE2 inhibitors and angiotensin II receptor blockers does not cause higher ACE2 plasma concentration [70]. There has even been evidence that COVID-19 patients with hypertension have lower mortality taking ACE2 inhibitors [71]. Therefore, those who take such medicines are recommended to continue administration [72].

It is assumed that SARS-CoV-2 penetrates into cells of different types (epithelial, immune, etc.) with the help of different receptors and helper molecules (ACE2, CD147, CD26, TMPRSS2, etc.), and changing expression of these receptors associated with age, sex, obesity, smoking and other risk factors can cause severe course of COVID-19 [73].

Of course, there are genetic factors that influence the COVID-19 severity. The analysis of genomes of 1,610 COVID-19 patients admitted to hospitals in Italy and Spain who had respiratory failure revealed common genetic features in these people. Many severe COVID-19 patients had certain chromosome 3 variants of gene complex, including genes encoding chemokines that interact with immune system molecules and are involved in the cytokine 'storm,' and reduced activity of a gene that helped regulate chemokines. Another feature of severe COVID-19 patients was the elevated activity of a gene encoding protein capable of interacting with ACE2 - a receptor used by SARS-CoV-2 for cell penetration. Studies have also linked the severity of COVID-19 to a region of chromosome 9 that determines blood group. COVID-19 patients with type II blood group were 1.5 times more inclined to respiratory failure than those with other blood groups, while patients with type I blood group were less likely to have severe course of COVID-19 [235].

It has long been known that COVID-19 is more severe in ethnic minorities living in European countries and the United States, including those from South Asia, Africa, Latin America, Indians, etc. The causes of this phenomenon remain unclear. The analysis of information from the UK Biobank on people tested for COVID-19 showed that the higher probability of severe COVID-19 in ethnic minorities (1.5-2 times) cannot be explained by the impact of socio-economic and cardiometabolic factors, including different levels of vitamin D [258].

The US CDC, which is probably the most authoritative institution for combating infectious diseases in the world, names the following three main symptoms of COVID-19: fever (high tempera- 
ture), dry cough and difficult breathing. These symptoms can be severe or not; the disease can even pass without symptoms.

Based on the analysis of 56 thousand COVID-19 cases in China, the WHO has presented the following distribution of symptoms: fever (87.9\%), dry cough (67.7\%), weakness (38.1\%), sputum (33.4\%), shortness of breath (18.6\%), sore throat (13.9\%), headache (13.6\%), muscle pain (14.8\%), cold sensation (11.4\%), nausea and vomiting (5.0\%), runny nose (4.8\%), diarrhoea (3.7\%), cough with blood $(0.9 \%)$, and eye redness $(0.8 \%)$. Such symptoms as loss of taste and smell, fainting, dermatological manifestations (including urticaria) and lymphocytopenia are also observed [74]. Loss of taste and smell is a specific symptom that almost clearly indicates COVID-19, as it is very rare in other infectious diseases. Recently, another unusual symptom has been observed, a hearing loss or tinnitus, which can persist long post-recovery [232].

Lymphocytopenia is also an important diagnostic sign that helps to predict further course of the disease, because lowering CD3+, CD4+ and CD8+ T-lymphocytes in COVID-19 often correlates with higher mortality rates [75]. The peripheral blood mononuclear cells of COVID-19 patients are characteristic of activating the p53 signalling pathway, apoptosis stimulation and autophagy. SARS-CoV-2 is known to infect $\mathrm{T}$ lymphocytes by fusing protein $\mathrm{S}$ with membrane of target cell. It likely does not reproduce in $\mathrm{T}$ lymphocytes, just like MERS-CoV, but causes apoptosis in them [76]. Also, patients often present a high concentration of iron-containing protein ferritin, which is involved in the activation of macrophages for enhancing the secretion of inflammatory cytokines [77].

The most dangerous complications of COVID-19, which may lead to death, are pneumonia, acute respiratory distress syndrome, multiple organ failure, and septic shock [78]. Cardiovascular complications such as heart failure, arrhythmia, cardiac inflammation, and thrombosis are also numerous [79]. Approximately $20-30 \%$ of patients that have been exposed to COVID-19 in the past have elevated liver enzymes, indicating liver damage [80]. In children, infection with SARS-CoV-2 can lead to the development of paediatric multisystem inflammatory syndrome, which has signs similar to Kawasaki disease and can be fatal [81]. Unlike children with mild COVID-19 or Kawasaki syndrome, children with MIS-C do not have antibodies to the two coro- naviruses that cause seasonal colds, and are characterized by low levels of interleukin-17A, which cause inflammation and autoimmune disorders [253]. Although it should be noted that children have rare severe COVID-19 complications and often sustain the infection asymptomatically. According to a study involving nearly 400 SARS-CoV-2 infected children and adolescents (under 21), 6 to 13-year-old children are less likely to have symptoms of COVID-19 than those younger or older. Only $61 \%$ of infected children aged 6 to 13 years manifested symptoms, compared with $75 \%$ of infected study participants under 6 years and $76 \%$ of those over 13 years. About a third of infected children had an infected sibling and did not come into close contact with infected adults, meaning the virus spread from child to child [257].

Despite COVID-19 is considered predominantly respiratory disease of adults (mostly people over 65), SARS-CoV-2 is quite capable of damaging kidneys, liver, heart, and almost every organ system. The phenomenon was confirmed by studies of gene expression of 28 molecular factors that might facilitate or limit the ingress of SARS-CoV-2 into tissues of various organs. The results showed that the virus had alternative routes of penetration into the lungs, central nervous system and heart, and could infect the intestines, kidneys and placenta. Some groups of prostate and testicular cells have also been found vulnerable to SARS-CoV-2, which to some extent may explain the higher susceptibility of men to the infection [272].

Complications associated with activation of the blood clotting system (pulmonary embolism, stroke, myocardial infarction, etc.) are observed in about $30 \%$ of critically ill patients. This can be caused by inflammation of the endothelium (internal envelope of blood vessels), which leads to abnormal blood clotting in all blood vessels and damage to various organs, which explains many of the COVID-19 symptoms [82].

More than 300 studies worldwide have identified the prevalence of neurological abnormalities in patients with COVID-19 [83]. Thus, scientists of the University of Liverpool (UK) diagnosed 62\% of COVID-19 patients with cerebrovascular pathology (ischemic stroke, intracerebral haemorrhage, vasculitis), and $31 \%$ of patients with mental status changes (neonatal psychosis, neurocognitive syndrome, affective and mental disorders), while $41 \%$ of patients had mental disorders having encephalopathy or encephalitis [84]. It has recently been suggested that 
COVID-19 causes respiratory failure and death due to damaging not lungs but the brainstem, which is the command center controlling breathing, even in unconscious patients. There is considerable evidence that SARS-CoV-2 can penetrate the blood-brain barrier and enter the brain. Coronavirus is likely to stay there for a long time and become active over many years, like the chickenpox virus, which infects spinal nerve cells in children and relapse in adulthood, causing shingles [85].

Conclusive evidence has revealed that SARS$\mathrm{CoV}-2$ can penetrate the brain and cause serious consequences. This was proved by experiments on human brain organelles infected with SARS-CoV-2, in which concomitant metabolic changes were observed in infected and neighbouring neurons. Neuronal infection could be prevented by blocking ACE2 antibodies or administering cerebrospinal fluid from a COVID-19 patient. Experiments on mice that express large amounts of human ACE2 have shown that brain infection, not respiratory infection, is the leading cause of death. Finally, the autopsy of patients died from COVID-19 presented SARS-CoV-2 in neurons of the cerebral cortex and outlined the pathological features of this infection, including a small number of immune cell infiltrates [260].

Scientists suggested that various lesions in COVID-19 patients could be explained by a threephase mechanism of SARS-CoV-2 action. At the first phase, the virus binds to ACE2 expressed in significant amounts in the cells of lungs, arteries, heart, kidneys and intestines, infects and damages them, causing a cytokine 'storm.' At the second phase, cytokines increase vascular permeability, which leads to oedema and the spread of inflammation, while hypercoagulation cascades lead to the development of small and large blood clots that damage various organs. At the third phase (if it occurs), the virus penetrates the blood-brain barrier and enters the brain, thus causing demyelination or neurodegeneration [86].

Increased vascular permeability, which leads to accumulation of fluid in tissues and oedema, is associated with disorders in the renin-angiotensin system RAS, including ACE and ACE2 enzymes, involved in the regulation of blood pressure and bodily fluid balance. This system regulates the kinin signalling pathway, in particular - its main enzyme, bradykinin, which is responsible for the development of inflammation and the cytokine 'storm,' considered an important component of COVID-19 pathogenesis.
The use of ACE2 by SARS-CoV-2 virus as a receptor for cell penetration leads to a decrease in extracellular concentration of this enzyme, which in turn increases bradykinin concentration, causes fluid accumulation in tissues and inflammation. Coagulation disorders, which are common in COVID-19 patients, can also activate the kinin system and bradykinin production [261].

Therefore, the pathogenesis of COVID-19 is based on causing damage to cells of the human body using two mechanisms: the direct cytotoxic effect of SARS-CoV-2 virus, and excessive response of the immune system to the virus (severe inflammation, cytokine 'storm,' killer cell attack). However, some admit that COVID-19 has another, additional mechanism that contributes to virus infection and cell damage - the so-called antibody-dependent enhancement (ADE). This mechanism causes enhancement of virus replication in the human body due to the fact that viral particles in combination with antibodies and complement components easily penetrate cells through Fc receptors that interact with antibodies, or through corresponding complement receptors.

The increase of viral load stimulates the secretion of pro-inflammatory cytokines by macrophages and occurrence of a cytokine 'storm.' Thus, specific antiviral antibodies that emerge in the body following the immune response, vaccination or administration of immunotherapeutic drugs, in particular convalescent serum, may not protect from viral infection, but, on the contrary, significantly worsen the situation. It turns out that only a large number of specific antiviral antibodies can neutralize the virus.

The ADE mechanism was first observed in members of the Flaviviridae family of viruses, which are the causative agents of West Nile fever, dengue fever, tick-borne encephalitis, and the like. The evidence amass that coronaviruses benefit from using the ADE mechanism. Thus, immunization against feline infectious peritonitis virus (FIPV) paradoxically increases the severity of the disease, and macrophage infection with FIPV virus can be amplified by strongly diluted neutralizing monoclonal antibodies to viral protein S. Similar results were obtained in in vitro experiments with SARS-CoV virus: concentrated serum against protein $\mathrm{S}$ protected cells from infection, yet facilitated infection and caused the death of even more cells for apoptosis after dilution. The possibility of using the ADE mechanism by SARS-CoV-2 places new demands on the safety of vaccines and immunotherapeutic medicines, actively globally developed in the present time [87]. 


\section{SARS-CoV-2 and COVID-19 diagnostics}

Among the many different, in particular modern, often very expensive and complicated methods of SARS-CoV-2 detecting and COVID-19 diagnostics, there are two groups of diagnostic tests that are most common and generally accepted. The first group of tests aims at direct identification of RNA of the virus (or parts thereof) by polymerase chain reaction (PCR), and the second one - on identification of antibodies to the virus in patients (regardless of whether the patient is currently a carrier of the virus or no), i.e. at searching for 'traces' of the viral infection. Such antibodies (usually IgG class) can remain in the patient's blood from several months to many years depending on many factors.

PCR tests for virus detection. At the beginning of the pandemic, the WHO developed nonprofit laboratory protocols, most of which were designed for diagnostics involving reverse transcription real-time polymerase chain reaction (rRT-PCR) [88].

The main 'targets' in the genome of SARS$\mathrm{CoV}-2$, used for the diagnostics in different countries using the PCR method [89] are presented in the Table above.

Many commercial tests have already been developed that detect the SARS-CoV-2. The Foundation for Innovative New Diagnostics (FIND) in Geneva, which supports the development and delivery of diagnostics to poor countries, has posted on its website [90] the information on 747 diagnostic tools, of which approximately 350 are based on enzyme-

Target genes in the SARS-CoV-2 Genome for PCRdiagnostics in different countries

\begin{tabular}{|l|c|}
\hline Countries, institutions & Target genes \\
\hline $\begin{array}{l}\text { China (Center for Disease } \\
\text { Control and Prevention) }\end{array}$ & ORF1ab, N \\
\hline $\begin{array}{l}\text { France (Pasteur } \\
\text { Institute of Paris) }\end{array}$ & RdRP2 (2 sites) \\
\hline $\begin{array}{l}\text { USA (Center for Disease } \\
\text { Control and Prevention) }\end{array}$ & N (3 sites) \\
\hline $\begin{array}{l}\text { Japan (National Institute } \\
\text { of In-fectious Diseases) }\end{array}$ & Pancorona, Spike \\
\hline Germany (Charité Clinic) & RdRP, E, N, HKU \\
\hline $\begin{array}{l}\text { Hong Kong } \\
\text { Thailand (National } \\
\text { Institute of Health) }\end{array}$ & SAR ORF1b- \\
\hline
\end{tabular}

linked immunosorbent assay and PCR tests for detection of the virus RNA (the list is constantly updated).

Most of the available diagnostic tools for detecting SARS-CoV-2 genetic material are rRT-PCR kits. Although the simultaneous detection of multiple target coronavirus RNA sequences by multiplex rRT-PCR is rather complicated and time-consuming process that can only be performed at a laboratory, as it requires special equipment, appropriate reagents, and trained personnel, this same type of diagnostics remains the main one at central laboratories for testing viral traces. Large companies, such as Roche Diagnostics, Thermo Fisher Scientific, Qiagen, and Quest Diagnostics, are expanding the possibilities for conducting such research by introducing automated SARS-CoV-2 testing systems [91].

Scientists of the Institute of Molecular Biology and Genetics of the National Academy of Sciences of Ukraine developed a domestic PCR coronavirus test at the request of the National Security and Defence Council of Ukraine well in February 2020. Its production was stipulated by a Decree of the President of Ukraine, yet failed because of funding problem. This Institute is developing now a double test for simultaneous detection of SARS-CoV-2 and influenza virus.

PCR-tests of both foreign and domestic produce are being used in Ukraine now, perhaps in a nonsufficient scope. However, we do not have the information about the quality of these tests. The unknown share of false-positive and false-negative tests makes the objective control of the epidemiological situation in Ukraine extremely difficult.

It has been reported that after recovery from COVID-19, 14\% of discharged patients with negative PCR test results returned positive after a while [92]. These observations have raised many new questions: are PCR-tests of samples taken from throat correct (perhaps the coronavirus still linger in lung cells); whether the virus can be a 'two-phase' one (like anthrax), remaining 'hibernating' before the onset of new symptoms; is it possible to reinfect a human after recovery following an insufficiently strong immune response (low level of antibodies to the virus). However, sudden positive results have been associated rather with a more prolonged infection [93] or the detection of residual RNA fragments of the virus, which are gradually destroyed in cells, than re-infection [94]. However, comparative genomic studies of SARS-CoV-2 isolates obtained from one person 
when repeating positive test results [236] proved that the possibility of re-infection cannot be ruled out.

Since a significant number of people infected with the SARS-CoV-2 virus have an asymptomatic disease course or the spread of virus begins before symptoms appear, it is crucially important to expand diagnostic testing to curb the disease proliferation. One of the options that may help is to develop tests for detection of SARS-CoV-2 based on the aggregation principle, according to which each sample is divided into several pools using a combinatorial aggregation strategy, and, therefore, it makes possible to identify all positive subjects in a set of samples using one testing round. In particular, a P-BEST test was developed to detect SARS-CoV-2 in saliva, which helped testing 384 samples combined into sets of 48 pools for 2 hours, which made possible to increase the effectiveness of the test 8 times and reduce testing costs the same, simultaneously revealing up to 5 positive carriers [263].

Serological tests for detection of antivirus antibodies or virus itself. Different manufacturers have developed a large number of tests for detection of antibodies to SARS-CoV-2, which determine the antibodies of IgM, IgA and/or IgG classes in the blood of patients with different sensitivity. The development of such tests is relatively simple task, as only obtaining recombinant virus antigens absorbed on the insoluble surface of the diagnostic for binding specific antibodies from the blood of infected human with subsequent detection of these antibodies, usually by Enzyme Linked Immunosorbent Assay, or ELISA, is required.

The main problem of serological tests that determine the presence of antibodies to the virus in the patient's blood is quite obvious - the first antibodies (IgM-class) do not appear immediately, but only 5-8 days after infection and gradually disappear, while more numerous and more specific IgGclass antibodies appear even later, reaching a maximum on Day 24-28, and can remain in the serum for years.

Antibody tests are used to monitor the formation of collective immunity in a population and to identify people who have recovered from COVID-19 (they may no longer have SARS-CoV-2 viruses). Such people can become donors of convalescent serum, which is now considered one of the real remedies for treatment of crucially ill patients.

Several domestically produced immune tests for detection of IgM and IgG antibodies to SARS$\mathrm{CoV}-2$ are already on sale in Ukraine, for example,
AT-Coronavirus-test-MBA manufactured by MedBioAlliance LLC and COVID-19 IgM/IgG produced by LLC Innovative Biological Technologies. In addition, scientists of Zabolotny Institute of Microbiology and Virology of the National Academy of Sciences of Ukraine in cooperation with PJSC NVK Diaprofmed developed an enzyme-linked immunosorbent diagnostic for the detection of IgM and IgG to SARS-CoV-2 in microwell plate [95]. However, as in the situation with PCR tests, we are still lacking data on the quality of foreign and domestic serological tests used in Ukraine.

The development of immune-diagnostics for the detection of not antibodies but the virus itself and antigens thereto is a more difficult task, as it requires highly specific monoclonal or recombinant antibodies to SARS-CoV-2 antigens. Sona Nanotech (Canada) has developed a test to detect SARS-CoV-2 antigens, the main 'target' of which is the $\mathrm{S} 1$ domain of the protein $\mathrm{S}$ of the coronavirus 'spike', which is responsible for the binding to ACE2 and penetration into epithelial cells of the respiratory tract. The company planned developing a double test for simultaneous detection of SARS-CoV-2 and influenza viruses [96].

A team of scientists from the Centre for Genomic Research of the Sinica Academy (Taiwan) claims that they were the first who in just 19 days retrieved several highly specific monoclonal antibodies that recognize nucleocapsid proteins $\mathrm{N}$ of SARS$\mathrm{CoV}-2$ and SARS-CoV alone and both these viruses simultaneously and do not react with proteins $\mathrm{N}$ of other human coronaviruses. These antibodies could have been the basis for development of rapid tests for detection of SARS-CoV-2 antigens. The scientists managed to obtain antibodies that quickly (saving two months compared to traditional methods) due to the involvement of antibody-antigen interaction models created by artificial intelligence used to obtain libraries of artificial antibodies instead of immunizing animals. The calculated DNA sequences that encode monoclonal antibodies were obtained by chemical synthesis; the antibodies were synthesized using these DNA in bacterial expression systems and selected by binding capacity [97].

There is now a significant need for so-called Point-Of-Care (POC) tests, which do not require complex laboratory equipment, and therefore can be done even at home. Using such tests contributes to clinical decision-making and reduces the burden on central laboratories. Cepheid was the first company in the United States that obtained permission from 
the FDA for using POC tests. The SARS-CoV-2 test developed by the company is performed on GeneXpert Systems automated devices without sending samples (nasopharyngeal smears, nasal washes or aspirates) to a laboratory and takes 45 minutes. At the same time, the operational capacity of these devices is limited, since one device cannot test more than one sample at a time, and the total number of devices in the United States (as of March 2020) is only 5 thousand each [98].

Recently, the FDA approved the FIA Sofia 2 SARS POC test manufactured by Quidel (USA) to detect the SARS-CoV-2 (or SARS-CoV) nucleocapsid protein in nasal washes within 15 min [99]. This immunochromatographic test uses the principle of fluorescent enzyme-linked immunosorbent assay 'sandwich-analysis', the result of which is determined automatically using the Sofia 2 analyzer [100]. Other companies have also received permission from the FDA for POC tests: Mesa Biotech (USA) test takes 30 minutes and is performed on Accula System-30 device, while the test of one of the world's largest companies - Abbott Diagnostics (USA) - lasts from 5 to $13 \mathrm{~min}$ and is performed on Abbott's ID Now platform numbering approximately 18 thousand each around the world [101].

Pharmact (Germany) has launched a rapid 20-minute test for detection of antibodies to three SARS-CoV-2 antigens (protein N, S1 and S2 domains of protein $S$ ). The test appeared to be extremely specific: it did not give any false-positive or false-negative result in 114 SARS-CoV-2-infected patients and 126 uninfected individuals. Its sensitivity to IgM on Days $4-10$ of getting sick was $70 \%$, on Days 11- 24 - 92.3\%, and sensitivity to IgG on Days 11 - 24 - 98.6\% [97].

It is known about the development of POC-tests based on the technique of targeted genome editing CRISPR-Cas. According to FIND, such research is carried out by companies MGI Tech Co. Ltd (China) and Sherlock Biosciences (USA) [90]. Mammoth Biosciences (USA), also working in this direction in cooperation with the University of California, San Francisco and the California Department of Public Health, recently announced the development and testing of a 45-minute diagnostic (including RNA isolation stage). The diagnostic uses a reverse transcription of viral RNA and a simplified loop-mediated amplification technique that does not require repeated heating and cooling cycles. Following the amplification, the nucleic acid binds to RNA probe
(gRNA), which recognizes $\mathrm{E}$ and $\mathrm{N}$ gene sequences of SARS-CoV-2 virus, as well as to lbCas12a enzyme, which destroys neighbouring unbound portions of single-stranded DNA, after which fluorescent reporter molecules confirm the presence of viral RNA [102].

This method is very simple to perform. In fact, only a test tube with reagents worth $\$ 1$, a pipette, a burner, and a pan with water are needed for the analysis. Although LAMP tests are less sensitive than RT-PCR (they can detect the virus in $90 \%$ of cases), they do not require expensive equipment and reagents and can be used in the field conditions and in areas with poor laboratory equipment.

Mass testing of the population is one of the important means of deterring the COVID-19 pandemic.

In April, the US National Institute of Health allocated \$ 1.5 billion for development of coronavirus tests, with the goal of providing millions of tests a week by the end of this summer. Therefore, diagnostic methods are now being actively developed that allow a significant number of samples to be tested simultaneously. For example, scientists of Pennsylvania State University (State College, USA) have invented a way to test samples of nearly 20,000 people at a time. Their method is based on adding 'molecular barcodes' to clinical samples before combining them, which, following the analysis, allow to determine samples with a positive result. As DNA sequencers can analyze hundreds of millions of DNA fragments simultaneously, researchers have estimated that sequencing tests can be used to analyze up to 100,000 samples in a single cycle. In contrast, a standard PCR device can only analyze dozens or hundreds of samples at a time. However, sequencing tests require a longer analysis time (at least 12 hours) and special equipment of centralized institutions [237].

\section{Pharmaceuticals for COVID-19 treatment}

Despite the efforts of the best laboratories and pharmaceutical companies, no specific and effective medicines against COVID-19 have been invented [103]. In this regard, WHO has initiated a global initiative for the "Solidarity" global clinical trial, which involved not only a search for new medicines, which could be specific against SARS-CoV-2 virus and for treatment of COVID-19, but also mass screening of available medicines (mostly antiviral), which have already been granted a permit for practical administration or clinical trials, for efficacy and so called 


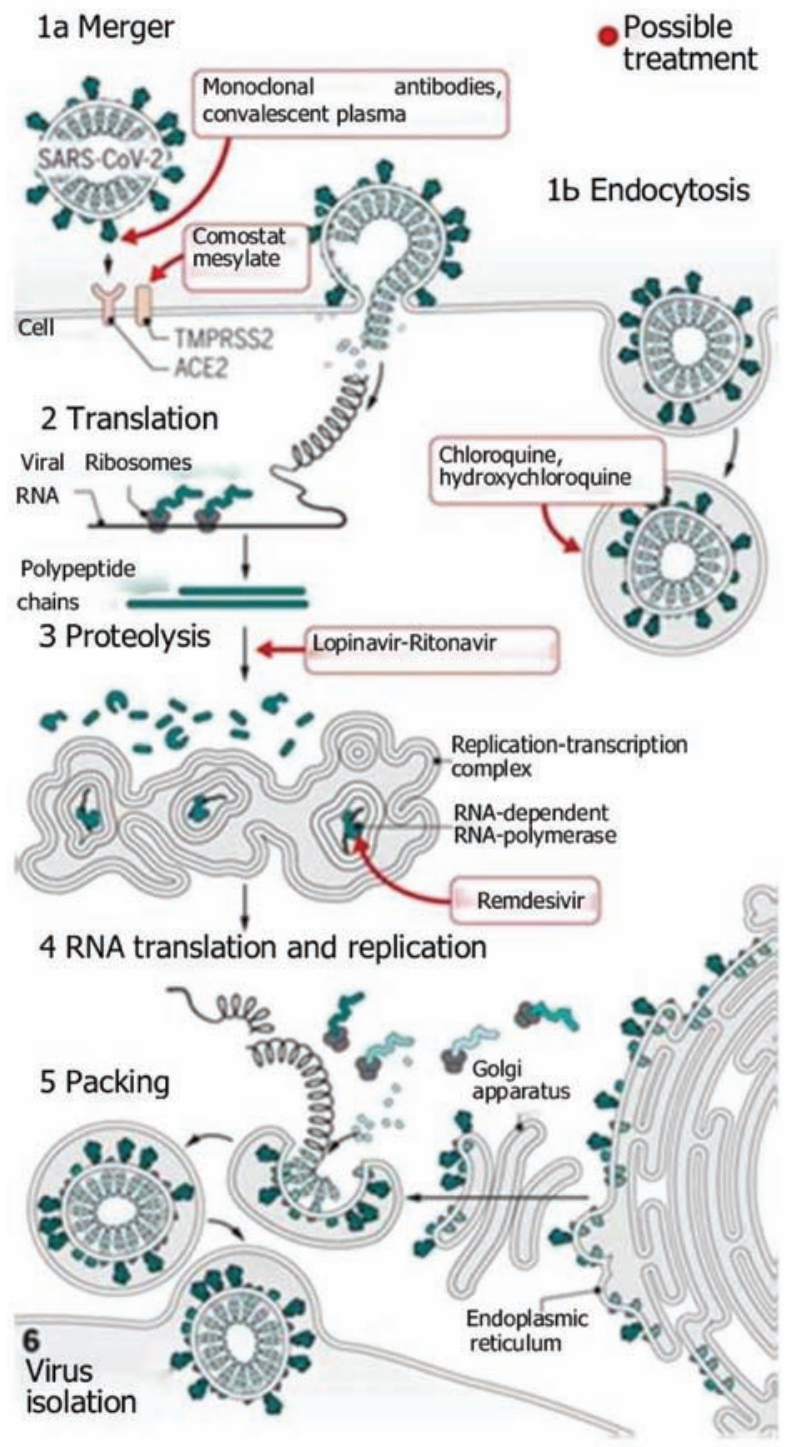

Fig. 3. Experimental treatment strategies used to try influencing different stages of coronavirus replication cycle (taken from article [104])

"repurposing" [104]. At that time, it was very likely that effective medicines for treatment of COVID-19 could be found before a vaccine for its prevention.

What medicines can be used to combat SARS$\mathrm{CoV}-2$ ? Scientists have proposed numerous therapeutic approaches aimed at blocking the various stages of the coronavirus replication cycle (Fig. 3). First, the virus may be prevented from penetrating the cell by blocking its interaction with receptors and helper molecules required for penetration. Such blockers may be recombined ACE2 or antibodies to SARS$\mathrm{CoV}-2$ surface proteins. In vitro studies have shown that recombinant ACE2 protein is able to slow the replication of SARS-CoV-2 and the spread of infection in tissues. The medicine on its base has already undergone clinical trials in China and demonstrated the protective effect on COVID-19 patients with acute respiratory distress syndrome [105].

Unlike 'natural' antibodies produced in infected humans against SARS-CoV-2 being largely the main weapon in combating the disease, a large number of laboratories are now working to create artificial antibodies of various structures that could be directed against virus spreading.

Different approaches can be used for this purpose $[106,107]$. The virus is known to interact with host target cell receptors (recognizes ACE2 and/ or NRP1 receptors) with its spike-like protein S, or more specifically, its receptor-binding domain (RBD). It is quite logical to assume that artificial antibodies to RBD, in particular humanized monoclonal antibodies synthesized by hybridomas, recombinant antibodies formed by corresponding cell cultures, and their smaller derivatives ( $\mathrm{scFv}$ ) and/or nanobodies will prevent the interaction of the virus with target cells [106]. Indeed, while immunizing rabbits with proteins S, S1, and RBD (not S2), strong neutralizing antibodies were formed. However, RBD immunization caused producing antibodies with 5 times greater affinity for native viral protein S [108]. Protein S, which binds to ACE2 cell receptor via RBD, is known to be $77.5 \%$ homologous in SARS-CoV and SARS-CoV-2. A monoclonal antibody capable of neutralizing both these types of coronaviruses has recently been retrieved. The authors [109] developed fully humanized monoclonal antibodies to SARS2-S1 virus subunit, which effectively bound to cells expressing the full-size protein $\mathrm{S}$ of SARS-CoV and SARS-CoV-2 viruses. These antibodies also strongly inhibited the interaction of SARS-CoV and SARS-CoV-2 viruses with VeroE6 cells ( IC $_{50}=0.061 \mu \mathrm{g} / \mathrm{ml}$ for both viruses).

Researchers of the Karolinska Institutet (Sweden) have isolated the alpaca nanobody Ty1, which binds to EVB viral domain, available in both "up" and "down" conformations, and sterically prevents RBD binding to ACE2 cell receptor. Ty1 neutralizes SARS-CoV-2 pseudovirus as a nanobody weighting $12.8 \mathrm{kDa}$, and the fusion of Tyl with $\mathrm{Fc}$ domain makes the design extremely efficient. A feature of nanobodies also found in wild camels is a very small size (less than one tenth) compared to the classical antibody. For this feature, nanobodies can be convenient research tools and therapeutic agents that do not cause foreign immune reactions in humans and 
can be easily and cheaply isolated on an industrial scale. Preclinical studies of Ty1 nanobody in animals are now beginning to test neutralizing activity and therapeutic potential in vivo [267].

The development of such 'target' antibodies began immediately after publication of the structure of virus genome, when the nucleotide sequence of RNA could unveil the amino acid sequence of protein $S$ and its RBD (largely similar to SARS protein S) and at least approximately calculate the spatial structure of the antigen-binding do-main of the constructed antibodies.

It's worth noting that antibodies to coronavirus epitopes (other than RBD) may also have strong protective properties, as there are other mechanisms to neutralize SARS-CoV-2 in addition to blocking the interaction of RBD with the ACE2 cell receptor. Thus, the monoclonal antibody 4A8 to N-terminal domain (NTD) of protein S does not interact with $\mathrm{RBD}$, but can neutralize SARS-CoV-2, probably on account of inhibiting the conformational changes of protein S [110].

Scientists at the Rockefeller University Molecular Immunology Laboratory have used a different approach [111]. More than 10 antibody samples were taken from the blood of more than 100 people who recovered from COVID-19, which effectively blocked the spread of the virus and inactivated it. The spatial structure of these antibodies has become the basis for development of artificial antibodies, from which they plan to create effective medicines against COVID-19. It should be noted that not only antibodies to RBD, but also to other parts of protein $S$ or other proteins on the surface of the virus can be virus-active antibodies.

Studies of specificity and antibody antivirus effect are extremely important for the development of a prophylactic vaccine against the virus, because vaccination should cause an immune response and call immune memory namely against those parts of the virus that prevent its development in an immunized human. Therapeutic antibodies and vaccines are not competitors, they rather complement than exclude each other. Both therapeutic antibodies (attention: this is not about the antibodies contained in the plasma of people who just recovered!) and vaccines are now undergoing clinical trials, though, probably, antibodies, which induce "passive" immunization will have much higher price. Thus, price for antibodies used for treatment of various malignant tumours (there are already dozens of them on the market) and
AIDS ranges from tens to hundreds of thousands of dollars per treatment course.

Of great interest are antibodies that do not show neutralizing properties in in vitro experiments, yet protect from coronavirus in vivo. A crystallographic study of such an antibody (CR3022) in combination with RBD showed that it recognizes the epitope formed when at least two of the three RBDs on the 'spike' of the virus are in 'up' conformation and somewhat turned [112].

The idea of producing and using highly effective antibodies for treatment of COVID-19 patients, which provide temporary protection against coronavirus when administered, has recently gained the popularity. Antibody-based medicines are commonly used to treat cancer and HIV, but some are also used for combating respiratory infections, such as respiratory syncytial viral infections in children. Biotechnology company Regeneron Pharmaceuticals (USA) has developed medicine REGN-EB3, which consists of three antibodies to Ebola virus. The medicine has been successfully tested to help reduce the mortality rate during the Ebola outbreak in the Congo in 2018. The company is now working on therapeutic antibodies against COVID-19 and conducting clinical trials of an antibody cocktail developed from human antibodies and ones of humanized mice with active human genes [111].

Other pharmaceutical companies are also working on therapeutic antibodies against COVID-19. First of all, it is Eli Lilly (USA) and AbCellera (Canada), who started the second phase of clinical trials of neutralizing antibody LY-CoV555 against COVID-19 with involvement of 400 mild and moderate COVID-19 patients on June 17, 2020. This antibody was developed using the blood of a patient who recovered from COVID-19 well in February [113].

Late summer, it was scheduled to start clinical trials of so-called Rockefeller antibodies - a preparation of three antibodies to different RBD epitopes developed by Rockefeller University (USA) using the results of a study involved 149 people recovered from COVID-19 [114]. Following finding antibodies with strong protective properties against the new coronavirus, Vanderbilt University (USA), in collaboration with the Cambridge University and the pharmaceutical company AstraZeneca (UKSweden), also conducting clinical trials. In August 2020, Sorrento Therapeutics (USA) started the first phase of clinical trials of neutralizing antibody STI1499 against COVID-19, which was developed by 
researchers from the University of Utrecht (Netherlands) [115].

Clinical trials of therapeutic preparations are carried out faster than those of vaccines. Despite this, the most promising therapeutic medicines based on antibodies may receive FDA approval no earlier than December 2020 or January 2021. This term roughly coincides with the most ambitious estimates of the time for COVID-19 vaccines market release. Moreover, preparations based on recombinant or monoclonal antibodies are usually very expensive, which, of course, will put obstacles to their widespread use for COVID-19 treatment. Therefore, many countries started using convalescent plasma from recovered people, which contains polyclonal antiviral antibodies, for treatment of patients with COVID-19. Initially, researchers had many concerns about threatening dangerous complications as infectious agents can be transmitted with plasma; in rare cases, transfusion may lead to circulatory overload (TACO), when the patient's body cannot adapt the growing blood volume, or to acute lung injury (TRALI), when transferred antibodies damage the pulmonary vessels or to the ADE (antibody-dependent enhancement). Despite the risks, convalescent plasma transfusions have been used in China and the United States (where the method has been provisionally approved by FDA [116]). Clinical trials showing reliable results are now being conducted in many countries [117].

However, preliminary results of current clinical trial of convalescent plasma in 426 patients with COVID-19 conducted at the Erasmus University Medical Center of Rotterdam (Netherlands), have shown that most COVID-19 patients already have high titers of neutralizing antibodies at the time of admission. Therefore, antibody testing should be performed and priority risk groups identified to establish patients, which could benefit from transvalescent plasma transfusion [118]. On September 1, 2020, FDA, following President Trump's order, authorized the emergency use of convalescent plasma for treatment of hospitalized COVID-19 patients, although noted that lacking clinical trial data precluded the final approval of this medicine [241].

It should be noted that convalescent plasma has been successfully used in previous epidemics of SARS, MERS, Ebola and other infectious diseases. Therefore, there is every reason to recommend blood plasma of COVID-19 recovered people having no viruses for treatment of critically ill pa- tients in Ukraine. Even more effective would be administration of an immunoglobulin fraction isolated from blood plasma containing specific antibodies. Recently, Biopharma (Kyiv) called on citizens who have recovered from COVID-19 to become plasma donors for development a medicine against the disease [119]. Interestingly, men appeared to be more promising plasma donors, as among people who recovered from COVID-19, $43 \%$ of men, and only $29 \%$ of women had high antiviral antibody titers [120].

The world's leading companies producing plasma-based medicines supported by Bill \& Melinda Gates Foundation and Microsoft established the Plasma Alliance CoVIg-19 organization to develop plasma-based preparations for treatment of the new coronavirus. The organization plans to conduct clinical trial of hyperimmune immunoglobulin against COVID-19 [122]. Interestingly, Emergent BioSolutions (USA) is developing not only a medicine based on human polyclonal antibodies, but also a product based on antibodies of horses immunized with SARS-CoV-2. In July 2020, SAb Biotherapeutics (USA) began testing the medicine SAB-185, which contained human polyclonal antibodies derived from plasma of transgenic cattle immunized with the protein SARS-CoV-2 [123]. The amino acid sequence of retrieved antibodies is completely human, but the corresponding genes contain bovine regulatory elements that optimize their expression in plasma cells of cattle. Transgenic animals are clones of one genotype that produce up to 45 litres of plasma per month, and the yield of antibodies is up to $25 \mathrm{~g} / \mathrm{l}$. GigaGen (USA) uses a genetically modified cell line to produce human polyclonal antibodies, which contains a complete repertoire of immunoglobulin genes from 5-10 people who have recovered from COVID-19 [124]. Monoclonal antibodies capable of neutralizing various types of coronaviruses are currently being actively studied, as the idea of a universal vaccine against coronaviruses should still be considered in the near future because of the high probability of new coronavirus pandemics.

Another approach that may prevent coronavirus from entering the cell is using the TMPRSS2 serine protease inhibitors. This protease is required for SARS-CoV-2 to penetrate the cell [30], although its biological role in the body remains unclear. In experiments on mice model, it was shown that knockout mice, which did not synthesize TMPRSS2 protease, were no different from normal animals [31]. Camostat mesylate licensed in Japan and South 
Korea for treatment of pancreatitis inhibits the TMPRSS2 protease. Clinical trials of this medicine against SARS-CoV-2 began in April 2020 at the University of Aarhus (Denmark) [125], and in May - at Yale University (USA) [126].

The penetration of SARS-CoV-2 into cells can also be precluded by medicines that influence endocytosis. In April 2020, a huge number of publications stated that antimalarial medicines Chloroquine and Hydroxychloroquine could be used for treatment of COVID-19 as they increased $\mathrm{pH}$ inside endosomes, preventing the fusion of membranes and the release of viral RNA in cytosol, and also inhibited the entry of the virus into the cell at account of altering the glycosylation of ACE2 receptor and 'spike' protein of the coronavirus [127]. Initially, the information on successful administration of these preparations against SARS-CoV-2 came from China, later clinical trial of Hydroxychloroquine in combination with antibiotic Azithromycin (HCQ/AZ) started in the United States.

President Donald Trump has made a loud (now infamous) statement that effective medicines against COVID-19 would soon be approved in the United States. Under pressure from Trump, FDA granted unprecedented permission for mass use of HCQ/AZ in New York City before the medicine was thoroughly tested for toxicity and specificity, which caused a wave of outrage among many scientists and former FDA officials. Nevertheless, many countries have begun using HCQ/AZ to treat people with COVID-19, having created a deficiency of Chloroquine needed to treat patients with malaria and autoimmune diseases. In France, patients started widely demand prescription of the medicine, and a well-known French microbiologist, physician, and clinical trial director Didier Raoult, largely promoted Chloroquine, being supported by President Emmanuel Macron.

Swedish hospitals soon announced that they had stopped using Hydroxychloroquine and HCQ/ $\mathrm{AZ}$ for dangerous side effects and the lack of evidence of antiviral activity of these medicines. Thus, the administration of HCQ/AZ led to hospitalization of several people with symptoms of intoxication and death of one patient [130]. These medicines have been shown to be quite toxic and, according to FDA, contribute to serious heart rhythm problems, and can cause pathological changes in the blood, lymphatic system, kidney damage and liver failure. On June 15,2020 , FDA revoked the permits for the emergency use of Chloroquine and Hydroxychloroquine as medicines for COVID-19 treatment, and numerous trials of these preparations in many countries were stopped [131].

One of the most promising medicines hoped to help combating COVID-19 was Remdesivir, a nucleotide analogue that is a specific inhibitor of RNAdependent RNA polymerase (RNAdRNAp) required for proliferation of the virus in the host cell. [132]. Chinese scientists have revealed the structure of RNAdRNAp-Remdesivir complex, which has made it possible to better understand the mechanism of stopping elongation of viral RNA [133]. The inhibitory effect of Remdesivir on RNAdRNAp has been confirmed in vitro for SARS-CoV, MERS-CoV and SARS-CoV-2 [134].

Several large-scale clinical trials of Remdesivir have been conducted in both China and the United States with financial support from the US National Institute of Health and the inventing company Gilead Sciences (USA). The results of the study showed a reduction of hospital stay of patients taking Remdesivir from 15 to 11 days [135], and a clinical improvement in 36 of 53 patients (68\%) admitted to hospital for severe course of COVID-19 [136]. It was assumed that the maximum effect of Remdesivir was manifested when used at early stages of the disease [137]. At the same time, the authors of some studies have put forward a number of concerns limiting the interpretation of the results. Despite the ambiguity of available results, on May 1, 2020, FDA authorized the emergency use of Remdesivir for treatment of COVID-19 patients in the United States [138], and subsequently, Remdesivir obtained appropriate permits in Japan [139] and Europe, where it was manufactured under Veklury trade name.

Gilead Sciences was conducting additional research in other groups of patients, including children, and then started research of an inhaled medicine for early-stage patients treated at home. In addition, a clinical trial of the combination of Remdesivir with the anti-inflammatory synthetic inhibitor JAK-Olumiant (Baricitinib) manufactured by Eli Lilly (USA) has been initiated [140]. Remdesivir-like medicines, including the ribonucleoside analogue EIDD-2801 and its metabolite EIDD-1931 ( $\beta$-D-N4hydroxycytidine), which was developed for treatment of influenza by DRIVE (Emory University, USA), and those that have shown activity against pandemic coronaviruses, were also being actively studied. Interestingly, EIDD-2801 appeared to be 3-10-fold more potent inhibitor of SARS-CoV-2 replication than Remdesivir [132]. In July 2020, Ridgeback Bio- 
therapeutics (USA) launched Phase II clinical trial of efficacy of EIDD-2801 for COVID-19 treatment [141]. It has also been reported that another antiviral medicine, BOLD-100 (Bolt Therapeutics, Canada), was more effective than Remdezivir. The medicine is a small ruthenium-based molecule that selectively inhibits stress-induced regulation of the chaperone GRP78, which is important protein for recognition of host cells, virus penetration and replication [238].

Another possible preparation for treatment of COVID-19, which attracted the attention of scientists, was Lopinavir-Ritonavir (LPV/r) - a combined antiviral medicine used to combat HIV. Lopinavir is an inhibitor of viral HIV protease, which disrupts the development of viral capsid, inhibits HIV replication with formation of immature viral particles that cannot infect human cells. Ritonavir is similar to cytochrome P450 and acts as a pharmacokinetic enhancer of Lopinavir [142]. It has been reported that Lopinavir acts in vitro on SARS-CoV-2 [143], after which the medicine was included in the research program Solidarity sponsored by WHO [144]. The trial has shown that LPV/r does not give any advantages for patients with COVID-19 compared to standard treatment [145]. At the same time, the results of studies of the LPV/r efficacy in combination with interferon beta-1b and Ribavirin (nucleotide analogue, RNA-dependent RNA polymerase inhibitor) are quite promising [146]. However, on July 4, 2020, WHO excluded LPV/r from the Solidarity clinical trial program [147].

In silico study [148] has shown that Nitazoxanide, a thiazolide-class medicine with antiparasitic and antiviral activity discovered in the 1980s by Jean-François Rossignol at the Pasteur Institute is an effective inhibitor of papain-like protease (PL) of SARS-CoV-2 virus. Nitazoxanide was recommended for further in vivo studies after demonstrating inhibition of SARS-CoV-2 at low virus concentrations [150].

In order to find viable preparations for treatment of COVID-19, all human body proteins were screened for the ability to interact with SARS$\mathrm{CoV}-2$. 332 proteins were found, 66 of which were 'targets' of available medicines. Using this approach, 69 pharmaceuticals were identified, of which 27 have already been tested, 14 are undergoing clinical trials, and 28 are undergoing pre-clinical trials [151].

An interesting example of fruitful collaboration of several research groups in the search for a specific medicine against COVID-19 was a study involving modern methods of computer-aided drug design and high-capacity virtual screening. The 'target' of the future medicine was taken the main protease (Mpro) of SARS-CoV-2 virus, which plays an important role in replication and transcription of the virus. Finally, after screening of 10,000 different compounds, the low toxic medicine Ebselen, a synthetic organoselen molecule with anti-inflammatory, antioxidant, and cytoprotective properties, was selected as a specific agent for treatment of COVID-19. Preliminary studies have shown that Ebselen had inhibitory activity against SARS-CoV-2 in a cell sample, which can be explained by irreversible inhibition of the main protease of coronavirus through development of covalent bonds with the thiol group of cysteine (Cys-145) of the active centre [152]. Subsequent studies have proved that Ebselen may be a promising medicine against COVID-19 because it binds to the viral protease Mpro between domains II and III and is an allosteric regulator of access to the catalytic region of the molecule [262].

To identify medicines that can be repurposed on combating COVID-19, Biovista (USA) used the artificial intelligence platform Biovista Project Prodigy AI. As a result, it was announced that 6 preparations could be used to treat COVID-19 patients. First, it is an antifibrinolytic agent aprotinin and angiotensin II receptor blocker irbesartan - for soothing the cytokine 'storm' and reduction of viral load. Second, it was suggested to use Caplacizumab and ezetimibe/atorvastatin as potential agents against blood clotting and inflammation. Third, two bioactive compounds, lycopene and vitamin $\mathrm{D}$, have been identified potentially useful for treatment of COVID-19 patients. It's worth noting that Biovista has significant experience in predicting the efficacy of medicines for certain diseases using artificial intelligence. The first of such predicted drugs was Dimebolin, which the company considered would be useful for patients with epilepsy and multiple sclerosis. This prediction was later confirmed by experiments on animal models, and Biovista obtained the appropriate patents. Interestingly, artificial intelligence has identified Lopinavir/Ritonavir (Kaletra) as relatively ineffective in COVID-19, while its combination with Remdezivir - as extremely effective. Actual experimental data have confirmed the benefits of this combination of medicines [270].

To establish fast and cheap production of new antiviral drugs, Synthia artificial intelligence software has been developed, which offers manufactu- 
rers the most effective and cost effective strategy for the synthesis of drugs using cheap and easily available raw materials. Thus, Synthia has found new solutions for the manufacture of 11 of the 12 proposed antiviral drugs, in particular for Umifenovir and Favipiravir. The only drug for which the software could not come up with a new method of synthesis was Remdezivir [231].

Another category of medicines that can be used to treat COVID-19 patients are agents that inhibit the hyperreactivity of the immune system. The fact is that excessive immune response is often the cause of severe COVID-19, so-called cytokine 'storm' and elevated mortality, especially in young people. Therefore, it was suggested to use such immunosuppressive medicines as Tocilizumab or Actemra - a humanized monoclonal antibody to human interleukin-6 receptor; Anakinra - a recombinant protein, which is interleukin-1 receptor antagonist; other medicines for treatment of rheumatoid arthritis, which inhibit the action of interleukin-6, etc. [153]. Clinical trial of Anakinra in combination with a monoclonal antibody to IFN- $\gamma$ (Emapalumab) was scheduled to complete in Sweden in 2020 [154]. The results of phase III clinical trials of Actemra by Roche (Switzerland) did not demonstrate sufficient efficacy of this medicine for treatment of COVID-19 [242], so FDA did not recommend using monoclonal antibodies that inhibit interleukin-6 for treatment of COVID-19. [241]. Steroids have also been suggested, but many feared that their administration would lead to patients' vulnerability to other infections, including nosocomial ones. Unexpected were data of a successful clinical trial of Dexamethasone, a synthetic glucocorticosteroid with anti-inflammatory and immunosuppressive properties, for treatment of COVID-19 patients. This success became possible for massive and thorough clinical trial of Dexamethasone in Britain. Perhaps, this clinical trial is now often recalled as an example of improper trial organization, which calls into question the results obtained even for promising preparations. According to the results of the "Recovery" study conducted by the Oxford University in the UK, Dexamethasone reduced mortality by about one-third (from 40 to $28 \%$ ) in patients on mechanical ventilation and by one-fifth (from 25 to $20 \%$ ) - for oxygen-dependent patients [156]. The advantage of Dexamethasone, which was synthesized in 1957 and, despite numerous side effects still widely used in the therapy of autoimmune diseases, over modern medicines is that it is very cheap and available worldwide. Dexamethasone is now included in COVID-19 therapy protocols in many countries, including Ukraine [157].

Clinical trials involving 1,700 people from 12 countries showed that not only dexamethasone but also other corticosteroids, including hydrocortisone and methylprednisolone, were able to reduce mortality in COVID-19 patients: after 28 days of followup, the fatality risk was $32 \%$ and $40 \%$ for those who took a steroid and those who took a placebo, accordingly [254]. However, it's worth noting that corticosteroids may be ineffective or even detrimental for patients with mild symptoms or on the early stages of COVID-19.

Recently, the information emerged on the probable perspectivity of another long-known antiinflammatory medicine Colchicine developed on the basis of the poisonous meadow saffron (late autumn flower, Colchicum autumnale) alkaloid first registered in 1947 in France, for treatment of COVID-19. Colchicine was used for treatment of joint edema as early as in the second millennium BC, and for treatment of gout from the VI century. It is an inhibitor of microtubule polymerization, interleukins 1 and 6 , as well as a colony-stimulating factor of granulocytes and macrophages, which makes it powerful anti-inflammatory agent. Clinical trials conducted in Greece have revealed the anti-inflammatory and anti-thrombogenic effects of Colchicine in the treatment of COVID-19 patients [158].

The administration of nonsteroid anti-inflammatory drugs (NSAIDs) for managing fever in COVID-19 patients appeared to be a controversial question. Doubts about using NSAIDs for COVID-19 therapy were raised by the Minister of Health of France Olivier Veran, who, based on the statements of some physicians, announced that NSAIDs can worsen the course of the disease, and only paracetamol (acetaminophen) should be taken to relieve the fever [159]. NSAIDs are inhibitors of cyclooxygenase, which catalyses the development of prostaglandins, inflammation mediators. Some NSAIDs (e.g., Indomethacin) are able to block coronaviral RNA synthesis regardless of cyclooxygenase inhibition. SARS-CoV-2 can directly bind to the cyclooxygenase promoter (COX-2), thus increasing its expression and, therefore, prostaglandin production and inflammation. On the other hand, prostaglandin PGE2 may inhibit coronavirus replication [160]. Despite the complexity of interaction between coronavirus and NSAIDs, to date, there is no evidence that 
NSAIDs can worsen the symptoms of COVID-19 [161].

Recently, the inhibitors of kallikrein-kinin system which contributes to accumulation of fluid in tissues and development of inflammation have gained more and more attention. There are currently two such approved medicines: Icatibant (a blocker of bradykinin B2 receptors) and the monoclonal antibody Lanade-lumab, which inhibits kallikrein in blood plasma (medicines that inhibit tissue kallikrein have not yet been approved). Patients with COVID-19 taking Icatibant demonstrated a pronounced improvement in oxygenation. Randomized clinical trials of both medicines are currently being conducted in the United States in critically ill COVID-19 patients, and a new kallikrein plasma inhibitor from Takeda (Japan) is being studied in the Netherlands [261].

As the processes of hypercoagulation and thrombosis play an important role in the pathogenesis of COVID-19, it is proposed to use medicines preventing blood clotting as a therapy [162]. It is known that anticoagulant therapy with low molecular weight heparin led to an improvement in severe COVID-19 patients manifesting signs of coagulopathy (increased D-dimer concentration) [163]. Given the anticoagulant therapy requires careful monitoring of the patient's blood clotting, it makes sense to mention that diagnostics developed in the 1990s by the Department of Molecular Immunology of the Palladin Institute of Biochemistry of the National Academy of Sciences of Ukraine were among the world's first tests to quantify D-dimer, which is one of the thrombosis markers. The same Institute has developed tests for simultaneous quantification of both D-dimer and soluble fibrin, the latter being extremely important for monitoring the state of the blood coagulation system and the thrombosis threat $[164,165]$.

Immunotherapeutic approaches to COVID-19 therapy are also being developed by the Center for Vaccines and Immunology of the University of Georgia (USA) and CEL-SCI Corporation (USA), which have resulted in a ligand antigenic epitopes presentation system (LAEPS), which contributes to anti-inflammatory immunomodulatory response and stimulates CD8 T-cells to attack virus-infected 'target' cells due to peptides of NP SARS-CoV-2 protein. Previous studies on animal models have shown that LEAPS immunogens can save from other lethal infections, including those caused by herpes simplex virus (HSV) and influenza H1N1 virus, as well as stop the progression of inflammation in rheumatoid arthritis [166]. In addition, the possibility of using anti-COVID-19 immunotherapy with involvement of genetically engineered CAR/TCR T-cells, which have been proven highly effective in the treatment of cancer, arthritis and hepatitis B [167], is being studied.

Unexpectedly promising may appear Famotidine, a medicine against heartburn, which is cheap and widely available (in particular, in Ukraine it is produced by several pharmaceutical companies) [168]. Screening of virtual SARS-CoV-2 protein ligands has shown that Famotidine can interact with 3-chymotrypsin-like protease, which plays an important role in virus replication [239]. Other researchers believe that Famotidine facilitates the course of COVID-19 due to its antihistamine effect on mast cells, which may be involved in excessive inflammatory reactions and cytokine 'storm' [240]. Although the mechanism of Famotidine action in COVID-19 remains unclear, it is currently undergoing a clinical trial on 1,200 individuals in the New York State.

Other candidates for the role of COVID-19 therapy are currently tried vasodilators, lipoic acid, mesenchymal stem cells, Bevacizumab (humanized monoclonal antibody to vascular endothelial growth factor) [169], and some other pharmaceuticals used in Chinese traditional medicine [170], in particular compounds with antimalarial activity, such as Artemisinin contained in Artemisia annua and its synthetic derivative - Artesunate [171], etc.

Data on administration of well-known antiviral drugs - interferons - can be both interesting and important. At the beginning of the pandemic in China, interferons were used to protect health workers involved in the treatment of COVID-19 patients, and none of the 2,415 people who received daily nasal alpha interferon drops were infected with the virus [172]. It is especially important that interferons can be used both prophylactically and for prevention of complications at the onset of the disease.

Although the FDA believes that data to assess the potential benefits of interferon in early disease versus toxicity risks are insufficient, the use of interferons for treatment of patients with severe or critical COVID-19 should be prohibited [243]. Even low doses of chest X-ray (slightly higher than a CT dose, but lower than the dose used for treatment of lung cancer) can reduce pneumonia in critically ill COVID-19 patients to an extent sufficient for with- 
drawal of artificial lung ventilation. Low-dose radiation usually does not have a direct antiviral effect, but can compensate the overreaction of the immune system, known as a cytokine 'storm.' Similar treatments have previously been used for the therapy of viral pneumonia associated with influenza in 1918, as well as the arthritis. Several clinical trials of this treatment have recently been initiated in the United States and other countries [268].

Clinical trials of hundreds of substances that may be effective as COVID-19 therapy and already approved for use in other diseases are underway. This strategy is called repurposing, i.e. 'reorientation of use.' Periodically, new publications appear on the prospects of the next medicine, but after a brisk discussion, it usually turns out that either the study was conducted only in vitro not on living organisms, or clinical data are not so promising, or there were certain manipulations with patient screening, etc. Combinations of various medicines, primarily antivirals, are now being actively studied, but so far, no significant progress has been achieved. Therefore, if COVID-19 is suspected, self-medication is not an option, and sick individual should immediately seek medical care. Scientists warn that using even known, but untested for viral effect medicines can be dangerous to health (as happened with Chloroquine and its derivatives): "Such drugs are directed rather against us than the coronavirus" [173].

Stem cells, in particular mesenchymal stem cells (MSC) are widely studied and already widely used in clinics to fight numerous diseases. A group of scientists and clinicians at the University of Miami, USA have made an interesting investigation on the possible use of MSC to cure COVID-19 patients [298]. In double blind randomized trial of 24 COVID-19 patients with acute respiratory distress syndrome it was found that two intravenous infusions of umbilical cord mesenchymal stem cells (UC-MSCs), at a dose of 100 million cells per infusion, given 72 hours apart, led to the significantly improved patient survival and time to recovery and such treatment was associated with a significant decrease of inflammatory cytokines [298].

The above brief review of already tested medications makes possible to conclude that treatment of COVID-19 is almost completely anti-symptomatic - against manifestations of the disease caused by SARS-CoV-2, or against possible numerous, often multi-organ complications. Currently, only two medicines were officially approved in the United States for treatment of COVID-19 complications.
These are specifically acting Remdesivir (inhibits virus replication) and unspecific Dexamethasone that has been tested and is effective as suppressant of patient's hyperimmune response to the virus. These medicines can be complemented by convalescent plasma of recovered patients, which have sufficiently high titers of antiviral (specific) antibodies.

Finally, it is worthwhile mentioning two important points. The first one is that when US President Donald Trump was hospitalized with COVID-19 among medicines, which were used to treat him were antibodies (a mixture of two monoclonal anti-SARS S protein antibodies), Remdesivir, Famotidine, Dexamethazone, vitamin $\mathrm{D}$, a daily aspirin, zinc and melatonin [279]. Zink plays multiple roles in the cell but referring to the SARS-CoV-2 infection, intracellular $\mathrm{Zn}^{2+}$ may inhibit its replicative cycle as $\mathrm{Zn}^{2+}$ does of some other viruses. More particularly, $\mathrm{Zn}^{2+}$ was shown to inhibit polyprotein processing in cells infected with human rhinovirus and coxsackievirus B3 [303]. As to Melatonin, which regulates the body's circadian rhythm and sleep-wake cycle, it can be a possible treatment for those who contract the coronavirus, and it was associated with a $30 \%$ reduced likelihood of testing positive for COVID-19 [304].

The second point is that though there were encouraging results from the remdesivir clinical trials earlier this year and the FDA official approval for the remdesivir treatment of COVID-19, which we mentioned above, interim results from the World Health Organization's highly anticipated Solidarity trial appear to show that none of the four repurposed antiviral drugs tested have a meaningful effect in reducing COVID-19 deaths, the need for ventilators or the duration of hospitalization [280]. (I quote very important conclusion): 'The trial investigated remdesivir, hydroxychloroquine, a lopinavir-ritonavir combo and interferon beta-1a. The randomized study was conducted in 405 hospitals across 30 countries and involved 11,266 people. "The unpromising overall findings from the regimens tested suffice to refute early hopes, based on smaller or non-randomized studies, that any will substantially reduce inpatient mortality, initiation of ventilation or hospitalization duration," say the interim results'[280] (unquote).

That is why the hopes that the world will have anti SARS-CoV-2 drugs in the Autumn of 2020 well before the anti-SARS-CoV-2 vaccines development and arrival were not realized and vaccines successfully started to fight COVID-19 at the very end of 2020 but we shall discuss it below. 


\section{Development of immunity against SARS-CoV-2}

The probability of developing the disease in an individual infected with coronavirus depends on many factors related to the virus itself (e.g. the pathway of infection, the ability to penetrate the cell, the infecting dose, etc.) and the human body (genotype, immune system status, comorbidities, the state of internal organs, etc.). The spread of the disease largely depends on how the immune system responds to causative agent of an infectious disease. The reaction of the immune system to various pathogens can be ranging from development of lifelong immunity to almost complete lack of protection. So far, only preliminary data are available on the development of immunity against the coronavirus SARS-CoV-2 causing COVID-19. The best approach in this situation is to build a conceptual model - a set of assumptions about the development of immunity against SARS-CoV-2 based on current knowledge about the immune system and its response to such viruses and further verification of each component of the model, including observations and experiments.

To a large extent, our perception of immunity against SARS-CoV-2 was formed not on the basis of information on SARS-CoV-1 or MERS-CoV viruses, which infected a relatively small number of people, but on data on other human coronaviruses that are causing various respiratory diseases each year, ranging from the common cold to pneumonia. As a result of infection with these coronaviruses (four known at the moment), the developed immunity (not always strong) lasts at least one year. Immunological memory after infection with seasonal human coronaviruses (hCoVs) may potentially contribute to cross-protection against SARS-CoV-2. Ng et al. report that in a cohort of 350 SARS-CoV-2-uninfected individuals, a small proportion had circulating IgG antibodies that could cross-react with the S2 subunit of the SARS-CoV-2 spike protein [301]. By contrast, COVID-19 patients generated IgA, IgG, and IgM antibodies that recognized both the S1 and S2 subunits. The anti-S2 antibodies from SARS-CoV-2-uninfected patients showed specific neutralizing activity against both SARS-CoV-2 and SARS-CoV-2 S pseudotypes [301].

A study of humans recovered from SARS or MERS showed that immunity persisted for two years after SARS and for almost three years after MERS. At the same time, the neutralizing ability of antiviral antibodies (the ability to inhibit virus replication) gradually decreased throughout the study period. Other data suggest that immunity to SARS is longlasting (up to 10 years), while immunity to MERS is active for a much shorter period of time [174].

So far, the studies of SARS-CoV-2 humoral immune response persistence have provided the controversial outcome. Thus, a study conducted by Chinese scientists showed that humoral immunity to SARSCoV-2 did not last long - from 2 to 3 months, and in the next 8 weeks the level of antiviral antibodies fell in $13 \%$ of patients with symptoms of COVID-19, and in $40 \%$ of individuals without such symptoms. The findings call into question the idea of 'immunity passports' that some countries wanted to give to people that recovered from COVID-19, had positive antibody test results, and could allegedly travel freely, work, and not follow lockdown restrictions [175].

A study conducted by Icelandic scientists involving about 30,000 people (including more than 1,200 people tested positive for the virus and recovered from COVID-19) provided more optimistic results. Approximately $90 \%$ of recovered people had antibodies to SARS-CoV-2: the level of these antibodies increased for two months after diagnosis and then remained flat throughout the 4-month study. It has also been shown that only $0.9 \%$ of the Icelandic population has interacted with SARS-CoV-2 [256].

These results are based on analyzing IgG antibody blood levels. However, so far there is little data on the grade of T-cell immunity against the virus, which can play a much greater protective role, persist much longer, and whose condition may not correlate with the levels of circulating antibodies. Thus, $\mathrm{T}$ lymphocytes are important for the immune response to the virus. In addition to CD4+ T helper cells, which play a central role in the induction of antibody synthesis, CD8+ T cells specific to any of virus proteins can kill virus-infected cells. The most immunogenic is the virus protein S; therefore, while developing vaccines, scientists focus on it as the most promising target.

Recently, CD4+ T memory cells reactive to the virus were found in the blood of $20-50 \%$ of individuals who have never encountered SARSCoV-2, their ability to cross-react with other human coronaviruses proven, and 142 corresponding T-cell epitopes identified [228]. It is obvious that some people have developed immunity as a result of coronavirus infection, able, to some extent, protect them from SARS-CoV-2, which partly explains the heterogeneity of COVID-19 course in different people, or different geographical regions that differ 
in prevalence of infections caused by human coronaviruses. Perhaps this is why the population of developed and rich countries has more severe course of COVID-19 than the population of poor countries, which is more likely to come into contact with infectious diseases, including human coronaviruses, for a number of economic and social and cultural reasons leading to over-crowding, insane living conditions, poor nutrition, etc.

Based on the results of these studies, we can make assumptions about the development of immunity in COVID-19 patients. It is clear that following SARS-CoV-2 infection, most people develop an antiviral immune response (some stronger, some weaker). We assume that this immune response provides some protection for people in the medium term, at least for a year, and then its effectiveness may deteriorate. If this is true, then infecting more and more people in the population will lead to the development of so-called collective immunity. As more people become immune to the virus, an infected person will have less chance to contact with an individual susceptible to the infection. If the collective immunity covers a significant part of the population (over 60\%), then the virus will not spread so rapidly even without epidemiological measures.

Even if we take into account that the number of COVID-19 cases has not been accurately determined because of limited testing (for example, in Italy and some other countries, when it was underestimated, perhaps tens or hundreds of times), it can still be argued that the majority of the world's population is still susceptible to infection and collective immunity is just beginning taking shape. Thus, a comparison of SARS-CoV-2 antibody panel in the general population of Hong Kong before and after the outbreak of COVID-19, and Hong Kong residents evacuated from Hubei province, showed that most people remain susceptible to COVID-19 and future pandemic waves are inevitable in the absence of a specific antiviral vaccine [176]. Therefore, long-term control of SARS-CoV-2 can only be expected when most people become immune through infection or effective vaccination. How large such a majority should be (perhaps 60-70\%) depends on other features of the infection, which remain unknown. It has been also believed that a threshold for achieving collective immunity may be much less than $60 \%$ due to formation of cross-reactive T-cells following coronavirus colds [229].

However, it is not known how long the immunity to SARS-CoV-2 will sustain in the majority of the population. It has recently been proven that an individual who has recovered from SARS-CoV-2 can become re-infected in a few months. To support the finding, a comparative analysis of two SARSCoV-2 isolate genomes obtained from a Hong Kong patient during two episodes of coronavirus infection was performed (the second episode of asymptomatic infection occurred 142 days after the first symptomatic episode). It turned out that the viral genomes of the first and second episodes differed significantly from each other [236]. Similar results were obtained in a study of SARS-CoV-2 re-infection of a Nevada patient, but in this case the course of re-infection was more severe than the first time. The question of whether immunity influences the severity of COVID-19 symptoms upon re-infection is extremely important, especially in the context of vaccine development.

Is it possible that the immune system not only failed to protect against the virus, but also worsened the situation? Yes, it is theoretically possible. For example, some cases of severe COVID-19 are exacerbated by 'insidious' immune response that damage healthy tissues. People who survived the phenomenon in the first infection may have immune cells ready to respond even more actively a second time. Another possibility is the existence of an antibody-dependent enhanced (ADE) virus replication mechanism, in which antibodies formed during the first encounter with SARS-CoV-2 help the virus instead of fighting it during re-infection. Much more information is needed to understand how common re-infection is, what causes it, and what factors influence the severity of COVID-19 recurrence. It is not yet known whether the immune system can protect against SARS-CoV-2 infection, whether vaccines will only sooth symptoms during a second infection, or turn vaccinated individuals into asymptomatic SARS-CoV-2 carriers, which will put vulnerable populations at risk, especially elderly people who poorly respond to vaccines [266]. Therefore, SARS$\mathrm{CoV}-2$ will possibly be able to continue circulating in the human population, despite the collective immunity developed by natural infection or vaccines.

The suggestions given above on the human immunity against SARS-CoV-2 or at the course of COVID-19 were carried out based on the available information at the time of the publication of the Ukrainian version of this article (August 2020). Four months have passed, new articles with new data were published, and the author wishes to refer to one of 
the most recent and most comprehensive publication on the immunity to SARS-CoV-2 in Science on January 06 [299]. Moreover, this article brought good news that immunological memory to SARS-CoV-2 lasts much longer than it was suggested before. In particular, simultaneous measurement of circulating antibodies, memory B cells, CD8+ T cells, and CD4+ T cells specific for SARS-CoV-2, in a group of subjects (in 254 samples from 188 COVID-19 cases) with a full range of disease were carried out from short time points after infection out to 8 months later. By studying these multiple compartments of adaptive immunity in an integrated manner, it was observed that each component of SARS-CoV-2 immune memory exhibited distinct kinetics. Almost all individuals at 5 to 8 months post-symptom onset had IgG to SARS-CoV-2 Spike and RBD. Also memory $B$ cells specific for the Spike protein and/or RBD were detected in almost all COVID-19 cases, with no apparent half-life at 5 to 8 months post-infection. Seems that SARS-CoV-2 memory T cells and B cells are capable of substantially limiting SARS-CoV-2 dissemination and/or cumulative viral load, resulting in reduced COVID-19 disease severity. General findings suggested that in most examined people (of both gender) a robust immune response to the coronavirus lasted for at least eight months, and there are signs that it could even last years [299, 300]. CDC also brought good news to celebrate new 2021 year [302] by publishing the results of a new coronavirus immunity study from South Korea that indicated asymptomatic patients and those with mild COVID-19 cases would develop a strong immune response that could be detectable via antibody tests up to 8 months after the infection [302].

Vaccines against SARS-CoV-2 and COVID-19. The whole world is looking forward to the vaccine against SARS-CoV-2 and, accordingly, against COVID-19. The director of the National Institute of Allergy and Infectious Diseases (NIAID) and the White House's chief adviser for coronavirus issues, Professor Anthony Fauci, warned well in March 2020 [177] that the first vaccines would be available no earlier than in 12-18 months. The Coalition for Epidemic Preparedness Innovations estimated [178] that at least $\$ 2$ billion was needed to develop such a vaccine over the next 12-18 months.

Given the crucial need to develop an effective SARS-CoV-2 vaccine as soon as possible that could save millions of people from death and/or disability, an interesting idea was proposed to combine the ef- forts of scientists from leading laboratories and pharmaceutical companies of the world [179] by analogy with such well-known large-scale scientific projects as, for example, the Manhattan Nuclear Weapons Project, the Human Genome Project, or CERN. Such a coordinated approach to vaccine development cannot only potentially save millions of lives, but also save tons of money and help the mankind better prepare for the next pandemic. Perhaps, the current situation shows that this idea has not yet worked.

During past SARS and MERS epidemics, a research was initiated to develop a vaccine, but extinction of outbreaks caused stop funding and the work was not completed. The results of these studies can hardly be fully used to develop a vaccine against COVID-19, as analysis of antigenic structure showed different most immunogenic epitopes of 'spike' protein S in SARS-CoV-2 and SARS-CoV [180].

So far, SARS-CoV-2 virus has been relatively stable (3-4-times) compared to the influenza virus, and not prone to a significant number of mutations due to its genome structure and the presence of a 'replication error correction' in it. Thus, the genomes of most common influenza A and B viruses each comprise eight single-stranded viral RNA segments, which are capable for reassortment - the exchange of viral RNA segments between viruses. On the contrary, SARS-CoV-2 genome is a single strand of a positive polyadenylated RNA. Having travelled from China to the United States, it acquired only 4 - 10 mutations. And this gives researchers hope for the development of a stable vaccine that will remain effective for a long time [181]. However, this vaccine must be thoroughly tested for safety, as amino acid sequences of the viral and human body proteins sometimes contain similar fragments, so the side effects of the vaccine may be autoimmune diseases, especially when used in people with a genetic predisposition to autoimmunity. By the way, it was reported that coronavirus caused autoimmune retinal disease in a model experiment [77].

There are also other concerns: will the vaccine protect against the coronavirus, or will it cause antibody-dependent enhancement of virus replication, or exacerbation of hyperimmune reactions leading to the death of patients with severe COVID-19?

One of the world's first vaccines against COVID-19 was created by the American biotechnology firm Moderna under cooperation with NIAID. Its clinical trial began 64 days after the virus genome was published. On May 18, 2020, Moderna an- 
nounced the first results of the clinical trial [182]: its mRNA-1273 vaccine against COVID-19 elicited an immune response in humans and protected mice from lung infections caused by coronavirus SARS$\mathrm{CoV}-2$. The data, which the company published in a press release, were considered very reliable, and therefore Moderna shares have risen significantly in price.

Almost simultaneously with Moderna, other leading pharmaceutical companies and research institutes in USA, the United Kingdom, China, Germany, and France undertook developing the vaccine, and were later joined by institutions from Japan, Korea, Canada, India and other countries. There are currently (WHO, December, 2020) more than 200 prototypes of vaccines based on various principles known and more than 50 COVID-19 vaccine candidates are undergoing clinical trials.

How does the 'ideal' vaccine for COVID-19 prevention look like? Clinically important the following three main factors: 1 ) mandatory reliable immune response that generates long-term neutralizing antibodies to SARS-CoV-2 antigens (e.g., proteins S and/or N); 2) the vaccine should induce strong Tlymphocyte immunity; 3) the vaccine should neither have any serious side effects nor be accompanied by such phenomena as antibody-dependent cellular cytotoxicity, vaccine-associated respiratory disease, cytokine 'storm,' etc. [183].
Researchers use different approaches to developing a vaccine (Fig. 4). In total, there are 7 main platforms. Among them, two are based on nucleic acids: RNA or DNA, which, in turn, can be distributed according to certain characteristics associated with, say, the method of delivery. These are new generation vaccines. None of them was licensed up to December 2020, but they have already been tested on volunteers [184].

The third category is protein-based vaccines (also called subunit vaccines). This group covers a wide range of techniques for preparation of immunostimulatory viral protein antigens, and includes the largest number of modern candidates for the vaccine against COVID-19 [185]. Coronavirus proteinbased vaccines, like nucleic acids, are a novel technique, but some have already been used in clinical practice, such as Gardasil against human papilloma virus.

The fourth and fifth categories are viral vectors similar to those used in gene therapy. These include vectors that do not replicate and vectors that replicate.

Two other categories are SARS-CoV-2 viruses themselves: either inactivated [186] or weakened ones [187]. There are also vaccines that do not fall into any of the above categories. These are vaccines based on virus-like particles or those using not SARS-CoV-2 as a viral vector, but a killed rabies

\section{A Vaccine Platforms}

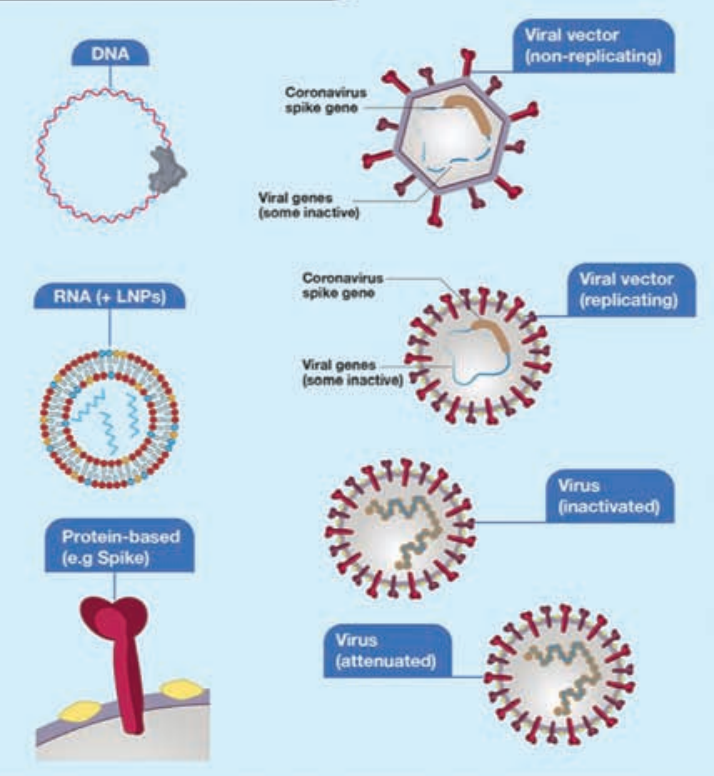

B Vaccine Candidates

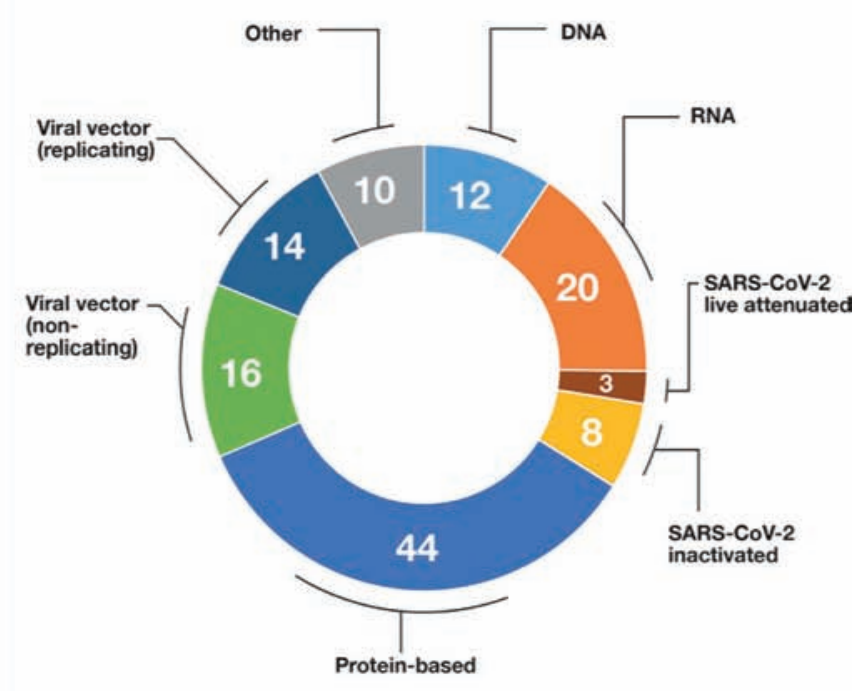

Fig. 4. Approaches to the development of a vaccine against SARS-CoV-2: $a$ - basic approaches; $b$ - distribution of candidate vaccines in groups with different approaches (taken from article [183]) 
pathogen (CORAVAX) and/or a modified equine pox virus (TX-1800) [183].

Nucleic acid-based vaccines. This group includes the already mentioned mRNA-1273 vaccine by Moderna (USA) based on mRNA encoding a prefusion stabilized form of spike protein (S), which the company has chosen together with researchers from the Center for Vaccine Research (VRC) of the National Institute of Allergy and Infectious Diseases. Very similar to Moderna is the mRNA-vaccine developed by BioNTech company in cooperation with the US pharmaceutical giant Pfizer [281]. BioNTech, a small German company working on mRNA vaccines to treat cancer, designed the COVID-19 vaccine. They tested more than 20 different stretches of mRNA coding for portions of SARS-CoV-2 spike protein, which the virus uses to bind to human cells, that were most likely to be taken up and expressed by dendritic cells, which "present" spike to the immune system to initiate antibody and $\mathrm{T}$ cell responses against the virus [281]. Pfizer-BioNTech vaccine was the first one to be announced highly effective and was the first in the world to get emergency use authorization (EUA) for the vaccine from the U.S. Food and Drug Administration (FDA) on December 11, 2020 and the Moderna was second on December 18, 2020 [282].

The main advantages of such vaccines consist in the fact that they cause a reliable immune response, they can be quickly developed and manufactured (Fig. 5). The only one evident drawback is that mRNA vaccines for a long-term storage need deep-freeze temperatures - minus $70^{\circ} \mathrm{C}$ for PfizerBioNTech and minus $20^{\circ} \mathrm{C}$ for Moderna vaccine.

Another candidate is $\mathrm{CVnCoV}$ vaccine from the German company CureVac AG, based on constructed RNA, which has not yet been registered.

Dan Baruch and colleagues at Harvard Medical School (USA) investigated DNA vaccine against COVID-19. This type of vaccine causes the recipient's cells to produce pathogen or its components, which in turn stimulates the immune system. The researchers developed a number of candidates for the DNA vaccine that express various forms of SARSCoV-2 spike protein and tested them on 35 rhesus macaque models. Humoral and cellular immune responses were observed in vaccinated animals, including neutralizing antibody titers comparable to those found in macaques and humans recovered from COVID-19. After vaccination, all animals were exposed to SARS-CoV-2, and the vaccine encoding

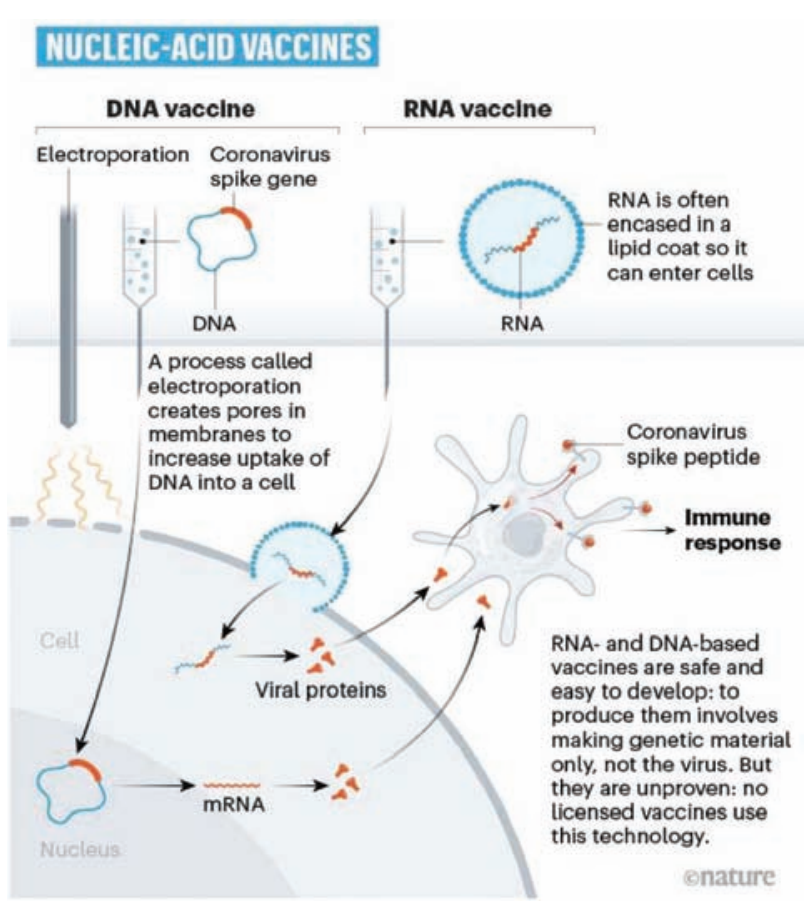

Fig. 5. The principle of action of nucleic acid-based vaccines (taken from article [185])

all protein S reduced the average viral load in bronchoalveolar washes and nasal mucosa compared with placebo controls.

According to the WHO [189], two such vaccines already undergo clinical trials. One of them INO-4800 from the company Inovio Pharmaceuticals (USA), which is administered intradermally with subsequent electroporation, encodes a spike $S$ glycoprotein. The Inovio method has been tested on more than 2,000 people with more than 6,000 injections, and it has proven to be quite safe and easily tolerated. These vaccines give a reliable immune response, they can be quickly and easily developed and manufactured, they do not require a cold chain for storage.

Another vaccine, Symvivo's (Canada) BacTRLSpike, is a DNA-plasmid that expresses a three-dimensional spike glycoprotein and a hybrid transporter protein from Bifidobacterium longum, which is delivered to the epithelial cells of the colon for immune response through lymphoid tissue of the colon. This vaccine has the same advantages as the previous one, and it is administered orally. The first phase of the clinical trial was completed in August, and up to 10,000 people were scheduled to be involved in Phases II/III [183].

Vector-based vaccines (Fig. 6). Among the most well-known and promising vaccines is AZD1222 


\section{VIRAI-VECTOR VACCIIIES}

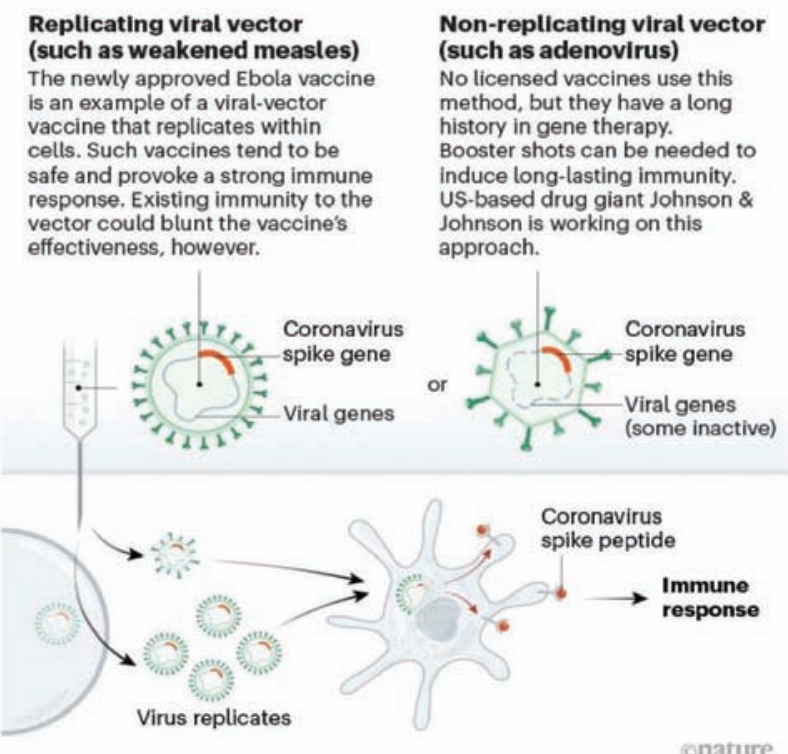

Fig. 6. The principle of action of vaccines based on viral vectors (taken from article [185])

(registered under the name ChAdOx1 nCoV-19), developed by scientists at the Jenner Institute in Oxford University in cooperation with AstraZeneca Plc. This vaccine, usually called as Oxford-AstraZeneca, is produced from the ChAdOx1 adenovirus, which is a weakened version of the common cold virus of chimpanzees that has been genetically modified so that it cannot infect humans. The structure of ChAdOx1 was added with genetic material (DNA) used for obtaining SARS-CoV-2 spike protein. By ChAdOx1 nCoV-19 vaccinating, the developers hope to force the body to recognize the spike protein and produce an immune response to it, which will help stop the SARS-CoV-2 virus from penetrating human cells and thus prevent infection [190]. Phase I of the clinical trial on healthy volunteers began in April 2020 with more than 1,000 immunizations and the next phase of the trial involved up to 10,260 adults and children and a number of partner institutions across the country [191]. Very encouraging results of Phase I and II clinical trials of ChAdOx1 nCoV19 vaccine on 1,077 volunteers have been published [192]. The vaccine induced strong T-cell immunity (peak on Day 14) and development of IgG antibodies against spike protein S on Day 28 of vaccination. AstraZeneca Plc has received 1.2 billion USD from the United States and produced about 30 million doses in the UK in September. In contrast to mRNA vaccines, this vaccine doesn't need deep freezing for long storage and can be stored at the fridge temperature $\left(+2\right.$ to $\left.+4^{\circ} \mathrm{C}\right)$.

The Oxford-AstraZeneca partnership was the first major developer to publish detailed data from phase III trials in a peer-reviewed journal, Lancet on December 8 [283, 284]. This vaccine attracts much attention as it looks effective, cheap (\$3-4 a dose), easy for storage (at plus 2 to $4^{\circ} \mathrm{C}$ ) and thus - for distribution. Nevertheless, it also rises a number of lingering unknowns, including questions about the most effective dosing regimen and how well it works in older adults. The vaccine analysis included data from four ongoing blinded, randomised, controlled trials done across the UK, Brazil, and South Africa between April 23 and Nov 4, 2020, with 23848 participants. Participants aged 18 years and older were randomly assigned (1:1) to ChAdOx1 nCoV19 vaccine or control (meningococcal group $\mathrm{A}, \mathrm{C}$, $\mathrm{W}$, and Y conjugate vaccine or saline) [283]. Owing to a measurement error, some participants received less of the vaccine in the first of their two doses. In participants who received two standard doses, vaccine efficacy was $62 \%$ and in participants who received a low dose followed by a standard dose, efficacy was $90 \%$ Overall vaccine efficacy across both groups was over $70 \%$. It is interesting to explain how a higher efficacy could be achieved from a lower initial dose, and trial investigators have said that a separate trial is needed and planned to follow up on the finding. Furthermore, the low-dose arm of the trial did not include anyone over the age of 55, though earlier studies of the vaccine showed that immune responses in people over 55 were comparable to those in younger study participants, suggesting that the vaccine will work well in older adults. Another question was whether the vaccine was capable of fighting asymptomatic infections; an immunization that could do that could be key to shaping the course of the pandemic. The Oxford-AstraZeneca team is the only one of the three leading vaccine developers that monitored for asymptomatic infections, by collecting weekly swabs from some participants to determine whether they had the coronavirus but did not become ill. The data showed that the low-dose vaccine regimen was about $60 \%$ effective at reducing asymptomatic infections, but it was unclear whether the standard dose significantly reduced them at all [283].

Chinese scientists have published the results of earlier studies of another type vaccine $\mathrm{Ad} 5-\mathrm{nCoV}$ (CanSino Biologics Inc., China) based on recombinant adenovirus type 5 (Ad5), which also expresses 
spike protein [193]. The study involving 108 people was conducted at several laboratories. Those who were administered the vaccine had a moderate immune response to the virus with a peak 28 days following the vaccination.

However, the Ad5 virus has been encountered by many people, and some experts fear that most already have antibodies to Ad5, and therefore this vector may be not adequately effective. Although the vaccine elicited an immune response, the available data are based on a short-term follow-up, and thus, it is still unclear whether lasting immunity will be achieved. In addition to pain at the injection site, about half of participants also reported fever, weakness, headache, and about one in five suffered muscle pain. Participants knew what dose of vaccine they were receiving - low, medium or high, which may have influenced their assessment of side effects. And although this vector has been well tested in gene therapy, its manufacture in large quantities can be problematic [185]. After completion of the Phase II trials, the CanSino Biologics vaccine was approved for use for one year by Chinese military on 25 June 2020 [225].

Another example of approved adenovirus vaccine is the Russian vaccine against COVID-19, developed by the Gamaley Research Institute of Epidemiology and Microbiology in Moscow. This vaccine uses two different adenoviruses that express the protein $\mathrm{S}$; the first dose of the vaccine contains adenovirus Ad26 (also used in the COVID-19 vaccine developed by Johnson \& Johnson and its Janssen subsidiary), the second dose of the vaccine contains Ad5 adenovirus (as the experimental vaccine of the Chinese company CanSino Biologics). The vaccine was administered to 76 volunteers in the early phases of two trials, but the results of these trials and other preclinical studies have not been published yet. Phase III trial was planned to conduct in the United Arab Emirates, Saudi Arabia and other countries. Unexpectedly, on August 11, 2020, Russian President Vladimir Putin announced that Russia's state health regulator became the first in the world to approve a vaccine against COVID-19 for wide-spread use, although phase III trial of the vaccine have not been started yet. The vaccine is planned to be gradually administered to citizens, first of all, medical workers and teachers. Scientists around the world and the WHO have condemned the decision as hasty, unsafe and unethical, which could not only endanger the health and lives of people taking the vaccine, but also, in the event of negative consequences, under- mine confidence in vaccination against COVID-19 and will further strengthen already strong anti-vaccine sentiment in the world [226].

Vaccines based on SARS-CoV-2 virus proteins (Fig. 7). The vaccine NVX-CoV2373 of the American company Novavax uses the recombinant SARS-CoV-2 spike protein in the prefusion state as an antigen. Recombinant protein is expressed in genetically engineered Sf9 insect cells. Properly folded and post-translationally modified protein is included in a nanoparticle composition together with Matrix$M$ saponin-based adjuvant of the same company. The main advantages of this vaccine are the possibility of quick development and manufacture [183]. The Novavax platform has previously been tested in Phases I, II and III of several trials for seasonal influenza,

\section{PROTEIN-BASED VACCINES}

\section{Proteln subunits}

Twenty-eight teams are working on vaccines with viral protein subunits most are focusing on the virus's spike protein or a key part of it called the receptor binding domain. Similar vaccines against the SARS virus protected monkeys against infection but haven't been tested in people. To work, these vaccines might require adjuvants - immune-stimulating molecules delivered alongside the vaccine - as well as multiple doses.

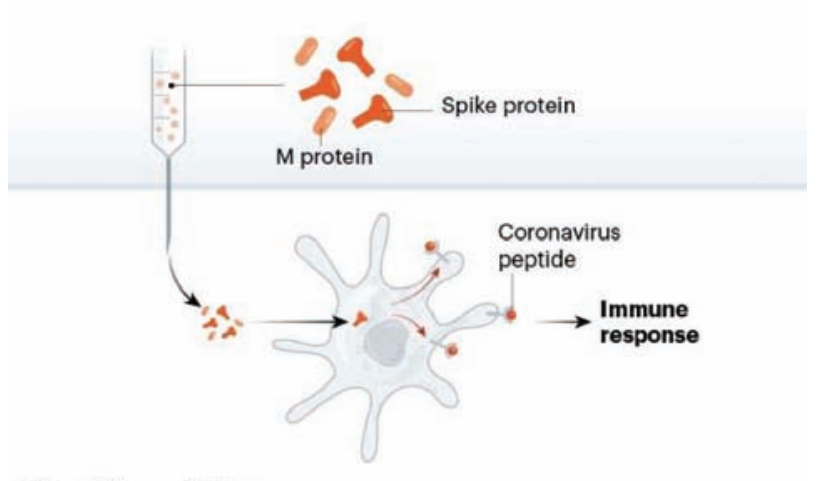

\section{Virus-llke particles}

Empty virus shells mimic the coronavirus structure, but aren't infectious because they lack genetic material. Five teams are working on 'virus-like particle' (VLP) vaccines, which can trigger a strong immune response, but can be difficult to manufacture.

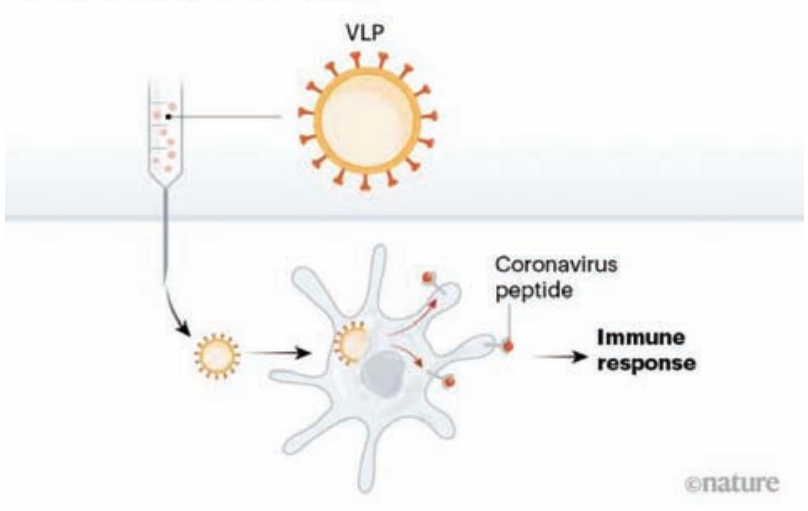

Fig. 7. The principle of action of protein-based vaccines (taken from article [185]) 
Ebola and RSV, and it has been proven safe. Preliminary data of Phase I NVX-CoV2373 was scheduled for July, followed by Phase II for 2,200 volunteers from different countries, the results of which had to appear by the end of 2020. [244, 285].

Vaccines based on SARS-CoV-2 virus (Fig. 8). Perhaps, most of currently known vaccines are based on attenuated or inactivated causative agents. This approach was used by the Chinese company Sinovac Biotech from Beijing, which started testing the CoronaVac vaccine (formerly PiCoVacc) based on chemically inactivated (with beta propiolactone) SARS-CoV-2 with alum as adjuvant [173, 286]. Phases I and II were successfully conducted in China, Phase III testing was done in Brasil, Turkey and some other countries with the aim to start commercialization in February-March, 2021 (phase III couldn't been performed in China because of lack of COVID-19 patients). The Ukrainian Lekhim group of pharmaceutical companies has signed an exclusive distribution agreement with Sinovac Biotech for the supply of CoronaVac vaccine to Ukraine and has already started designing facilities for its production in Kharkiv [224].

Another Chinese company, Sinopharm, has registered two clinical trials of vaccines, also based on inactivated virus, but it is still not clear whether this is a trial of two different vaccines or only one of them. In addition, trials have been reported for a vaccine based on attenuated influenza virus adapted to SARS-CoV-2 surface protein expression, perhaps the information obtained is insufficient [183]. Studies of the effectiveness of different routes of administration of vaccine encoding SARS-CoV-2 protein S on monkey and transgenic mice models with the human ACE2 receptor have shown that the intranasal vaccine form may be more effective than the injectable one. For example, in mice vaccinated by injection, no virus was found in the lungs after SARS-CoV-2 infection, yet a small amount of viral RNA was detected. In contrast, mice vaccinated intranasally had perfectly clean lungs. Therefore, the nasal vaccine completely prevented infection [259].

Despite some success in preclinical and clinical trials already reported in July, August and September, 2020, experts were still quite reticent about the possibility of a rapid release of the vaccine on the market. They explained this by the need to be careful because of unprecedentedly short timing of trials under the 'accelerated' principle in order to avoid disappointments, as it was with the AIDS vaccine,

\section{VIRUSUACCINES}

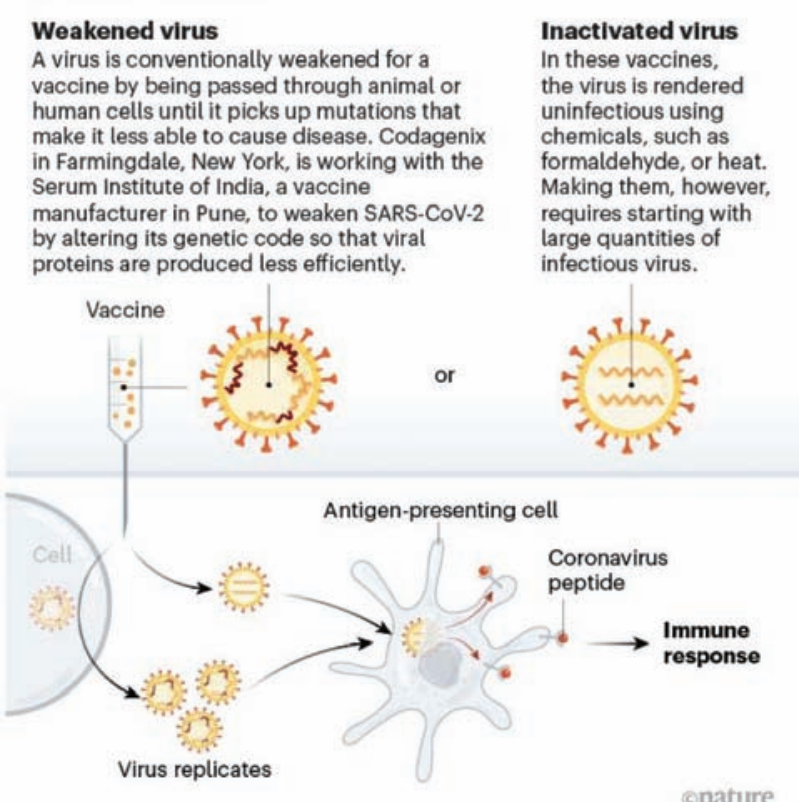

Fig. 8. The principle of action of virus-based vaccines (taken from article [185])

which was never created due to HIV peculiarities. This is the opinion expressed in argumented detail in the July issue of the Scientific American [194] by the prominent American scientist William Hezeltine, whom I was lucky enough to come across at Harvard University in 1981. Such fears were based on the fact that coronaviruses had long been known to 'distort' the immune system so that even after the body disposed of the pathogen, it was quite able to re-infect and cause the disease relapse. The structure of SARS-CoV-2 suggests the serious problems may occur during vaccine development. Yes, some COVID-19 patients produced neutralizing antibodies able to kill the virus, but not all of them. Therefore, it is still unknown whether the vaccine will stimulate the production of such antibodies in all people. It is also unclear how long these antibodies can protect against the infection. Concerns are also raised about adjuvants used in vaccines because they might cause serious side effects, in some cases even in young healthy people.

It's worth noting that some large pharmaceutical companies, in the struggle for leadership, may try to hide information about the side effects of their vaccines using various methods: publishing partial information in press releases and creating a "pink picture" in the media; comparing side effects of vaccines not with placebo, but with vaccines against 
other infections; removal of any mention of using analgesics and antipyretics (e.g., acetaminophen) from publications, etc. [217].

Such a strategy only heightens scepticism, antivaccine sentiment and could seriously harm global vaccination campaign and the fight against COVID-19. Especially considering the fact that recently the supporters of the anti-vaccine movement have begun to spread misinformation and/or nonsense about the vaccine against COVID-19 more actively through global social networks. For example, they claim that the vaccine contains monkey brains, was developed by the CIA to seize power over the world, or pitches invisible tattoos to track people.

Despite the lack of common sense in such statements, the number of people refusing vaccination is still very high. According to a CNN survey of May 2020, a third of Americans said they would not administer a coronavirus vaccine, even if it was cheap or free and widely available. Therefore, governments, the media, and NGOs should make every effort to push forward an educational campaign to counter propaganda. However, the WHO believes that as many vaccines as possible should be tested, since it is not possible to predict how many of them will be promising [195]. This WHO reference [195] is regularly updated and displays information at the date when one opens it. On January 2021 it reads as follows: "Once a safe and effective vaccine becomes available, it will be vital that it is accessible to everyone who needs it. WHO will continue to work to align R\&D, fast-track regulatory approvals and manufacturing so that all populations in all countries can access a vaccine as early as possible”. We hope that such effective vaccines are affordable not only in many countries that allocate large funds for their development, but also, as the UN and WHO insist, all over the world, regardless of the economic situation in the countries. At the same time, we should be aware that even effective vaccines will not provide immunity to all immunized people (perhaps 70$80 \%$ ). In addition, it is still unknown how long the effect of vaccine will last and whether revaccination will be need annually if SARS-CoV-2 continues to proliferate in the world. These problems will be a challenge for physicians and biologists in the near future.

Besides taking part in competitions for creating a specific vaccine against SARS-CoV-2, scientists also explored the possibility of non-specific enhancing immunity against COVID-19 when using vaccines against other diseases (tuberculosis, poliomyelitis, etc.), as well as genetically modified immune cells [185].

It has been noted that SARS-CoV-2 is spread more slowly in countries where the BCG vaccine (BCG - bacillus Calmette-Guerin) has been used for eradication of tuberculosis in the population [197]. It has long been known that the BCG vaccine improves the immunity against certain viruses. In the United States, it is used to treat bladder cancer, effectively stimulating the immune system to kill cancer cells [198]. Recently, the BCG vaccine has been shown to reduce mortality from neonatal sepsis due to rapid induction of neutrophils [199]. In addition in vivo experiments have confirmed that BCG causes epigenetic reprogramming of human monocytes, resulting in the induction of cytokines, including IL-1b, which is important for the development of antiviral immune response [200]. The Murdoch Children's Research Institute of Melbourne, Australia, has been testing the BCG vaccine as a preventive agent against COVID-19 since March 27, 2020 involving 10,000 health professionals from Australia, Spain and the Netherlands [201]. At the same time, publications on the effect of BCG on SARS-CoV-2 and COVID-19 reveal the conflicting data, as some results confirm this effect, and some, vice versa, indicate its absence [202-205]. Recently published results of a clinical trial conducted by Trained Therapeutix Discovery (Dallas, Texas, USA) showed that BCG trained immunity could reduce infectious respiratory diseases (including COVID-19) in the elderly people by $80 \%$ [219].

The idea of using a live polio vaccine to counter COVID-19 in the United States is actively promoted by Konstantin Chumakov, director of the FDA's vaccine research division. He is son of the famous Soviet virologists Mikhail Chumakov and Marina Voroshilova, who in 1959 first tested a live polio vaccine developed by Albert Seibin (American virologist of Jewish descent emigrated from Russia in 1921) on their three children. After that they conducted large-scale trial in the USSR and described the emergence of temporary protection in vaccinated patients against other viral infections, probably by nonspecific stimulation of the immune system [206]. Konstantin Chumakov and Robert Gallo recently published an article in the Science [202] pointing out the possibility of controlling COVID-19 with vaccines that are not specific to COVID-19, but can prevent SARS-CoV -2 infection and/or to improve the course of the disease on account of non-specific 
stimulation of patients' immunity. Such vaccines include attenuated (live but weakened) vaccines against tuberculosis (BCG), pertussis or poliomyelitis. By the way, Robert Gallo is a virologist, immunologist and oncologist, one of the most famous biologists in the world, who discovered the interleukin-2 (IL-2) and the RNA structure of the human immunodeficiency virus (HIV). He would undoubtedly have won the Nobel Prize if not a scandal caused by the controversy over the authorship of the discovery of HIV virus with Luc Montagnier. I was lucky enough to meet Professor Gallo and visit his laboratory in 1981, when he was working at the National Cancer Institute in Bethesda (USA). At that time neither HIV nor AIDS were known and we had a discussion on IL-2 and on anti-cancer immunity, in particular on the possible use of monoclonal antibodies to cancer antigens in anti-cancer therapy.

\section{Epidemic mathematical models and prospects for lifting the quarantine}

The first results of the resonance modelling research were presented on February 16, 2020 in the report by the National Laboratory of the Imperial College of Great Britain [207]. Based on the distributed stochastic model, a prognostic analysis of COVID-19 spread was performed taking into account the parameters of the disease propagation, which were measured at the initial stage of the pandemic, mainly in China and South Korea. The model demonstrated the catastrophic (as it sounded at that time) consequences of the 'no countermeasures' scenario for the healthcare systems of the United States and the United Kingdom - 2.5 million and 500 thousand deaths respectively in June 2021, which caused the dramatic change of state anti-epidemic policy (in reality, as of January 10, 2021 there are 21,8 million of confirmed cases and 366 thousand deaths in USA and 3,0 million of confirmed cases and 80 thousand deaths in the UK). Interesting to note that in the article "SARS: UK public health response - past, present and future" published in 2003 and dedicated to the SARS epidemic in 2003 it was written: "Although the World Health Organisation has now declared SARS 'contained', the possibility of re-emergence is ever present. All countries will need to be vigilant and plan their response to the possibility of a renewed SARS epidemic” [287].

Since the beginning of the epidemic, dozens of scientific papers have been published on the development of prognostic models, methods for predicting the spread of COVID-19 and calibrating the parameters of these models according to the disease statistics. A comparative analysis of methods and models using data from different regions of China [208] showed that the most successful forecasting statistical criteria appeared to be several variants of SEIR-class epidemiological compartmental models (Susceptible, Exposed, Infected, and Resistant) used by most developed countries. An important advantage of SEIR models is the ability to model scenarios for the effect of introduction or cancellation of lockdown and other counter measures, as well as the ability to use as parameters of medical information models, such as incubation period, average recovery time and more.

Taking into account these factors and the successful experience of implementing SEIR models in other countries, the working group at the Presidium of the NAS of Ukraine developed the SEIR_U model for calculating balance ratios for several compartments of the main population categories during the epidemic: S - susceptible to disease; E - exposed, but without manifestations of the disease; I - infected with a confirmed disease that can infect others; $R$ - those not able to get sick as they are immune to the disease, or have died. The current implementation of the SEIR_U model allows taking into account asymptomatic patients, has 3 levels of COVID-19 course complexity for patients with symptoms, and allows to calculate the number of patients at hospitals [209].

The incubation term was estimated using simulations, which allowed health authorities to decide on a 14-day quarantine (although these results should be treated with caution, as some people may infect other after the 14-th day). Now mathematical models are used not only to assess the parameters of coronavirus spread, but also to study possible future scenarios, retrospective assessment of the efficacy of specific interventions, and identify promising strategies. In addition, masked face recognition digital techniques and the technology for assessment of the distance between people using echolocation to control social distancing [248], etc are being actively developed. Many countries have now begun to develop and introduce digital contact tracking programs for those infected. However, digital contact tracking is hampered by technical and ethical challenges, in particular the ability to accurately identify closeness between individuals and store such information confidentially. Thus, although modelling is a valuable tool for testing new ideas, it should be accompanied 
by a careful consideration of practical applicability [233].

The epidemiological measures, which are currently the main weapon for combating the COVID-19 pandemic, have a negative impact on the economy and cause considerable concerns in society. Therefore, the governments of many countries have drawn up and published in advance step-by-step lockdown exit plans, which set out the conditions for implementing each stage of easing the lockdown requirements, as well as action plans for gradual recovery of the most affected sectors.

An example of such a plan is the Roadmap for COVID-19 lockdown exit in the USA [210], which consists of 4 stages (phases).

Phase I. Slow expansion. The COVID-19 epidemic is spreading in all US states. To slow it down, social distancing measures have been introduced in each state until the spread slows significantly and the infrastructure becomes capable of controlling the outbreak and caring for sick people.

Phase II. Lifting restrictions state-by-state. Some states will be able to move to Phase II when they become capable of safe diagnostics, treat, and isolation of all COVID-19 patients, and monitoring their contacts. At this phase, schools and businesses can reopen, and normal life may be gradually restored. However, some physical distancing measures still need to be observed (e.g., a ban on mass gatherings continues) to prevent a recurrence of the infection. Restrictive measures continue for persons over 60 , persons suffering from chronic diseases, and other groups of the population at increased risk of developing COVID-19.

Public hygiene should be at a high level. Careful cleaning of crowded areas and disinfection of frequently touched surfaces should be the must. It is also necessary to actively identify and isolate patients and monitor their contacts. At the beginning of Phase II, the public is invited to limit gathering; it is also recommended to wear fabric non-medical face masks to reduce the risk of asymptomatic spread especially in the non-ventilated and closed spaces. Patients should stay at home and take the COVID-19 test. Testing should become more common, such as diagnostics at hospital premises with the help of POC tests. If there are differences within a state, the restrictions may be lifted at the regional level under appropriate coordination.

Phase III. Development of immunity and cancellation of the distancing. Physical distancing and other phase II measures can be cancelled when safe and effective tools become available to reduce the risk of COVID-19: treatment with therapeutic agents that can save patients with severe symptoms or prevent severe course of COVID-19 in patients belonging to risk groups; or safe and effective vaccination against COVID-19.

Phase IV. Recovery to the next pandemic. Once we manage to defeat the COVID-19 epidemic, we need to make sure that the United States is ready for a new threat of infectious diseases. This will require investment in research and development initiatives, expanding healthcare infrastructure and the network of health facilities, increasing staff in these areas, and setting up a clear governance structure to implement preparedness plans.

In addition, the document outlines steps that can be taken to control the epidemic, including the transition to instruments/tools and approaches rather targeting the infected people than mitigating the effects of the epidemic among the entire population of uncontrolled regions. It is also proposed to measure all indicators needed to determine when these transitions are viable and to ease restrictive measures.

EU countries have also developed and were implementing plans to exit the lockdown. Austria, the Czech Republic, and Denmark were the first to initiate this process, followed by Italy, Spain, France, Germany, Greece, Poland, and Portugal.

In Ukraine, on April 24, 2020, a plan for a phased lockdown lifting consisting of five stages [212] was made public, according to which the first stage of easing lockdown measures began on May 11, the second - on May 22, and the third - since June 1, 2020 [213]. However, the official easing of lockdown measures, the onset of summer and the holiday season has contributed to an increase in the number of lockdown violations by the population and an increase in the incidence of COVID-19 in Ukraine (as in some European countries). We are eager to believe that Ukrainians will not let a negative scenario come true and realize the need to observe social distancing and using individual protective means in public places, despite weakening the lockdown, as well as adapt to so-called 'untouch economy,' in which we will be urged to live for a long time.

Most of what is written in this article above is based on the information published before September 2020 in the world's scientific articles and which appeared in the preliminary publication in Visnyk of the National Academy of Sciences of Ukraine, 2020; (8): 29-71. 
In November and December 2020 there were dramatic developments in the SARS-CoV-2 epidemics scene. Though much-anticipated development of anti-SARS-specific medicines didn't happen the real success story came with the development of highly effective anti-SARS-CoV-2 vaccines. And the first one was Pfizer in collaboration with BioNTech and Moderna immediately to follow. At the beginning of November both companies Pfizer - first and Moderna - second have presented the results of their mRNA vaccines' phase III clinical studies. Since November 9, Moderna and the pharma giant Pfizer have offered preliminary evidence that spike-based mRNA vaccines can achieve greater than $90 \%$ efficacy [290]. Pfizer/BioNTech vaccine (BNT162b2), like Moderna (mRNA-1273) uses messenger RNA (mRNA) to produce spike protein inside cells (Pfizer's vaccine delivers 30 micrograms of mRNA per dose and Moderna's vaccine - 100 micrograms of mRNA per dose), which induces the appropriate immune response to it and blocks the coronavirus. Both vaccines appear to work equally well in all populations studied, including the elderly and ethnic minorities, and people with conditions such as diabetes and heart disease that make them vulnerable to severe COVID-19 [290]. Operation Warp Speed, the U.S. government body to develop COVID-19 vaccines has invested $\$ 1$ billion in Moderna's COVID-19 vaccine R\&D and committed another \$1.5 billion to Moderna to purchase 100 million doses and \$1.9 billion to Pfizer for the same amount of its product, which was developed at BioNTech. Both vaccines require two doses separated by weeks (21 days after the first shot for the Pfizer-BioNTech vaccine and 28 days for Moderna) and both companies say there should be enough to vaccinate the entire United States by the spring [290].

On December 11, 2020, the U.S. FDA issued the first emergency use authorization (EUA) for the Pfizer-BioNTech COVID-19 Vaccine for the prevention of coronavirus disease 2019 (COVID-19) caused by severe acute respiratory syndrome coronavirus 2 (SARS-CoV-2) in individuals 16 years of age and older and allows the vaccine to be distributed in the U.S. [291]. Similar emergency use authorization by the FDA on December 18 allowed the Moderna COVID-19 Vaccine to be distributed in the U.S. for use in individuals 18 years of age and older [292]. The next day after the authorizations, both companies started vaccination in the U.S. Interestingly, the Pfizer vaccine was allowed to be used in the UK be- fore the USA and the first person to be officially vaccinated the UK and in the world on December 8 was 91 years old Ms. Margaret Keenan from Coventry being a part of a mass vaccination program in the UK [293]. Thousands of vaccinations had taken place across the UK on that day.

Having designed its own vaccine by Jenner Institute in Oxford University, which was further developed by Astra-Zeneca pharmaceutical company, the UK Medicines and Healthcare products Regulatory Agency approved this vaccine on December 30 for emergency supply in the UK for the active immunisation of individuals 18 years or older and first vaccinations to begin early in the New Year [294]. The Oxford-AstraZeneca partnership was the first major developer to publish detailed data from phase III large clinical trial of a COVID-19 vaccine. This vaccine could be among the cheapest (\$3 per dose) and easiest to distribute around the world (it doesn't need freezing temperature for storage) - suggest that the vaccine is safe and effective. But the data also highlights a number of lingering unknowns, including questions about the most effective dosing regimen and how well it works in older adults [295].

All these data on the vaccine effectiveness and their lack of considerable side effects give hope that COVID-19 vaccines could effectively stop the pandemic when widely distributed.

Besides recent good news on the vaccine development and on the immunity to SARS-CoV-19 [299-301], which may last much longer than it was frightening us quite recently, there are also other and very disturbing news dedicated to the appearance of new and dangerous coronavirus mutations, which were detected at the beginning in the United Kingdom and South Africa, and later in other countries. Below the reader may find a compilation of three important documents created and disseminated by the world's most authoritative organizations - WHO, CDC and European CDC [305-307].

Since the beginning of November, the UK has faced a rapid increase in COVID-19 cases in South East England, leading to enhanced epidemiological and virological investigations. On 14 December 2020, authorities of the UK reported to WHO a variant referred to as SARS-CoV-2 VOC 202012/01 (Variant of Concern, the year 2020, month 12, variant 01 or "B.1.1.7." ). This variant contains 23 nucleotide substitutions and is not phylogenetically related to the SARS-CoV-2 virus circulating in the UK before. While it is known and expected that viruses constantly change through mutation leading to 
the emergence of new variants, preliminary analysis in the UK suggests that this variant is significantly more transmissible than previously circulating variants, with an estimated potential to increase the reproductive number $(\mathrm{R})$ by 0.4 or greater with estimated increased transmissibility of up to $70 \%$ [305]. One possible explanation for the emergence of the variant is prolonged SARS-CoV-2 infection in a single patient, potentially with reduced immunocompetence. Such prolonged infection can lead to the accumulation of immune escape mutations at an elevated rate [305].

Analysis of the viral genome identified a large proportion of cases belonged to a new single phylogenetic cluster. The new variant is defined by multiple spike protein mutations (deletion 69-70, deletion 144, N501Y, A570D, D614G, P681H, T716I, S982A, $\mathrm{D} 1118 \mathrm{H})$ present as well as mutations in other genomic regions. Phylogenetic analysis has shown that though SARS-CoV-2 VOC 202012/01 from the UK and variant 501Y.V2 from South Africa both have the N501Y mutation, they are different virus variants.

SARS-CoV-2 (as an RNA virus) mutates regularly, acquiring about one new mutation in its genome every two weeks. RNA viruses are known to have higher mutation rates than DNA viruses [296] and some non-silent mutations can induce amino acid changes in the surface protein's primary structure and conformation and can significantly alter the viral function and/or interactions with neutralizing antibodies. Because S protein determines the infectivity of the virus and its transmissibility in the host, and this protein is the major antigen inducing protective immune responses, almost all vaccines under development are directed against $\mathrm{S}$ protein. As of May 6, 2020, 329 naturally occurring variants in $\mathrm{S}$ protein have been reported in the public domain. A preliminary study suggested that the increased fatality rate might be associated with the most dominant variant of SARS-CoV-2, which emerged in early February 2020 with a D614G substitution in the gene encoding the spike protein. Over a period of several months, the D614G mutation replaced the initial SARS-CoV-2 strain identified in China and by June 2020 became the dominant form of the virus circulating globally. This mutation may have induced a conformational change in the S protein, thereby resulting in its increased infectivity [297]. The SARS-CoV-2 virus with the D614G substitution does not cause more severe illness or alter the effec- tiveness of existing laboratory diagnostics, therapeutics or vaccines [307].

Many mutations are silent (i.e., cause no change in the structure of the proteins they encode) because they produce a three-letter codon that translates to the same amino acid (i.e., they are "synonymous"). Other mutations may change the codon in a way that leads to an amino acid change (i.e., they are "nonsynonymous"), but this amino acid substitution does not impact the protein's function.

VOC 202012/01 has 14 non-synonymous (amino acid [AA] altering) mutations, 6 synonymous (non-AA altering), and 3 deletions, notably including [305]:

- 69/70 deletion: this double deletion has occurred spontaneously many times, and likely leads to a change in the spike protein conformation.

- P681H: near the S1/S2 furin cleavage site, a site with high variability in coronaviruses. This mutation has also emerged spontaneously multiple times.

- ORF8 stop codon (Q27stop): This mutation is not in the spike protein but in a different gene (in open reading frame 8), the function of which is unknown. Similar mutations have occurred in the past. In Singapore, one strain with this type of mutation emerged and disappeared.

Among the potential consequences of these mutations are the following:

- Ability to spread more quickly in humans. D614G, has this property to spread more quickly.

- Ability to cause either milder or more severe disease in humans. There is no evidence that VOC 202012/01 produces more severe illness than other SARS-CoV-2 variants.

- Ability to evade detection by specific diagnostic tests. Most commercial polymerase chain reaction (PCR) tests have multiple targets to detect the virus, such that even if a mutation impacts one of the targets, the other PCR targets will still work.

- Decreased susceptibility to therapeutic agents such as monoclonal antibodies.

- Ability to evade vaccine-induced immunity. FDA-authorized vaccines are "polyclonal," producing antibodies that target several parts of the spike protein. The virus would likely need to accumulate multiple mutations in the spike protein to evade immunity induced by vaccines or by natural infection.

The last possibility - to evade vaccine-induced immunity is the most concerning because once a large proportion of the population is vaccinated, 
there will be immune pressure that could favour and accelerate the emergence of such variants by selecting for "escape mutants". Nevertheless, most experts believe escape mutants are unlikely to emerge because of the nature of the virus [307].

To some extent, the answer to the question of whether the mutation N501Y, which was found in both the SARS-CoV-2 VOC 202012/01 and 501Y. V2 variants in the receptor-binding domain (RBD) of spike protein, has any impact on anti-SARS vaccine performance was recently published [288]. The authors have generated isogenic N501 and Y501 SARS-CoV-2 variants and found that sera of 20 participants in a previously reported trial of the mRNAbased COVID-19 vaccine BNT162b2 (now known as Pfizer/BioNTech mRNA vaccine) had an equivalent neutralizing activity to the N501 and Y501 viruses [288]. This finding means that this mutation doesn't prevent the vaccine's activity to initiate recipient's immune response against the SARS-CoV-2 VOC 2020 12/01 virus.

What awaits us in the future? In the spring, scientists predicted 250 million people worldwide will be infected and 1.75 million will die, as of 2021. In reality, as of January 10, 2021, WHO reports 88 million confirmed cases and 1.907 million deaths in the world. SARS-CoV-2 virus will not disappear soon and will continue to spread gradually, periodic introduction of strict lockdown measures will become commonplace. The COVID-19 vaccine will provide protection at least for six months, but probably longer - for a year or two. Vaccine distribution time will be, and already is now, different between different countries depending on various reasons but mainly financial and political. The future will largely depend on the extent to which we will restore social contacts and whether we will be able to continue taking preventive measures. If immunity to SARS-CoV-2 persists less than a year, then annual outbreaks of COVID-19 may occur until 2024 or even longer.

Nowadays, the epidemic situation with COVID-19 differs significantly by country. Such countries as China, New Zealand Singapore and Rwanda have reached low morbidity rates following tough measures and are now easing restrictions observing isolated outbreaks. One of effective options to contain a pandemic is to track contacts, perhaps the actions must be quick and effective: $80 \%$ of contacts must be tracked for several days to control an outbreak. In other countries (USA, Brazil), the incidence is rising rapidly after governments lifted quarantine too quickly or failed to effectively introduce it across the country.

When the quarantine is eased, people may think the epidemic is over, although this is a misleading impression. In fact, the risk of infection is greater than people can imagine. For example, researchers of the Massachusetts Institute of Technology (MIT) in Cambridge, USA, after analyzing COVID-19 tests from 84 countries, found that the infection rate was 12 times and the mortality rate $50 \%$ higher than officially reported. Perhaps, it's worth noting that people's behaviour regarding safety measures in crowded places (social distance, hand washing, wearing masks) has changed: according to research conducted in Mexico, after easing the quarantine, $70 \%$ of the population continued taking preventive measures.

The COVID-19 epidemic situation was expected to worsen with the onset of autumn and winter in temperate and cold climates, as it happens every year in the case of other human respiratory viruses. Dry winter air improves viral stability and transmission, as well as impairs the immune protection of the respiratory tract. In addition, in cold weather, people are more likely to stay indoors where there is a higher risk of airborne transmission of viruses. We are witnessing these expectations now in most countries - in USA, Europe and beyond.

Scientists fear that co-infection with various viruses (SARS-CoV-2, influenza, other human coronaviruses and respiratory-syncytial virus - RSV) may increase the number of severe cases and worsen the epidemic situation. After all, it is still not clearly known whether infection with other human coronaviruses can provide any efficient protection against SARS-CoV-2. To stop the pandemic, SARS-CoV-2 must be eradicated worldwide, which most scientists believe is almost impossible, or people must develop sufficient immunity in response to an infection or vaccine. Studies show that the level of protection against SARS-CoV-2 in 11 European countries is $3-4 \%$, and in the United States - from 1\% to 6.9\%. However, any future scenario remain only conjecture, as this is the first time when humanity has encountered such a pandemic, and COVID-19 is very much different from pandemic influenza in its epidemic features [264].

In conclusion, it is worth repeating some already well-known facts. The COVID-19 world pandemic, caused by the coronavirus SARS-CoV-2, has led to a global turmoil that is unprecedented in its consequences for the healthcare system, the econo- 
my and social life. Further development of the situation depends, on the one hand, on the evolution of the virus (increase or decrease of its aggressiveness, infectivity, and impact on the human body), and on the other - on the success of human efforts to curb the spread of the virus, observance of anti-epidemiological measures, development of effective antiviral medicines, diagnostics, and vaccines. It is very likely that SARS-CoV-2 (or its derivatives) may become associate of our lives for many years in future, and humanity has to adapt to the corresponding changes in everyday life.

Lockdowns have played a positive role in controlling the pandemic in most countries around the world, including Ukraine, where it was introduced at the right time. Now the lockdown measures are weakening, which leads at early stages to an increase in the number of infected people. However, the main guarantee of successful completion of this stage is strengthening control (and self-control) over compliance with the requirements under conditions of weakened lockdown. Unfortunately, our hopes for the development of anti-SARS medicines did not realise yet but the timely development of effective vaccines became a real scientific success.

Finally, I would like to recall the words of Alain Leschner, Honorary Director General of the American Association for the Advancement of Science, which reflect the obvious fact for all of us: "Following the COVID-19 pandemic, which has significantly and negatively affected the education of a new generation of young scientists, science must be made stronger, and our task now is to provide them with all possible assistance for the sake of the future science” [214].

Author's note. The limited volume of the publication precluded citing much important additional material. This article is a modified, slightly extended and much-updated version of an article published in Visnyk of the National Academy of Sciences of Ukraine, 2020; (8): 29-71

The author expresses his sincere gratitude to his colleagues in the Department of Molecular Immunology of Palladin Institute of Biochemistry of the National Academy of Sciences of Ukraine - senior researchers Svetlana Romanyuk, PhD and Yaroslava Maksymovych, PhD for extremely valuable help in preparing materials for the article, as well as to Doctor of Physical and Mathematical Sciences Igor Brovchenko for the information on the epidemic mathematical models, and to Academician of the
NAS of Ukraine Professor Volodymyr Shyrobokov for editing the classification of coronaviruses.

\section{ПОЛЮВАННЯ ВЧЕНИХ НА KOPOHABIPУC SARS-COV-2: СТРАТЕГІЇ ПОДОЛАННЯ ПАНДЕМІї}

\section{С. В. Комісаренко}

Інститут біохімії ім. О. В. Палладіна НАН України, Київ; e-mail:svk@biochem.kiev/ua

Коронавірус SARS-CoV-2 викликає коронавірусне захворювання 2019 року (COVID-19), яке у 2020 році стало пандемією та глобальною загрозою для усього світу. На 10 січня, 2021 року 218 країн та територій доповіли про 90,783 мільйонів підтверджених випадків захворювання та 1,945 мільйонів смертей. Метою цієї статті було коротко оглянути і проаналізувати численну інформацію про цей вірус та захворювання COVID-19 та надати загальне уявлення про відповідні проблеми. Зокрема, навести інформацію про біологію коронавірусу, його походження, структуру та шляхи поширення, про властивості i особливості захворювання COVID-19, його діагностику, створення ліків та формування імунітету. Особливу увагу приділено створенню вакцин проти SARS-CoV-2 та ефективності протиепідемічних заходів (карантину). Також обговорено можливості математичного моделювання епідемічного процесу та перспективи скасування карантину. Нарешті, наведені дані щодо небезпечного варіанту VOC 2020 12/1 мутації вірусу, яка призвела до його інтенсивного поширення та можливий вплив цієї мутації на існуючу діагностику вірусу та на вакцинацію проти нього.

\section{К л юч о в $\quad$ слов в $\quad$ SARS-CoV-2} коронавірус, пандемія COVID-19, шляхи зараження, діагностика COVID-19, противірусний імунітет, вакцини, моделі епідемічного процесу. варіант SARS-CoV-2 - VOC 2020 12/1.

\section{References}

1. Reimann HA. Landmark article Dec 24, 1938: An acute infection of the respiratory tract with atypical pneumonia. A disease entity probably caused by a filtrable virus. JAMA. 1984; 251(7): 936-944. 
2. Severe acute respiratory syndrome. https://en.wikipedia.org/ wiki/Severe_acute_respiratory_syndrome.

3. Middle East respiratory syndrome. https://en.wikipedia.org/ wiki/Middle_East_respiratory_syndrome.

4. Fox K, Trucco F, Ulloa C, Ehlinger M. Covid-19 is now on every continent as Antarctica records its first out-break. CNN, December 22, 2020

5. In Ukraine - the first case of coronavirus. Ukrayinska pravda. March 3, 2020 (in Ukrainian). https://www.pravda.com.ua/ news/2020/03/3/7242332/

6. Wee SL, McNeil DG Jr. China Identifies New Virus Causing Pneumonialike Illness. https://www.nytimes. com/2020/01/08/health/china-pneumonia-outbreak-virus. html

7. Lu R, Zhao X, Li J. et al. Genomic characterisation and epidemiology of 2019 novel coronavirus: implications for virus origins and receptor binding. Lancet. 2020; 395(10224): 565-574.

8. Beaudette FR, Hudson CB. Cultivation of the virus of infectious bronchitis. J Am Vet Med Assoc. 1937; 90: 51-58.

9. Tyrrell DA, Bynoe ML. Cultivation of a novel type of commoncold virus in organ cultures. Br Med J. 1965; 1(5448): 14671470.

10. Woo PC, Lau SK, Huang Y, Yuen KY. Coronavirus diversity, phylogeny and interspecies jumping. Exp Biol Med (Maywood). 2009; 234(10): 1117-1127.

11. Derek Wong's Virology. http://virology-online.com/viruses/ CORZA4.htm

12. Phylogeny of SARS-like betacoronaviruses including novel coronavirus SARS-CoV-2. https://nextstrain.org/groups/blab/ sars-like-cov

13. Davidson H. First Covid-19 case happened in November, China government records show — report. https://www.theguardian. com/world/2020/mar/13/first-covid-19-case-happened-innovember-china-government-records-show-report

14. Huang C, Wang Y, Li X. et al. Clinical features of patients infected with 2019 novel coronavirus in Wuhan, China. Lancet. 2020; 395(10223): 497-506.

15. Osborne H. Coronavirus Outbreak May Have Started As Early As September, Scientists Say. https://www.newsweek.com/ coronavirus-outbreak-september-not-wuhan-1498566

16. Zhou P, Yang XL, Wang XG. et al. A pneumonia outbreak associated with a new coronavirus of probable bat origin. Nature. 2020; 579(7798): 270-273.

17. Readfearn G. How did coronavirus start and where did it come from? Was it really Wuhan's animal market? https:// www.theguardian.com/world/2020/apr/28/how-did-thecoronavirus-start-where-did-it-come-from-how-did-itspread-humans-was-it-really-bats-pangolins-wuhan-animalmarket

18. Liu P, Jiang JZ, Wan XF, Hua Y, Li L, Zhou J., Wang X, Hou F, Chen J, Zou J, Chen J. Are pangolins the intermediate host of the 2019 novel coronavirus (SARS-CoV-2)? PLoS Pathog. 2020; 16(5): e1008421.

19. Andersen KG, Rambaut A, Lipkin WI, Holmes EC, Garry RF. The proximal origin of SARS-CoV-2. Nat Med. 2020; 26(4): 450-452.

20. Shinkman PD. U.S. Spy Agencies Weigh In on Coronavirus Rumors. https://www.usnews.com/news/national-news/ articles/2020-04-30/coronavirus-not-man-made-director-ofnational-intelligence-says

21. Sanger DE. Pompeo Ties Coronavirus to China Lab, Despite Spy Agencies' Uncertainty. https://www.nytimes. com/2020/05/03/us/politics/coronavirus-pompeo-wuhanchina-lab.html
22. Pennisi E. How bats have outsmarted viruses - including coronaviruses - for 65 million years. Science. Jul. 22, 2020.

23. Scudellari M. The sprint to solve coronavirus protein structures - and disarm them with drugs. Nature. 2020; 581(7808): 252255.

24. Zhang L., Lin D., Sun X. et al. Crystal structure of SARS$\mathrm{CoV}-2$ main protease provides a basis for design of improved $\alpha$-ketoamide inhibitors. Science. 2020; 368(6489): 409-412.

25. Wu F, Zhao S, Yu B, Chen YM, Wang W, Song ZG, Hu Y, Tao ZW, Tian JH, Pei YY, Yuan ML, Zhang YL, Dai FH, Liu Y, Wang QM, Zheng JJ, Xu L, Holmes EC, Zhang YZ. A new coronavirus associated with human respiratory disease in China. Nature. 2020; 579(7798): 265-269.

26. Schmidt A, Wolff MH., Weber O. Coronaviruses with specia emphasis on first insights concerning SARS. Springer, 2005. 232 p.

27. Wrapp D, Wang N, Corbett KS, Goldsmith JA, Hsieh CL, Abiona O, Graham BS, McLellan JS. Cryo-EM structure of the 2019-nCoV spike in the prefusion conformation. Science. 2020; 367(6483): 1260-1263.

28. Zhang X, Li Sh, Niu Sh. ACE2 and COVID-19 and the Resulting ARDS. Postgrad Med J. 2020; 96(1137): 403-407.

29. Watanabe Ya, Allen JD, Wrapp D, McLellan JS, Crispin M. Site-specific glycan analysis of the SARS-CoV-2 spike. Science. 2020; 369(6501): 330-333.

30. Hoffmann M, Kleine-Weber H, Schroeder S, Krüger N, Herrler $\mathrm{T}$, Erichsen S, Schiergens TS, Herrler G, Wu NH, Nitsche A, Müller MA, Drosten C, Pöhlmann S. SARS-CoV-2 Cell Entry Depends on ACE2 and TMPRSS2 and Is Blocked by a Clinically Proven Protease Inhibitor. Cell. 20206; 181(2): 271-280.e8.

31. Sakai K., Ami Y., Tahara M. et al. The Host Protease TMPRSS2 Plays a Major Role in in Vivo Replication of Emerging H7N9 and Seasonal Influenza. Viruses J Virol. 2014; 88(10): 56085616.

32. Vankadari N, Wilce JA. Emerging WuHan (COVID-19) Coronavirus: Glycan Shield and Structure Prediction of Spike Glycoprotein and Its Interaction With Human CD26. Emerg Microbes Infect. 2020; 9(1): 601-604.

33. Wang K, Chen W, Zhou YS. et al. SARS-CoV-2 invades host cells via a novel route: CD147-spike protein. bioRxiv. https:// doi.org/10.1101/2020.03.14.988345

34. Castelvetri LC, Ojha R, Pedro LD. et al. Neuropilin-1 facilitates SARS-CoV-2 cell entry and provides a possible pathway into the central nervous system. BioRxiv preprint. https://doi. org/10.1101/2020.06.07.137802

35. Jia Y, Shen G, Zhang Y, Huang KS, Ho HY, Hor WS, Yang $\mathrm{CH}$, Li C, Wang WL. Analysis of the mutation dynamics of SARS-CoV-2 reveals the spread history and emergence of RBD mutant with lower ACE2 binding affinity. BioRxiv. 2020. https://doi.org/10.1101/2020.04.09.034942

36. hang L, Jackson CB, Mou H, Ojha A, Rangarajan ES Izard T, Farzan M, Choe H. The D614G mutation in the SARS-CoV-2 spike protein reduces S1 shedding and increases infectivity. BioRxiv. June 12, 2020. https://doi. org/10.1101/2020.06.12.148726

37. Thao TTN, Labroussaa F, Ebert N, V'kovski P, Stalder H, Portmann J, Kelly J, Steiner S, Holwerda M, Kratzel A, Gultom M, Schmied K, Laloli L, Hüsser L, Wider M, Pfaender S, Hirt D, Cippà V, Crespo-Pomar S, Schröder S, Muth D, Niemeyer D, Corman VM, Müller MA, Drosten C, Dijkman R , Jores J, Thiel V. Rapid reconstruction of SARSCoV-2 using a synthetic genomics platform. Nature. 2020; 582(7813): 561-565. 
38. Sun J, Zhuang Zh, Zheng J. et al. Generation of a Broadly Useful Model for COVID-19 Pathogenesis, Vaccination, and Treatment. Cell. 2020; 182: 1-10.

39. Gaglia M, Lakdawala S. What we do and do not know about COVID-19's infectious dose and viral load. https:// theconversation.com/what-we-do-and-do-not-know-aboutcovid-19s-infectious-dose-and-viral-load-135991

40. Wang W, Xu Y, Gao R, Lu R, Han K, Wu G, Tan W. Detection of SARS-CoV-2 in Different Types of Clinical Specimens. JAMA. 2020; 323(18): 1843-1844.

41. Meyerowitz EA, Richterman AG, Quick MPH. A Summary of the COVID-19 Literature So Far. Medscape. May 18, 2020. https://www.medscape.com/viewarticle/930588

42. To KK, Tsang OT, Yip CC, Chan KH, Wu TC, Chan JM, Leung WS, Chik TS, Choi CY, Kandamby DH, Lung DC, Tam AR, Poon RW, Fung AY, Hung IF, Cheng VC, Chan JF, Yuen KY. Consistent Detection of 2019 Novel Coronavirus in Saliva. Clin Infect Dis. 2020; 71(15): 841-843.

43. Sex and Coronavirus Disease 2019 (COVID-19). https://www1. nyc.gov/assets/doh/downloads/pdf/imm/covid-sex-guidance. pdf

44. Mandavilli A. Infected but Feeling Fine: The Unwitting Coronavirus Spreaders. The New York Times. July 9, 2020. https://www.nytimes.com/2020/03/31/health/coronavirusasymptomatic-transmission.html

45. Petri W. Infected with the coronavirus but not showing symptoms? A physician answers 5 questions about asymp-tomatic COVID-19. The Conversation. https:// theconversation.com/infected-with-the-coronavirus-but-notshowing-symptoms-a-physician-answers-5-questions-aboutasymptomatic-covid-19-137029

46. van Doremalen N, Bushmaker T, Morris DH, Holbrook MG, Gamble A, Williamson BN, Tamin A, Harcourt JL, Thornburg NJ, Gerber SI, Lloyd-Smith JO, de Wit E, Munster VJ. Aerosol and Surface Stability of SARS-CoV-2 as Compared with SARS-CoV-1. N Engl J Med. 2020; 382(16): 1564-1567.

47. Sungnak W, Huang N, Becavin C, Berg M, Queen R, Litvinukova M, Talavera-Lopez C, Maatz H, Reichart D, Sampaziotis F, Worlock KB, Yoshida M, Barnes JL, Lung HCA. SARS-CoV-2 entry factors are highly expressed in nasal epithelial cells together with innate immune genes. Nat Med. 2020; 26(5): 681-687.

48. All Your Coronavirus Questions, Answered. Time. May 8, 2020. https://time.com/5820118/coronavirus-questionsanswered/

49. Lewis D. Is the coronavirus airborne? Experts can't agree. Nature News. April 2, 2020. https://www.nature.com/articles/ d41586-020-00974-w

50. Harrison L. Speech May Spread More COVID-19 Than Feces. Medscape. 19 May 2020. https://www.medscape.com/ viewarticle/930799

51. Coronavirus: WHO rethinking how Covid-19 spreads in air. BBC News. 8 July 2020. https://www.bbc.com/news/ world-53329946

52. Rapid Expert Consultation on SARS-CoV-2 Survival in Relation to Temperature and Humidity and Potential for Seasonality for the COVID-19 Pandemic (April 7, 2020). https:// www.nap.edu/read/25771/chapter/1

53. Recommendation Regarding the Use of Cloth Face Coverings, Especially in Areas of Significant Community-Based Transmission. https://www.cdc.gov/coronavirus/2019-ncov/ prevent-getting-sick/cloth-face-cover.html

54. Advice on the use of masks in the context of COVID-19. https://www.who.int/publications-detail/advice-on-the-useof-masks-in-the-community-during-home-care-and-in- healthcare-settings-in-the-context-of-the-novel-coronavirus(2019-ncov)-outbreak

55. Estimating the number of infections and the impact of non-pharmaceutical interventions on COVID-19 in 11 European countries. https://www.imperial.ac.uk/media/ imperial-college/medicine/mrc-gida/2020-03-30-COVID19Report-13.pdf

56. Mizutani T. Signal transduction in SARS-CoV-infected cells. Ann NY Acad Sci. 2007. 1102: 86-95.

57. Zimmer C. DNA Inherited From Neanderthals May Increase Risk of Covid-19. The New York Times. July 4, 2020. https://www.nytimes.com/2020/07/04/health/coronavirusneanderthals.html

58. Osterweil N. Case Fatality Rate for COVID-19 Near $1.4 \%$, Increases With Age. https://www.medscape.com/ viewarticle/927870

59. Rabin RC. In Italy, Coronavirus Takes a Higher Toll on Men. https://www.nytimes.com/2020/03/20/health/coronavirusitaly-men-risk.html

60. Wenham C, Smith J, Morgan R. COVID-19: the gendered impacts of the outbreak. Lancet. 2020; 395(10227): 846-848.

61. Coronavirus in NY: Cases, maps, charts and resources. https:// www.syracuse.com/coronavirus-ny/

62. Wadman M. Sex hormones signal why virus hits men harder. Science. 2020; 368(6495): 1038-1039.

63. Zaiets K, Padilla R. Coronavirus, diabetes, obesity and other underlying conditions: Which patients are most at risk? https:// www.usatoday.com/in-depth/news/2020/04/15/coronavirusrisk-90-patients-had-underlying-conditions/2962721001/

64. Mallapaty S. Mounting clues suggest the coronavirus might trigger diabetes. https://www.nature.com/articles/d41586020-01891-8

65. Tan T, Khoo B, Mills EG. et al. Association Between High Serum Total Cortisol Concentrations and Mortality From COVID-19. Lancet Diabetes Endocrinol. 2020; 8(8): 659-660.

66. Balfour H. Blood test could identify those most at risk from COVID-19. Drug Target Review. 22 May 2020. https://www. drugtargetreview.com/news/61778/blood-test-could-identifythose-most-at-risk-from-covid-19/

67. Yan L, Zhang HT, Goncalves J. et al. An interpretable mortality prediction model for COVID-19 patients. Nat Mach Intell. 2020; 2: 283-288.

68. Yong ShJ. Vitamin D as an Independent Risk Factor for COVID-19 Death. https://medium.com/microbial-instincts/ lack-of-vitamin-d-as-an-independent-risk-factor-for-covid19-death-82365d0520fa

69. Fang L, Karakiulakis G, Roth M. Are patients with hypertension and diabetes mellitus at increased risk for COVID-19 infection? Lancet. 2020; 8(4): E21.

70. Sama IE, Ravera A, Santema BT. et al. Circulating Plasma Concentrations of Angiotensin-Converting Enzyme 2 in Men and Women With Heart Failure and Effects of ReninAngiotensin-Aldosterone Inhibitors. Eur Heart J. 2020; 41(19): 1810-1817.

71. Murray S. New Evidence Concerning Safety of ACE Inhibitors, ARBs in COVID-19. https://www.pharmacytimes.com/news/ new-evidence-concerning-safety-of-ace-inhibitors-arbs-incovid-19

72. de Simone G. Position Statement of the ESC Council on Hypertension on ACE-Inhibitors and Angiotensin Receptor Blockers. Council on Hypertension of the European Society of Cardiology. 13 Mar 2020. https://www.escardio.org/Councils/ Council-on-Hypertension-(CHT)/News/position-statementof-the-esc-council-on-hypertension-on-ace-inhibitors-andang 
73. Radzikowska U, Ding M, Tan G, Zhakparov D, Peng Y, Wawrzyniak P, Wang M , Li S, Morita H, Altunbulakli C, Reiger M, Neumann AU, Lunjani N, Traidl-Hoffmann C, Nadeau KC, O'Mahony L, Akdis C, Sokolowska M. Distribution of ACE2, CD147, CD26, and other SARS-CoV-2 associated molecules in tissues and immune cells in health and in asthma, COPD, obesity, hypertension, and COVID-19 risk factors. Allergy. 2020; 75(11): 2829-2845.

74. Report of the WHO-China Joint Mission on Coronavirus Disease 2019 (COVID-19). https://www.who.int/docs/defaultsource/coronaviruse/who-china-joint-mission-on-covid-19final-report.pdf

75. Liu R, Wang Y, Li J, Han H, Xia Z, Liu F, Wu K, Yang L, Liu X, Zhu C. Decreased T cell populations contribute to the increased severity of COVID-19. Clin Chim Acta. 2020;508:110-114.

76. Ying T, Li W, Dimitrov DS. Discovery of T-Cell Infection and Apoptosis by Middle East Respiratory Syndrome Coronavirus. J Infect Dis. 2016; 213(6): 877-879.

77. Shoenfeld Y. Corona (COVID-19) time musings: Our involvement in COVID-19 pathogenesis, diagnosis, treatment and vaccine planning. Autoimmun Rev. 2020; 19(6): 102538.

78. Cascella M, Rajnik M, Cuomo A, Dulebohn SC, Di Napoli R. Features, Evaluation and Treatment Coronavirus (COVID-19). (Treasure Island (FL): Stat Pearls Publishing, 2020).

79. Long B, Brady WJ, Koyfman A, Gottlieb M. Cardiovascular complications in COVID-19. Am J Emerg Med. 2020; 38(7): 1504-1507.

80. Xu L, Liu J, Lu M, Yang D, Zheng X. Liver injury during highly pathogenic human coronavirus infections. Liver International. 2020; 40(5): 998-1004.

81. Riphagen S, Gomez X, Gonzalez-Martinez C, Wilkinson N, Theocharis P. Hyperinflammatory shock in children during COVID-19 pandemic. Lancet. 2020; 395(10237): 1607-1608.

82. Kwon D. From Headaches to 'COVID Toes,' Coronavirus Symptoms Are a Bizarre Mix. Blood clots and inflammation may underlie many of these complications. https://www. scientificamerican.com/article/from-headaches-to-covidtoes-coronavirus-symptoms-are-a-bizarre-mix1/

83. Carod-Artal FJ. Neurological complications of coronavirus and COVID-19. Revista de Neurologia. 2020; 70(9): 311-322.

84. Brooks M. COVID-19 Tied to Wide Range of Neuropsychiatric Complications. Medscape. June 29, 2020. https://www. medscape.com/viewarticle/933136

85. Cormier Z. How Covid-19 can damage the brain. BBC News. 23 June 2020. https://www.bbc.com/future/article/20200622the-long-term-effects-of-covid-19-infection

86. Yasgur BS. Three Stages to COVID-19 Brain Damage, New Review Suggests. Medscape. June 29, 2020. https://www. medscape.com/viewarticle/933131

87. Negro F. Is antibody-dependent enhancement playing a role in COVID-19 pathogenesis? Swiss Med Weekly. 2020. 150: w20249.

88. Coronavirus disease (COVID-19) technical guidance: Laboratory testing for 2019-nCoV in humans. https://www. who.int/emergencies/diseases/novel-coronavirus-2019/ technical-guidance/laboratory-guidance

89. Summary table of available protocols in this document. https://www.who.int/docs/default-source/coronaviruse/ whoinhouseassays.pdf?sfvrsn=de3a76aa_2

90. SARS-CoV-2 Diagnostic Pipeline. https://www.finddx.org/ covid-19/pipeline/

91. Coronavirus Testing Picks Up in the U.S. Following Slow Start. https://www.diagnosticsworldnews.com/news/2020/03/17/ coronavirus-testing-picks-up-in-the-u.s.-following-slow-start
92. Liuqian L., Shulun H., Wei H. 14\% of Recovered Covid-19 Patients in Guangdong Tested Positive Again. https://www. caixinglobal.com/2020-02-26/14-of-recovered-covid-19patients-in-guangdong-tested-positive-again-101520415.html

93. Omer SB, Malani P, Del Rio C. The COVID-19 Pandemic in the US: A Clinical Update. JAMA. 2020; 323(18): 1767-1768.

94. Parry RL. Coronavirus patients can't relapse, South Korean scientists believe. https://www.thetimes.co.uk/article/ coronavirus-patients-cant-relapse-south-korean-scientistsbelieve-rkm8zm7d9

95. Ukraine has developed test systems to detect antibodies to coronavirus. The Day. April, 13, 2020. (in Ukrainian). https://day.kyiv.ua/uk/news/130420-ukrayina-rozrobyla-testsystemy-dlya-vyznachennya-antytil-do-koronavirusu

96. Sona Nanotech Inc. Buy. http://cdn.ceo.ca.s3-us-west-2. amazonaws.com/1f8clh6-SONA.SNANF.Initiation. Maxim.040220.pdf

97. Sheridan C. Fast, portable tests come online to curb coronavirus pandemic. https://www.nature.com/articles/d41587-02000010-2

98. Fletcher ER, Vijay SL. New COVID-19 Rapid Diagnostic Approved On 'GeneXpert' TB Platform; Could Pave Way For More Testing In Low- \& Middle-Income Countries. https:// healthpolicy-watch.org/new-covid-19-rapid-test-approvedfor-genexpert-tb-platform-could-pave-way-for-more-testingin-low-middle-income-countries/

99. Coronavirus (COVID-19) Update: FDA Authorizes First Antigen Test to Help in the Rapid Detection of the Virus that Causes COVID-19 in Patients. https://www.fda.gov/newsevents/press-announcements/coronavirus-covid-19-updatefda-authorizes-first-antigen-test-help-rapid-detection-viruscauses

100. Sofia 2 SARS antigen FIA. https://www.quidel.com/ immunoassays/rapid-sars-tests/sofia-2-sars-antigen-fia

101. Medical Companies Win Approval for Rapid Coronavirus Tests. https://www.wsj.com/articles/medical-companieswin-approval-for-rapid-coronavirus-tests-11585586147

102. Broughton JP, Deng X, Yu G. et al. CRISPR-Cas12-based detection of SARS-CoV-2. Nat Biotechnol. 2020; 38(7): 870874.

103. Sanders JM, Monogue ML, Jodlowski TZ, Cutrell JB. Pharmacologic Treatments for Coronavirus Disease 2019 (COVID-19). JAMA. 2020; 323(18): 1824-1836.

104. Kupferschmidt K, Cohen J. Race to find COVID-19 treatments accelerates. Science. 2020; 367(6485): 1412-1413.

105. Rodell CB. An ACE therapy for COVID-19. https://stm. sciencemag.org/content/12/541/eabb5676

106. Leslie M. Biologists invent a new way to fight viruses with llama blood and molecular superglue. https://www. sciencemag.org/news/2020/05/biologists-invent-new-wayfight-viruses-llama-blood-and-molecular-super-glue

107. Mulligan MJ, Lyke KE, Kitchin N. et al. Phase 1/2 Study to Describe the Safety and Immunogenicity of a COVID-19 RNA Vaccine Candidate (BNT162b1) in Adults 18 to 55 Years of Age: Interim Report. MedRXiv. https://doi.org/10.1 101/2020.06.30.20142570

108. Ravichandran S, Coyle EM, Klenow L. et al. Antibody signature induced by SARS-CoV-2 spike protein immunogens in rabbits. Sci Transl Med. 2020; 12(550): eabc3539.

109. Wang C, Li W, Drabek D, Okba NMA, van Haperen R, Osterhaus ADME, van Kuppeveld FM, Haagmans BL, Grosveld F, Bosch BJ. A human monoclonal antibody blocking SARS-CoV-2 infection. Nat Commun. 2020; 11(1): 2251. 
110. Chi X, Yan R, Zhang J. et al. A Neutralizing Human Antibody Binds to the N-terminal Domain of the Spike Protein of SARS-CoV-2. Science. 2020; 369(6504): 650-655.

111. Kramer J. Coronavirus Antibody Therapies Raise Hopes and Skepticism. Scientific American. May 29, 2020. https:// www.scientificamerican.com/article/coronavirus-antibodytherapies-raise-hopes-and-skepticism1/

112. Yuan M, Wu NC, Zhu X., et al. A highly conserved cryptic epitope in the receptor binding domains of SARS-CoV-2 and SARS-CoV. Science. 2020;368(6491): 630-633.

113. Jee Ch. A trial is under way of the first new antibody medicine developed to treat COVID-19. https://www. technologyreview.com/2020/06/01/1002475/trial-newantibody-medicine-developed-to-treat-covid-19/

114. Robbiani D.F., Gaebler C., Muecksch F. et al. Convergent antibody responses to SARS-CoV-2 in convalescent individuals. Nature. 2020; 584(7821): 437-442

115. Kupferschmidt K. Scientists put survivors' blood plasma to the test. https://science.sciencemag.org/content/368/6494/922

116. Etherington D. FDA now allows treatment of life-threatening COVID-19 cases using blood from patients who have recovered. https://techcrunch.com/2020/03/24/fda-nowallows-treatment-of-life-threatening-covid-19-cases-usingblood-from-patients-who-have-recovered/

117. Demura M., Takada N. Blood plasma treatment for coronavirus set for Japan trial. https://asia.nikkei.com/Business/HealthCare/Blood-plasma-treatment-for-coronavirus-set-forJapan-trial

118. Gharbharan A, Jordans CCE, van Kessel CG. et al. Convalescent Plasma for COVID-19. A randomized clinical trial. MedRXiv. 2020. https://doi.org/10.1101/2020.07.01.20139857

119. Biopharma encourages citizens who have undergone COVID-19 to become plasma donors for the development of drugs against coronavirus infection. Interfax-Ukraine. May, 8, 2020 (in Ukrainian). https://ua.interfax.com.ua/news/ general/661051.html

120. Lovett S. Coronavirus: Men produce more COVID-19 antibodies than women, study shows. https://www. independent.co.uk/news/health/coronavirus-antibodiesmen-women-blood-plasma-donor-a9579441.html

121. The fight against COVID-19 starts with you. https://www. covig-19plasmaalliance.org/en-US\#recruitment

122. Al Idrus A. Takeda, CSL-led alliance and NIH to test COVID-19 plasma treatment this summer. https://www. fiercebiotech.com/biotech/takeda-csl-led-alliance-and-nihto-test-plasma-treatment-summer

123. Cohen E. Human Trials Expected To Start Next Month For Covid-19 Treatment Derived From Cows' Blood. https:// www.sabbiotherapeutics.com/2020/06/16/human-trialsexpected-to-start-next-month-for-covid-19-treatmentderived-from-cows-blood/

124. Sheridan C. Convalescent serum lines up as first-choice treatment for coronavirus. https://www.nature.com/articles/ d41587-020-00011-1

125. The first patient tests new drug against COVID-19. https:// www.en.auh.dk/press-room/news-archive/2020/the-firstpatient-tests-new-drug-against-covid-19/

126. Camostat Mesylate in COVID-19 Outpatients. https:// clinicaltrials.gov/ct2/show/NCT04353284

127. Devaux CA, Rolain JM, Colson P, Raoult D. New insights on the antiviral effects of chloroquine against coronavirus: what to expect for COVID-19? Int J Antimicrob Agents. 2020; 55(5): 105938.

128. Piller C. Former FDA leaders decry emergency authorization of malaria drugs for coronavirus. https://www.sciencemag. org/news/2020/04/former-fda-leaders-decry-emergencyauthorization-malaria-drugs-coronavirus

129. Sciama Y. Is France's president fueling the hype over an unproven coronavirus treatment? https://www.sciencemag. org/news/2020/04/france-s-president-fueling-hype-overunproven-coronavirus-treatment

130. Some Swedish hospitals have stopped using chloroquine to treat COVID-19 after reports of severe side effects. https:// www.newsweek.com/swedish-hospitals-chloroquine-covid19-side-effects-1496368

131. FDA cautions against use of hydroxychloroquine or chloroquine for COVID-19 outside of the hospital setting or a clinical trial due to risk of heart rhythm problems. https://www.fda.gov/drugs/drug-safety-and-availability/fdacautions-against-use-hydroxychloroquine-or-chloroquinecovid-19-outside-hospital-setting-or

132. Remdesivir. https://en.wikipedia.org/wiki/Remdesivir\#cite_ note-:0-4

133. Yin W, Mao C, Luan X. et al. Structural basis for inhibition of the RNA-dependent RNA polymerase from SARS-CoV-2 by remdesivir. Science. 2020; 368(6498): 1499-1504.

134. Gordon CJ, Tchesnokov EP, Woolner E, Perry JK, Feng JY, Porter DP, Gotte M. Remdesivir is a direct-acting antiviral that inhibits RNA-dependent RNA polymerase from severe acute respiratory syndrome coronavirus 2 with high potency. J Biol Chem. 2020; 295(20): 6785-6797.

135. NIH Clinical Trial Shows Remdesivir Accelerates Recovery from Advanced COVID-19. https://www.niaid.nih.gov/newsevents/nih-clinical-trial-shows-Remdesivir-acceleratesrecovery-advanced-covid-19

136. Grein J., Ohmagari N., Shin D. et al. Compassionate Use of Remdesivir for Patients with Severe Covid-19. N Engl J Med. 2020;382(24):2327-2336.

137. FDA Allows For'Emergency Use' of Remdesivir, Experimental Coronavirus Drug. https://time.com/5831062/fda-allowsemergency-use-Remdesivir/

138. Coronavirus (COVID-19) Update: FDA Issues Emergency Use Authorization for Potential COVID-19 Treatment. https://www.fda.gov/news-events/press-announcements/ coronavirus-covid-19-update-fda-issues-emergency-useauthorization-potential-covid-19-treatment

139. Shimbun A. Japan approves Remdesivir for COVID-19 despite uncertainties. http://www.asahi.com/ajw/articles/13358075

140. Taylor Ph. Remdesivir closes in on receiving first EU approval for treatment for COVID-19. https://www.pmlive.com/ pharma_news/Remdesivir_closes_in_on_receiving_first_ eu_approval_for_treatment_for_covid-19_1343030

141. Ridgeback Biotherapeutics Announces Launch of Phase 2 Trials Testing EIDD-2801 as Potential Treatment for COVID-19. https://www.businesswire.com/news/ home/20200619005038/en/Ridgeback-BiotherapeuticsAnnounces-Launch-Phase-2-Trials

142. Lopinavir/ritonavir. https://en.wikipedia.org/wiki/Lopinavir/ ritonavir

143. Choy KT, Wong AY, Kaewpreedee P. et al. Remdesivir, Lopinavir, Emetine, and Homoharringtonine Inhibit SARSCoV-2 Replication in Vitro. Antiviral Res. 2020; 178: 104786.

144. The WHO Solidarity Trial for COVID-19 treatments officially launched in Indonesia. https://www.who.int/indonesia/news/ detail/24-04-2020-the-who-solidarity-trial-for-covid-19treatments-officially-launched-in-indonesia

145. Li Y, Xie Z, Lin W. et al. An exploratory randomized controlled study on the efficacy and safety of lopinavir/ ritonavir or arbidol treating adult patients hospitalized with mild/moderate COVID-19 (ELACOI). medRxiv. https://doi. org/10.1101/2020.03.19.20038984 
146. Hung IF, Lung KC, Tso EY. et al. Triple combination of interferon beta- $1 \mathrm{~b}$, lopinavir-ritonavir, and ribavirin in the treatment of patients admitted to hospital with COVID-19: an open-label, randomised, phase 2 trial. Lancet. 2020; 395(10238): 1695-1704.

147. WHO discontinues hydroxychloroquine and lopinavir/ ritonavir treatment arms for COVID-19. https://www. who.int/news-room/detail/04-07-2020-who-discontinueshydroxychloroquine-and-lopinavir-ritonavir-treatmentarms-for-covid-19

148. Kadhim AAH, Hadi NR, Abdulhussein M, Zamil ST, Zamil ST. Preprocessing of the Candidate Antiviral Drugs against COVID-19 in Models of SARS cov2 Targets. LPMA. 2020; 106(2): 240.

149. Rossignol JF, Maisonneuve H. Nitazoxanide in the treatment of Taenia saginata and Hymenolepis nana infections. Am J Trop Med Hyg. 1984; 33: 511-512.

150. Wang M, Cao R, Zhang L, Yang X, Liu J, Xu M, Shi Z, Hu Z, Zhong W, Xiao G. Remdesivir and chloroquine effectively inhibit the recently emerged novel coronavirus (2019-nCoV) in vitro. Cell Res. 2020; 30(3): 269-271.

151. Scientists Identify 69 Drugs to Test Against the Coronavirus. https://www.nytimes.com/2020/03/22/science/coronavirusdrugs-chloroquine.html

152. Jin Z, Du X, Xu Y. et al. Structure of $\mathrm{M}^{\mathrm{pr}} \mathrm{O}$ from SARS-CoV-2 and discovery of its inhibitors. Nature. 2020; 582(7811): 289293.

153. The Coronavirus Patients Betrayed by Their Own Immune Systems. https://www.nytimes.com/2020/04/01/health/ coronavirus-cytokine-storm-immune-system.html

154. Efficacy and Safety of Emapalumab and Anakinra in Reducing Hyperinflammation and Respiratory Distress in Pa-tients With COVID-19 Infection. https://clinicaltrials. gov/ct2/show/NCT04324021

155. Sagonowsky E. Roche's Actemra falls short in Italian study in early-stage COVID-19 pneumonia. https://www. fiercepharma.com/pharma/roche-s-actemra-fails-italianstudy-early-stage-covid-19-pneumonia

156. Horby P, Lim WSh, Emberson $\mathrm{J}$ et al. RECOVERY Collaborative Group Effect of Dexamethasone in Hospitalized Patients with COVID-19: Preliminary Report. MedRXiv. https://doi.org/10.1101/2020.06.22.20137273

157. Poperechna D. MOZ vneslo novyy preparat u protokol likuvannya COVID-19. Ukrayinska pravda. June 25, 2020. https://life.pravda.com.ua/health/2020/06/25/241465/

158. Yasgur BS. Colchicine Promising in COVID-19 Treatment? https://www.medscape.com/viewarticle/933198

159. Day M. Covid-19: ibuprofen should not be used for managing symptoms, say doctors and scientists. https:/www.bmj.com/ content/368/bmj.m1086

160. Ioannou P. Rapid Response: Re: Non-steroidal antiinflammatory drugs and COVID-19; An ambiguous correlation. https://www.bmj.com/content/368/bmj.m1185/rr-0

161. Godoy M. Concerned About Taking Ibuprofen For Coronavirus Symptoms? Here's What Experts Say. https:// www.npr.org/sections/health-shots/2020/03/18/818026613/ advice-from-france-to-avoid-ibuprofen-for-covid-19-leavesexperts-baffled

162. Klok FA, Kruip MJHA, van der Meer NJM, Arbous MS, Gommers DAMP., Kant KM, Kaptein FHJ, van Paassen J, Stals MAM, Huisman MV, Endeman $H$. Incidence of thrombotic complications in critically ill ICU patients with COVID-19. Thromb Res. 2020; 191: 145-147.

163. Tang N, Bai H, Chen X, Gong J, Li D, Sun Z. Anticoagulant treatment is associated with decreased mortality in severe coronavirus disease 2019 patients with coagulopathy. $J$ Thromb Haemost. 2020; 18(5): 1094-1099.

164. Lugovskoy EV, Kolesnikova IN, Gritsenko PG Komissarenko SV. Utilization of monoclonal antibodies for the quantification of molecular markers of hemostasis. $J$ Thromb Haemost. 2003; 1(Suppl. 1): CD084.

165. Lugovskoy EV, Gritsenko PG, Kolesnikova IN, Zolotareva EN, Chernishov VI, Nieuwenhuizen W, Komisarenko SV. Two monoclonal antibodies to D-dimer-specific inhibitors of fibrin polymerization. Thromb Res. 2004; 113(3-4): 251-259.

166. Collaboration initiated to develop COVID-19 immunotherapy. https://www.drugtargetreview.com/ news/58326/collaboration-initiated-to-develop-covid-19immunotherapy/

167. Could T-cell immunotherapy be the answer to COVID-19? https://www.drugtargetreview.com/news/60482/could-tcell-immunotherapy-be-the-answer-to-covid-19/

168. Borrell B. New York clinical trial quietly tests heartburn remedy against coronavirus. Science. Apr. 26, 2020. https:// doi.org/10.1126/science.abc4739

169. Koch S., Pong W. First up for COVID-19: nearly 30 clinical readouts before end of April. https://www.biocentury.com/ article/304658/nearly-30-trials-for-covid-19-could-start-toyield-data-in-the-next-couple-of-months

170. Lim GY. TCM and COVID-19: China conducting trials to test efficacy and safety of traditional herbal interventions. https:// www.nutraingredients-asia.com/Article/2020/04/06/TCMand-COVID-19-China-conducting-trials-to-test-efficacyand-safety-of-traditional-herbal-interventions

171. Chapin E. Artemisia Annua Could Be Promising Treatment for COVID-19. https://uknow.uky.edu/research/artemisiaannua-could-be-promising-treatment-covid-19

172. Wadman M. Can interferons stop COVID-19 before it takes hold? Science. 2020: 369(6500): 125-126. DOI: https://doi. org/10.1126/science.369.6500.125

173. Kupferschmidt K. These Drugs Don't Target the Coronavirus They Target Us. https://www.sciencemag.org/news/2020/04/ these-drugs-don-t-target-coronavirus-they-target-us

174. Lipsitch M. Who Is Immune to the Coronavirus? https://www. nytimes.com/2020/04/13/opinion/coronavirus-immunity. html

175. COVID-19 Antibodies Can Disappear After 2-3 Months, Study Shows. https://www.medscape.com/viewarticle/932671

176. To KKW, Cheng VChCh, Cai JP. et al. Seroprevalence of SARS-CoV-2 in Hong Kong and in residents evacuated from Hubei province, China: a multicohort study. Lancet Microbe. 2020; 1(3): e111-e118.

177. Dr. Fauci Explains The Timeline And Risks Of Creating A COVID-19 Vaccine. MSNBC. https://www.youtube.com/ watch?v=ZrWAqpPGAxQ

178. CEPI. https:/cepi.net/covid-19/

179. Berkley S. COVID-19 needs a big science approach. https:// science.sciencemag.org/content/367/6485/1407

180. Zheng M, Song L. Novel antibody epitopes dominate the antigenicity of spike glycoprotein in SARS-CoV-2 compared to SARS-CoV. Cell Mol Immunol. 2020; 17(5): 536-538.

181. Achenbach J. The coronavirus isn't mutating quickly, suggesting a vaccine would offer lasting protection. https:// www.washingtonpost.com/health/the-coronavirus-isntmutating-quickly-suggesting-a-vaccine-would-offerlasting-protection/2020/03/24/406522d6-6dfd-11ea-b148e4ce3fbd85b5_story.html

182. Moderna Announces Positive Interim Phase 1 Data for its mRNA Vaccine (mRNA-1273) Against Novel Coronavirus. https://investors.modernatx.com/news-releases/news- 
release-details/moderna-announces-positive-interim-phase1-data-its-mrna-vaccine

183. Funk CD, Laferriere C, Ardakani A. A Snapshot of the Global Race for Vaccines Targeting SARS-CoV-2 and the COVID-19 Pandemic. Front Pharmacol. 2020; 11: 937.

184. Cohen J. Vaccine designers take first shots at COVID-19. Science. 2020; 368(6486): 14-16.

185. Callaway E. The race for coronavirus vaccines: a graphical guide. Nature. 2020; 580: 576-577.

186. Gao Q., Bao L., Mao H. et al. Rapid development of an inactivated vaccine candidate for SARS-CoV-2. Science. 2020; 369(6499): eabc1932. DOI: https://doi.org/10.1126/ science.abc1932

187. Mueller S, Stauft CB, Kalkeri R. et al. A codon-pair deoptimized live-attenuated vaccine against respiratory syncytial virus is immunogenic and efficacious in nonhuman primates. Vaccine. 2020; 38(14): 2943-2948.

188. Yu J, Tostanoski LH, Peter L. et al. DNA vaccine protection against SARS-CoV-2 in rhesus macaques. Science. 2020; 369(6505): 806-811.

189. Draft landscape of COVID-19 candidate vaccines. WHO. https://www.who.int/who-documents-detail/draftlandscape-of-covid-19-candidate-vaccines

190. Oxford COVID-19 vaccine to begin phase II/III human trials. http://www.ox.ac.uk/news/2020-05-22-oxford-covid-19vaccine-begin-phase-iiiii-human-trials

191. Lauerman J. Oxford, AstraZeneca Begin Advanced Trials of Covid Vaccine. Bloomberg. 22 May 2020. https:// www.bloomberg.com/news/articles/2020-05-22/oxfordastrazeneca-begin-advanced-trials-of-covid-vaccine

192. Folegatti P.M., Ewer K.J., Aley P.K., et al. Safety and immunogenicity of the ChAdOx1 nCoV-19 vaccine against SARS-CoV-2: a preliminary report of a phase $1 / 2$, singleblind, randomised controlled trial. Lancet. 2020; 396(10249): 467-478.

193. Zhu FC, Li YH, Gua XH. et al. Safety, tolerability, and immunogenicity of a recombinant adenovirus type-5 vectored COVID-19 vaccine: a dose-escalation, open-label, non-randomised, first-in-human trial. Lancet. 2020; 395: 1845-1854.

194. Haseltine WA. Lessons for COVID-19 from the Early Days of AIDS. Scientific American. July 6, 2020.https://www. scientificamerican.com/article/lessons-for-covid-19-fromthe-early-days-of-aids/

195. Accelerating a safe and effective COVID-19 vaccine. https:// www.who.int/emergencies/diseases/novel-coronavirus-2019/ global-research-on-novel-coronavirus-2019-ncov/ accelerating-a-safe-and-effective-covid-19-vaccine

196. Draft landscape of COVID-19 candidate vaccines. WHO. 21 July, 2020. https://www.who.int/who-documents-detail/ draft-landscape-of-covid-19-candidate-vaccines

197. Ramesh S. Can BCG vaccine protect against Covid-19? Here's why the excitement needs to be tempered. https://theprint. in/science/can-bcg-vaccine-protect-against-covid-19-hereswhy-the-excitement-needs-to-be-tempered/401449/

198. Sparber S. Texas A\&M researchers hope tuberculosis vaccine might prevent coronavirus deaths. https://www.krgv.com/ news/texas-aandm-researchers-hope-tuberculosis-vaccinemight-prevent-coronavirus-deaths/

199. Brook B, Harbeson DJ, Shannon CP. et al. BCG vaccinationinduced emergency granulopoiesis provides rapid protection from neonatal sepsis. Sci Transl Med. 2020; 12(542): eaax4517.

200. Arts RJW, Moorlag SJCFM, Novakovic B, Li Y, Wang SY, Oosting M, Kumar V, Xavier RJ, Wijmenga C, Joosten LAB, Reusken CBEM, Benn CS, Aaby P, Koopmans MP,
Stunnenberg HG, van Crevel R, Netea MG. BCG Vaccination Protects against Experimental Viral Infection in Humans through the Induction of Cytokines Associated with Trained Immunity. Cell Host Microbe. 2018; 23(1): 89-100.e5.

201. A \$10M Grant Enables BCG Vaccine Trial to Expand Internationally, Enrol 10,000 Healthcare Workers. https:// www.combacte.com/press-releases/11244/

202. Chumakov K, Benn CS, Aaby P, Kottilil Sh, Gallo R. Can existing live vaccines prevent COVID-19? Science. 2020; 368(6496): 1187-1188.

203. Escobar LE, Molina-Cruz A, Barillas-Mury C. BCG vaccine protection from severe coronavirus disease 2019 (COVID-19). PNAS. 2020; 117(30): 17720-17726.

204. Hamiel U, Kozer E, Youngster I. SARS-CoV-2 Rates in BCGVaccinated and Unvaccinated Young Adults. JAMA. 2020; 323(22): 2340-2341.

205. Woodley M. Healthcare workers trial TB vaccine for coronavirus protection. newsGP. 27 Mar 2020. https:// www1.racgp.org.au/newsgp/clinical/healthcare-workers-totrial-tuberculosis-vaccine-f

206. Kramer AE. Decades-Old Soviet Studies Hint at Coronavirus Strategy. https://www.nytimes.com/2020/06/24/world/ europe/vaccine-repurposing-polio-coronavirus.html

207. Report 9: Impact of non-pharmaceutical interventions (NPIs) to reduce COVID-19 mortality and healthcare demand. https://www.imperial.ac.uk/media/imperial-college/ medicine/sph/ide/gida-fellowships/Imperial-CollegeCOVID19-NPI-modelling-16-03-2020.pdf

208. Yang Y.Q., Sun Q., Wang Y.X., et al. Epidemic situation analysis and trend forecast of New Coronavirus Pneumonia (NCP) in Chongqing (in Chinese). J Chongqing Normal University (Natural Science). 2020; 37(1).

209. Brovchenko I. Development of the mathematical model of Covid-19 epidemic spread in Ukraine. Svitohliad. 2020; 2(82): 2-14. (In Ukrainian).

210. National coronavirus response: A road map to reopening. https://www.aei.org/research-products/report/nationalcoronavirus-response-a-road-map-to-reopening/

211. European countries are easing quarantine restrictions. http:// lowcostavia.com.ua/europe-poslablyuye-karantynniobmezhennya/

212. Prime Minister Denys Shmyhal unveils a step-by-step quarantine exit plan. Government of Ukraine. Official website. April 24, 2020. https://www.kmu.gov.ua/en/news/ premyer-ministr-denis-shmigal-predstaviv-poetapnij-planznyattya-obmezhen

213. Ukrayina perekhodyt do nastupnoho etapu poslablennya karantynu. Ukrayinska pravda. June 1, 2020. (In Ukrainian). https://www.pravda.com.ua/news/2020/06/1/7253960/

214. Leshner A. Restart science stronger after COVID-19. Science. 2020; 369(6502): 262.

215. Atyeo C, Fischinger S., Zohar T. et al. Distinct Early Serological Signatures Track with SARS-CoV-2 Survival. Immunity. 2020; 53(3): 524-532.

216. Qin J, You C, Lin Q. et al. Estimation of incubation period distribution of COVID-19 using disease onset forward time: A novel cross-sectional and forward follow-up study. Sci Adv. 2020; 6(33): eabc1202.

217. Bastian H. Covid-19 vaccines with 'minor side effects' could still be pretty bad. https:/www.wired.com/story/covid-19vaccines- with-minor-side-effects-could-still-be-pretty-bad/

218. Mallapaty S. The coronavirus is most deadly if you are older and male - new data reveal the risks. Nature. 2020; 585(7823): 16-17.

219. Landmark trial shows trained immunity reduces respiratory infections in the elderly by $80 \%$. https://www.ktvn.com/ 
story/42573300/ landmark-trial-shows-trained-immunityreduces-respiratory-infec- tions-in-the-elderly-by-80

220. Hardingham-Gill T. The odds of catching Covid-19 on an airplane are slimmer than you think, scientists say. https:// edition.cnn.com/travel/article/odds-catching-covid-19flight- wellness-scn/index.html

221. Grubaugh ND, Hanage WP, Rasmussen AL. Making sense of mutation: what D614G means for the COVID-19 pandemic remains unclear. Cell. 2020; 182(4): 794-795.

222. COVID-19 and Animals. https://www.cdc.gov/coronavirus/2019-ncov/daily-life-coping/animals.html

223. Grimm D. What does the COVID-19 summer surge mean for your cats and dogs? https://www.sciencemag.org/ news/2020/08/

224. https://www.lekhim.ua/ru/news/lekhim-harkov-pristupilk-proektirovaniyu-moshchnostey-dlya-proizvodstvaprofilakticheskih-0

225. Ad5-nCoV COVID-19 vaccine. https://www.precisionvaccinations.com/vaccines/ad5-ncov-covid-19-vaccine

226. Callaway E. Russia's fast-track coronavirus vaccine draws outrage over safety. https://www.scientificamerican.com/ article/rus- sias-fast-track-coronavirus-vaccine-drawsoutrage-over-safety/

227. Cohen E, Vigue D. US government slow to act as anti- vaxxers spread lies on social media about coronavirus vaccine. https:/edition.cnn.com/2020/08/12/health/anti-vaxxerscovid- 19/index.html

228. Mateus J., Grifoni A., Tarke A. et al. Selective and crossreactive SARS-CoV-2 T cell epitopes in unexposed humans. Science. 2020; 370(6512): 89-94.

229. Wallace-Wells D. The Good (But Not Great) News About T- Cells and Herd Immunity. https://nymag.com/intelligencer/2020/08/reasons-for-covid-19-optimism-on-t-cellsand-herd- immunity.html

230. Davis Ch. Dr. Fauci predicts drugmakers will likely produce 1 billion COVID-19 vaccines by the end of 2021 https:// www.busi- nessinsider.com/fauci-drugmakers-will-have-1billion-covid-vac- cines-by-2021-2020-8

231. Service RF. AI invents new 'recipes' for potential COVID-19 drugs. https://www.sciencemag.org/news/2020/08/aiinvents-new- recipes-potential-covid-19-drugs

232. Groth L. New COVID-19 Side Effect Troubles Even Doctors. https://www.msn.com/en-us/health/medical/new-covid-19side- effect-troubles-even-doctors/ar-BB17vTrH

233. Metcalf CJE, Morris DH, Park SW. Mathematical models to guide pandemic response. Science. 2020; 369(6502): 368369.

234. Patterson EI, Elia G, Grassi A. et al. Evidence of exposure to SARS-CoV-2 in cats and dogs from households in Italy. bioRxiv. 2020. Jul 23;2020.07.21.214346.

235. Willingham E. Genes may influence COVID-19 risk, new studies hint. https://www.scientificamerican.com/article/ genes-may- influence-covid-19-risk-new-studies-hint

236. To K.K., Hung I.F., Ip J.D. et al. COVID-19 re-infection by a phylogenetically distinct SARS-coronavirus-2 strain confirmed by whole genome sequencing. Clin Infect Dis. 2020. Aug 25:ciaa1275.

237. Guglielmi G. The explosion of new coronavirus tests that could help to end the pandemic. Nature. 2020; 583(7817): 506-509.

238. Drug candidate outperforms remdesivir as COVID-19 antiviral in cell assays. https://www.drugtargetreview.com/ news/69240/drug-candidate-outperforms-remdesivir-ascovid-19- antiviral-in-cell-assays/

239. Wu C, Liu Y, Yang Y. et al. Analysis of therapeutic targets for SARS-CoV-2 and discovery of potential drugs by computational methods. Acta Pharm Sin B. 2020; 10(5): 766 788.

240. Halford B. Can Pepcid treat COVID-19? https://cen.acs.org/ pharmaceuticals/Pepcid-treat-COVID-19/98/i25

241. What's New in the Guidelines. https://www.covid19treatmentguidelines.nih.gov/whats-new/

242. Disappointing Results From First Phase 3 Trial of Tocilizumab for COVID-19. https://www.idse.net/Covid- 19/ Article/07-20/Disappointing-Results-From-First-Phase-3Trial- of-Tocilizumab-for-COVID-19/59141

243. Interferons (Alfa, Beta). https://www.covid19treatmentguidelines.nih.gov/immune-based-therapy/ immunomodulators/ interferons/

244. Carlson R. NVX-CoV2373 SARS-CoV-2 Vaccine. https:// www.precisionvaccinations.com/vaccines/nvX-cov2373sars- cov-2-vaccine

245. Mauvais-Jarvis F., Klein S.L., Levin E.R. Estradiol, Progesterone, Immunomodulation, and COVID-19 Outcomes. Endocrinology. 2020; 161(9): bqaa127.

246. Orlov M, Wander PL, Morrell ED. et al. A Case for Targeting Th17 Cells and IL-17A in SARS-CoV-2 Infections. $J$ Immunol. 2020; 205(4): 892-898.

247. Loey M, Manogaran G, Taha MHN, Khalifa NEM. A hybrid deep transfer learning model with machine learning methods for face mask detection in the era of the COVID-19 pandemic. Measurement (Lond). 2020; 167: 108288.

248. Cogley M. 'Bat-like' sensor could help social distancing. https://www.telegraph.co.uk/technoogy/2020/06/06/batlike-sensor- could-help-maintain-social-distancing-offices/

249. Zimmer MA, Zink AK, Weiber CW. et al. Hypernatremia- a manifestation of COVID-19: a case series. A A Pract. 2020; 14(9): e01295.

250. Kang Z, Luo S, Gui Y. et al. Obesity is a potential risk factor contributing to clinical manifestations of COVID-19. Int $J$ Obes (Lond). 2020; 44(12): 2479-2485.

251. Bansal R, Gubbi S, Muniyappa R. Metabolic Syndrome and COVID 19: Endocrine-Immune-Vascular Interac-tions Shapes Clinical Course. Endocrinology. 2020; 161(10): bqaa112.

252. Finkel Y, Mizrahi O, Nachshon A. et al. The coding capacity of SARS-CoV-2. Nature. 2020. https://doi.org/10.1038/ s41586-020-2739-1.

253. Consiglio CR, Cotugno N, Sardh F. et al. The immunology of multisystem inflammatory syndrome in children with COVID-19. Cell. 2020; 183(4): 968-981.e7.

254. WHO Rapid Evidence Appraisal for COVID-19 Therapies (REACT) Working Group, Sterne JAC, Murthy S, Diaz JV. et al. Association Between Administration of Systemic Corticosteroids and Mortality Among Critically Ill Patients With COVID-19: A Meta-analysis. JAMA. 2020; 324(13): 1330-1341.

255. Anthropozoonotic and zoonotic transmission of SARS-CoV-2 onmink farms. bioRxiv. 2020. 09.01.277152. https://doi. org/10.1101/2020.09.01.277152

256. Gudbjartsson DF, Norddahl GL, Melsted P. et al. Humoral Immune Response to SARS-CoV-2 in Iceland. $N$ Engl J Med. 2020; 383(18): 1724-1734.

257. Hurst JH, Heston SM, Chambers HN. et al. SARSCoV-2 infections among children in the biospecimens from respiratory virus-exposed kids (BRAVE Kids) study. medRxiv. 2020. 08.18.20166835; https://doi. org/10.1101/2020.08.18.20166835

258. Raisi-Estabragh Z, McCracken C, Bethell MS. et al. Greater risk of severe COVID-19 in Black, Asian and Minority Ethnic populations is not explained by cardiometabolic, socioeco $\neg$ nomic or behavioural factors, or by $25(\mathrm{OH})$ - 
vitamin D status: study of 1326 cases from the UK Biobank. J Public Health (Oxf). 2020; 42(3): 451-460.

259. Hassan AO, Kafai NM, Dmitriev IP. et al. A Single-Dose Intranasal ChAd Vaccine Protects Upper and Lower Respiratory Tracts against SARS-CoV-2. Cell. 2020; 183(1): 169-184.e13.

260. Song E, Zhang C, Israelow B. et al. Neuroinvasion of SARS- CoV-2 in human and mouse brain. bioRxiv. 2020. 06.25.169946; https://doi.org/10.1101/2020.06.25.169946

261. Dasgupta A. Is a Bradykinin Storm Brewing in COVID-19? https://www.the-scientist.com/news-opinion/is-abradykinin-storm- brewing-in-covid-19--67876?fbclid = IwAR3rfjXquUU_fh9yKKyLfvAcyZyqXs2Na0NV2uT9b9ZV0V0ppI06X_AHzg

262. Menendez CA, Bylehn F, Perez-Lemus GR. et al. Molecular characterization of ebselen binding activity to SARS-CoV- 2 main protease. Sci Adv. 2020; 6(37): eabd0345.

263. Shental N, Levy S, Wuvshet V. et al. Efficient high-throughput SARS-CoV-2 testing to detect asymptomatic carriers. Sci Adv. 2020; 6(37): eabc5961.

264. Scudellari M. How the pandemic might play out in 2021 and beyond. https://www.nature.com/articles/d41586-02002278-5

265. Brooks M. Vitamin D deficiency may boost COVID-19 risk. https://www.medscape.com/viewarticle/936928

266. Ledford H. Coronavirus reinfections: three questions scientists are asking. https://www.nature.com/articles/ d41586-020- 02506-y

267. Hanke L, Vidakovics Perez L, Sheward DJ. et al. An alpaca nanobody neutralizes SARS-CoV-2 by blocking receptor interaction. Nat Commun. 2020; 11(1):4420.

268. Doheny K. Low-dose radiation therapy may help COVID-19 patients. https://www.webmd.com/lung/news/20200618/ low-dose- radiation-therapy-may-help-covid-patients

269. Watson S. Coronavirus on Surfaces: What's the Real Risk? https://www.webmd.com/lung/news/20200903/coronaviruson-sur-faces-whats-the-real-risk

270. Brooks M. Six potential treatments for COVID-19 identified. https://www.medscape.com/viewarticle/936912

271. Callaway E. The coronavirus is mutating - does it matter? https://www.nature.com/articles/d41586-020-02544-6

272. Study maps how COVID-19 infects various organs in the body. https://www.drugtargetreview.com/news/70070/ study-maps- how-covid-19-infects-various-organs-in-thebody/

273. McNamara D. Infectious COVID-19 can persist in gut for weeks. https://www.medscape.com/viewarticle/937256

274. Nature NEWS 18 September 2020. COVID. https://www. nature.com/articles/d41586-020-00502-w.

275. Coronaviruses cause respiratory infections in humans. https://www.nature.com/articles/d41586-020-002627?utm_source=twt_nnc\&utm_medium=social\&utm _ campaign=natu renews\&sf229556213=1

276. Regime of access : https://globalhealthnewswire.com/ research/2020/05/07/coro- navirus-structure-clue-to-highinfection-rate

277. Konwarh R. Nanobodies: Prospects of Expanding the Gamut of Neutralizing Antibodies Against the Novel Coronavirus, SARS-CoV-2. Front Immunol. 2020; 11: 1531.

278. COVID-19. Analysing the Threat. Eds. Lele A., Roy K. 2020. $454 \mathrm{p}$.

279. Trump receives experimental antibody treatment for COVID-19 diagnosis. Erika Edwards - TODAY - Saturday, October 3, 2020.

280. Solidarity trial finds no joy in antiviral drugs. Nature briefing. October 16, 2020.
281. Cohen J. Champagne and questions greet first data showing that a COVID-19 vaccine works. Science. Nov. 9, 2020. doi: 10.1126/science.abf6414

282. FDA Takes Additional Action in Fight Against COVID-19 By Issuing Emergency Use Authorization for Second COVID-19 Vaccine. FDA News Release. December 18, 2020.

283. Oxford COVID-vaccine paper highlights lingering unknowns about results. Nature News. December 08, 2020.

284. Voysey M, Clemens SAC, Madhi SA, Weckx LY, Folegatti PM, Aley PK, Angus B, Baillie VL, Barnabas SL, Bhorat QE, Bibi S, Briner C, Cicconi P, Collins AM, Colin-Jones R, Cutland CL et al. Safety and efficacy of the ChAdOx1 nCoV19 vaccine (AZD1222) against SARS-CoV-2: an interim analysis of four randomised controlled trials in Brazil, South Africa, and the UK. Lancet. 2021; 397(10269): 99-111.

285. Meredith Wadman M. Will a small, long-shot U.S. company end up producing the best coronavirus vaccine? Science. Nov. 3, 2020. doi: 10.1126/science.abf5474.

286. Cohen J. With global push for COVID-19 vaccines, China aims to win friends and cut deals. Science. Nov. 25, 2020. doi: 10.1126/science.abf8838

287. SARS: UK public health response - past, present and future. J.Y.Chow, S.R.Anderson, V.Delpech, et al. Commun. Dis. Public Health. 2003, Sep; 6 (3): 209-15. PMID: 14708270.

288. Neutralization of N501Y mutant SARS-CoV-2 by BNT162b2 vaccine-elicited sera. Xuping Xie, Jing Zou, Camila R. Fontes-Garfias, et al. bioRxiv. Jan. 07, 2021. doi: https://doi. org/10.1101/2021.01.07.425740

289. Li Q, Wu J, Nie J, Zhang L, Hao H, Liu S, Zhao C, Zhang Q, Liu H, Nie L, Qin H, Wang M, Lu Q, Li X, Sun Q, Liu J, Zhang L, Li X, Huang W, Wang Y. The Impact of Mutations in SARS-CoV-2 Spike on Viral Infectivity and Antigenicity. Cell. 2020;182(5):1284-1294.e9.

290. Cohen J. Vaccine wagers on coronavirus surface protein pay off. Science. 2020; 370(6519): 894-895.

291. Pfizer-BioNTech COVID-19 Vaccine. FDA News Release. December 11, 2020

292. FDA Takes Additional Action in Fight Against COVID-19 By Issuing Emergency Use Authorization for Second COVID-19 Vaccine. FDA News Release. December 18, 2020

293. Covid-19 vaccine: First person receives Pfizer jab in UK. BBC. 8 December 2020

294. AstraZeneca's COVID-19 vaccine authorised for emergency supply in the UK. Astra-Zeneka. 30 December, 2020

295. Oxford COVID-vaccine paper highlights lingering unknowns about results. By Heidi Ledford. Nature News. 08 December, 2020. https://doi.org/10.1038/d41586-020-03504-w

296. Duffy S. Why are RNA virus mutation rates so damn high? PLoS Biol. 2018;16(8):e3000003.

297. Becerra-Flores M, Cardozo T. SARS-CoV-2 viral spike G614 mutation exhibits higher case fatality rate. Int J Clin Pract. 2020;74(8):e13525.

298. Lanzoni G, Linetsky E, Correa D, Messinger Cayetano S, Alvarez RA, Kouroupis D, Alvarez Gil A, Poggioli R, Ruiz P, Marttos AC, Hirani K, Bell CA, Kusack H, Rafkin L, Baidal D, Pastewski A, Gawri K, Leñero C, Mantero AMA, Metalonis SW, Wang X, Roque L, Masters B, Kenyon NS, Ginzburg E, Xu X, Jianming Tan 9 , Caplan AI, Glassberg MK, Alejandro R, Ricordi C. Umbilical cord mesenchymal stem cells for COVID-19 acute respiratory distress syndrome: A double-blind, phase 1/2a, randomized controlled trial. Stem Cells Transl Med. 2021 Jan 5.

299. Dan JM, Mateus J, Kato Y, Hastie KM, Yu ED, Faliti CE, Grifoni A, Ramirez SI, Haupt S, Frazier A, Nakao C, Rayaprolu V, Rawlings SA, Peters B, Krammer F, Simon V, Saphire EO, Smith DM, Weiskopf D, Sette A, Crotty S. 
Immunological memory to SARS-CoV-2 assessed for up to 8 months after infection. Science. 2021;eabf4063.

300. Good News: Natural Immunity to the Coronavirus May Last Years, Study Suggests. Ed Cara. GIZMODO. January 06, 2021.

301. Ng KW, Faulkner N, Cornish GH, Rosa A, Harvey R, Hussain S, Ulferts R, Earl C, Wrobel AG, Benton DJ, Roustan C, Bolland W, Thompson R,Agua-Doce A , Hobson P. et al. Preexisting and de novo humoral immunity to SARS-CoV-2 in humans. Science. 2020; 370(6522): 13391343.

302. CDC study offers the incredible coronavirus immunity news we need. Chris Smith - BGR - Thursday, January 7, 2021.
303. Rahman MT, Idid SZ. Can Zn Be a Critical Element in COVID-19 Treatment? Biol Trace Elem Res. 2021; 199(2): 550-558.

304. Melatonin Could Potentially Treat COVID-19, Study Says. By Carolyn Crist. Medscape Nov. 11, 2020.

305. Rapid increase of a SARS-CoV-2 variant with multiple spike protein mutations observed in the United Kingdom. ECDC report. 20 December, 2020.

306. CDC Interim: Implications of the Emerging SARS-CoV-2 Variant VOC 202012/01. Dec. 29, 2020.

307. SARS-CoV-2 Variants. WHO Disease Outbreak News. 31 December 2020. 